\title{
Getting "Woke" With Each Joke: Black Comediennes and Representational Resistance on YouTube
}

\author{
by
}

Shaunel London

A thesis submitted to the Faculty of Graduate and Postdoctoral Affairs in partial fulfillment of the requirements for the degree of

Master of Arts

in

Communication

Carleton University

Ottawa, Ontario

(C)2019

Shaunel London 


\begin{abstract}
This research looks at the relationship between comedy, alternative media, and representations of Blackness. Using case studies Akilah Hughes and Franchesca Ramsey, two Black comediennes on YouTube, this thesis asks: how do Black women use both political comedy and alternative media to challenge the stereotypical and racialized representations of themselves in traditional media? A theoretical framework of critical race studies, post-colonialism, intersectional and Black feminisms, postmodernism, and theories of comedy in conjunction with the thematic qualitative text analysis of 30 YouTube videos were used to answer the question. My findings determined that Black women use political comedy and alternative media platforms to satirize oppressive and discriminatory ideologies and behaviours, framing instances of every day racism in absurd and exaggerated terms, which ultimately provides nuanced representations of Black womanhood that affirm the sexist, racist, and racially charged experiences and microaggressions that Black women endure on a daily basis.
\end{abstract}




\section{Acknowledgements}

Thanks be to God for Your mercies these past two years and to my family, friends, colleagues, mentors, and church family for their continued support.

Merlyna, thank you for believing in me and believing in this project. It's been an intense year for us, but I am so privileged to have made this journey with you. Your feedback has sought to make the best of my research and your jokes have made our meetings fun. I couldn’t have asked for a better supervisor for myself and this research project.

To my second reader, Rena, thank you for supporting me in all my academic endeavours over the years. Your guidance and feedback on this project have been tough but realistic and it has honestly made my work more rigorous and grounded. Thank you.

Dr. Nduka, thank you for being such an amazing external examiner. Your feedback has been so thoughtful, seeking to make this work the best it can be, and your encouragement about this thesis and future research means so much to me. Thank you.

To the faculty and staff of the Communication and media studies department here, thank you for your knowledge, support, and encouragement. You were all open to hearing my thoughts and ideas and I am truly sad to leave this environment. A very special thank you to Sandra Robinson. You saw more in me than I thought I was capable of. Without your guidance and encouragement, I don't know if I would have seen a future for myself in graduate studies. I am so grateful.

I would like to thank the incoming 2017-18 PhD and MA cohort for all the writing boot camps, Mike's Place breaks, and conversations that helped bring this research to fruition. It's been a pleasure working beside you all. A special thanks to 
Carla and Alyssa for all the days of co-working, listening to me talk about comedy, and helping me work through my thoughts. Chelsea, you've been a constant in this process, talking me down from panic texts and exploring the (academic) world with me. Thank you for your friendship, and I am richer for having known you.

Thank you to my D\&D groups. From Barovia, to the Shadowfell, to Itharia - our sessions and Monday night shenanigans were a welcome distraction throughout this process. Rolling dice with you all has been a balm in the hectic weeks.

To my many friends who supported me even though I was completely missing in action, thank you. I look forward to sharing with you all the work I've done.

To my family: cousins, aunts, uncles. Thank you for checking in on me and praying for me.

Auntie Valerie, your support is immeasurable. I love you so very much. I am so grateful.

Lastly, a heartfelt thank you to my Dad and my sister, you are my rocks. Twelve years ago, I didn't see myself here, but even throughout all our losses, your love, support, and encouragement helped me through, for once I think we've got a win. My gratitude and love for you both is truly beyond words. 


\section{Table of Contents}

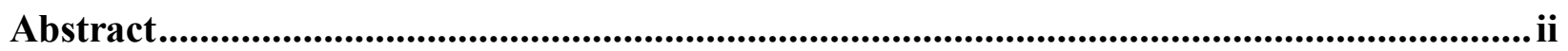

Acknowledgements .................................................................................................................................iii

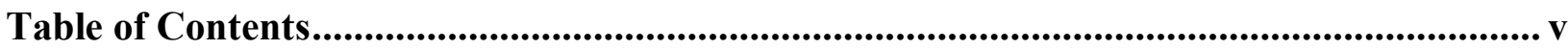

List of Tables ..................................................................................................................... vii

Chapter 1: Introduction ...............................................................................................................1

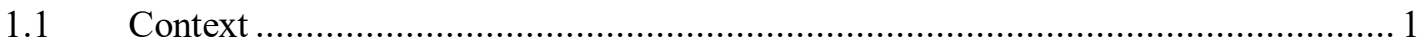

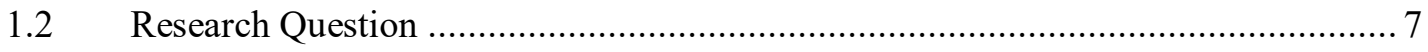

1.3 Researcher Identity, Intersectionality, and Positionality ........................................ 8

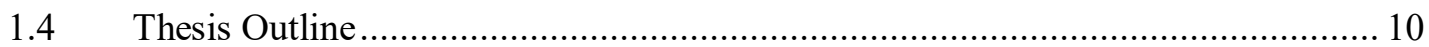

Chapter 2: Literature Review and Theoretical Framework................................................................12

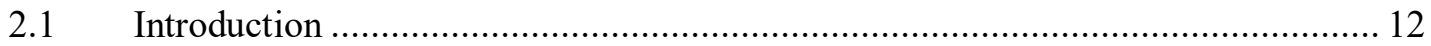

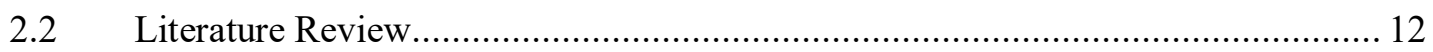

2.2.1 Humour as a Practice of Resistance in the Black Community ........................... 12

2.2.2 Black Women in Comedy on YouTube ……………................................... 15

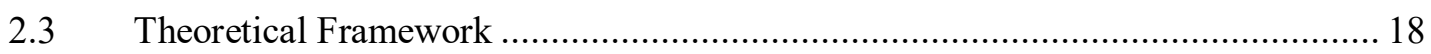

2.3.1 Intersectionality, Critical Race Theory, and Colonial Ideologies ...................... 18

2.3.2 Feminine Beauty, Fetishization, and Respectability Politics in the Colonialist

Context 24

2.3.3 Self-Definition and Postmodern Representation …….................................. 28

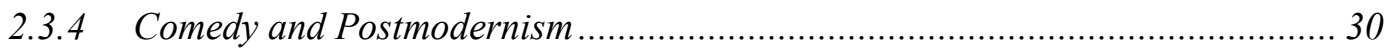

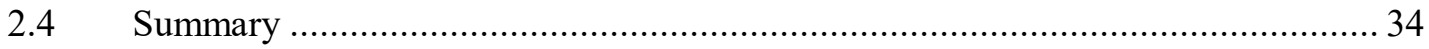

Chapter 3: Methodology ......................................................................................................................36

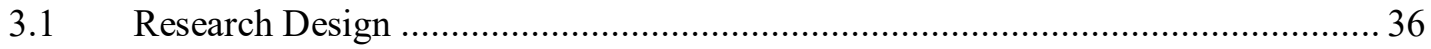




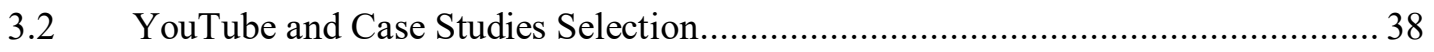

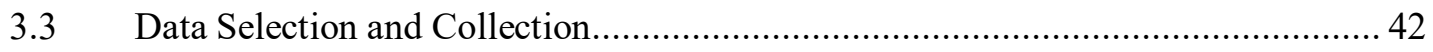

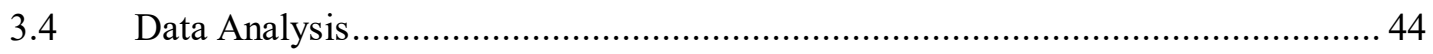

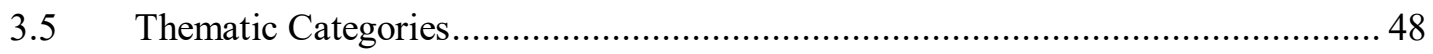

Chapter 4: Analyzing Akilah Hughes and Franchesca Ramsey .....................................................49

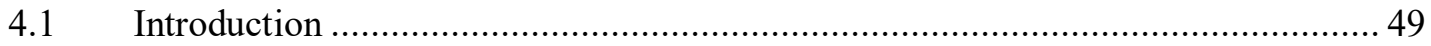

4.2 "Here's Thirty Seconds of Self-Indulgent Hair Angles" - YouTube and

Perpetuations of the White Feminine Beauty Ideal .................................................... 50

4.2.1 Black Hair and the White Feminine Ideal ....................................................... 52

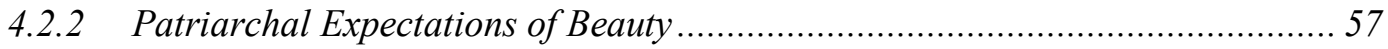

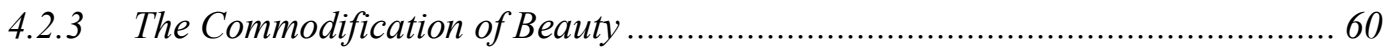

4.3 "If white people can say cracker, why can't I? - Rejection of Homophobia,

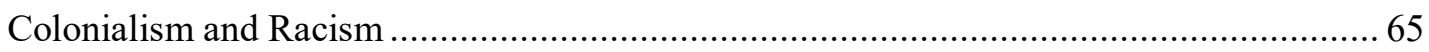

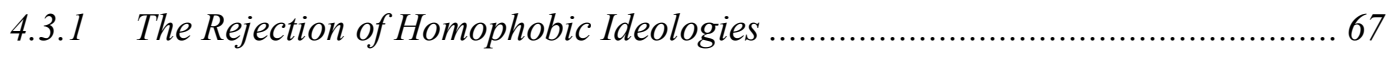

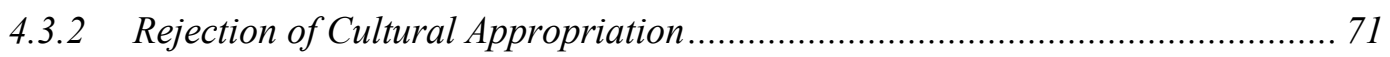

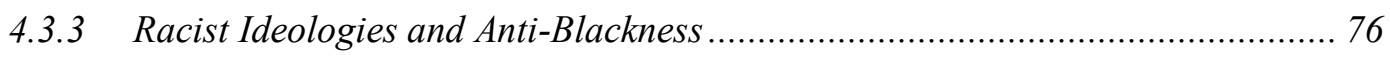

4.4 A (New) Black Womanhood: Displaying and Interrogating Notions of Self.......... 85

4.4.1 Microaggressions, Fetishization, and the Everyday ................................... 88

4.4.2 Navigating Social Expectations as a Black Woman .................................... 94

4.4.3 Everyday Black Womanhood and the Banal ............................................. 99

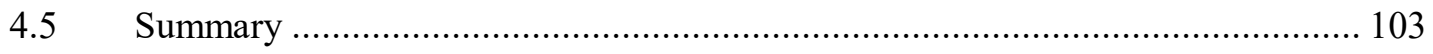

Chapter 5: Conclusion ...........................................................................................................................108

5.1 Research Questions, Argument, and Methodology ............................................ 109

5.2 Summary of Key Empirical Findings ...................................................... 110

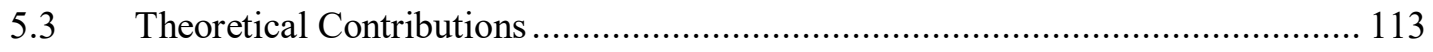


5.4 Recommendations for Future Research: Platform Studies, Banality, Black

Postmodern Political Satire as an Educational Tool .................................................... 115

5.5 Notes from the Researcher and Final Thoughts ............................................ 116

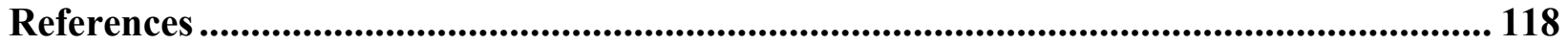




\section{List of Tables}

Table 1: List of Videos Analyzed from Akilah Hughes .............................................43

Table 2: List of Videos Analyzed from Franchesca Ramsey ...................................43

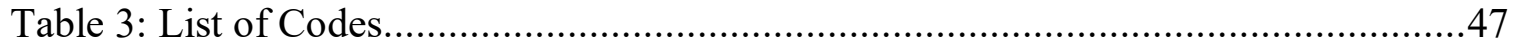

Table 4: List of Videos on Racism and Anti-Blackness ..........................................85 


\section{Chapter 1: Introduction}

\subsection{Context}

"When was the first time you saw yourself represented in literature?" Taken from the podcast Another Round with Heben and Tracy in the episode "Lit is Lit", Black and other non-white authors and public figures, like Ta-Nehisi Coates, Roxane Gay and Jeff Chang, answer this question inspired by the work of Marley Dias (Nigatu \& Clayton, 2016). In 2016, 11-year-old Dias was tired of reading books in school "about white boys and their dogs" (Flood, 2016, para. 3). She recognized that her white male teacher assigned these books because he could relate to them, but she could not. Wanting an opportunity to connect to literature that had Black girls as protagonists, Dias started the campaign to find 1000 books featuring Black girls as the main character called \#1000blackgirlbooks (Flood, 2016). When the episode ended, I was left with many book recommendations, but it also made me think about the first time I saw myself represented in literature. I remembered the book, Born Confused by Tanuja Desai Hidier, a story about a first generation South Asian American who lives straddling the lines of American and Indian cultures. This was something I continue to experience in my life, not feeling North American enough or West Indian enough. I can still recall what it felt like to finally read a book that outlined many of my personal experiences; I finally had confirmation that my experiences were real and valid. It made me feel like I was not alone, but I also wondered how often did my white friends have this feeling? All the time? How would my life be different if the books, television shows, and movies I saw all had little Black girls in them? 
This reflective question and the conversations that I continue to have around it encouraged me to think about other media and the first time I saw myself represented in them. This brought me to a YouTube video I saw in passing in 2012, "Shit White Girls Say... to Black Girls" by Franchesca Ramsey, a Black woman comedian (hereafter abbreviated to comedienne ${ }^{1}$ ) and activist on YouTube. In this video, Ramsey dresses as a white girl, using a blonde wig and "mock white girl" voice and says things like "not to be racist, but...why isn't there a White Entertainment Television?" and “Jews were slaves too. You don't hear us complaining about it all the time" as a way to show some of the discriminatory comments Black women face daily, even from individuals that consider themselves friends of the Black women they are speaking to (Slobe, 2018; Ramsey, 2012e). Ramsey parodies a popular twitter account, @shitgirlssay, which posted humorous comments about certain idioms women said like "can you pass me the blanket”. Utilizing the existing parody created, Ramsey expands the original to show some of the discriminatory comments people of colour deal with in a funny and educational way. How did this video make me laugh while still being educational? How did Ramsey recreate the same experience I had when reading Born Confused? Were my experiences exceptional or were there simply few accessible media representations of them? My master's thesis looks at videos from Franchesca Ramsey and another

\footnotetext{
${ }^{1}$ I use the French word comedienne as a shorthand for the phrase 'woman comedian' throughout this thesis. Although the term is contested, I use it not to separate women comedians from men as a way to delegitimize them, but rather to highlight that their experiences as Black women comedians is specialized to the intersection of these identity markers. Their women identities impact the content they create and for me, the term comedienne helps to center this reality in my work.
} 
comedienne on YouTube, Akilah Hughes, to investigate how alternative media ${ }^{2}$ like YouTube and comedy can create nuanced representations of Blackness and opportunities for marginalized individuals like myself to feel validated in their experiences.

Historically, traditional media has depicted Black women as mammies or the asexual, obedient, domestic servant, the hypersexualized and assertive jezebel, and the sapphire or the comical and assertive Black woman (Collins, 2009; Kretsedemas, 2010; Wright, 2014). From the sex-crazed, mixed race women in D.W. Griffith's opus to the Ku Klux Klan, Birth of a Nation (1915), to Olivia Pope in Scandal (2012-2018), Black women have been depicted as aggressive, ill tempered, and hypersexualized (Ashley, 2014; Kretsedemas, 2010; Wright, 2014). The representations I saw growing up fell into the stereotypes discussed above in addition to the "angry Black woman" or the Black woman who was "respectable" and behaved in a manner that would show how acceptable Blackness was to a white audience. I either saw upper class Black women or depictions of a lower socioeconomic Black experience.

While some upper-class portrayals were insightful, many representations relied on stereotypes based in racist and sexist ideologies, such as "a Black mother who works is bad caregiver" or "value is found in finding a Black man for a partner". Jackson (2014) states that Black women's image in popular culture has "relied on recycled stereotypes in which there is a constant assault on their womanhood" (p. 61). Historically, Black women have rarely been discussed in popular culture on their own terms. Instead, they are

\footnotetext{
${ }^{2}$ In this thesis, alternative media is the phrase used to describe media that is independently produced and distributed through the internet or web-based protocol, outside the realm of timed, networked, and gatekept nature of television and film. This definition of alternative media does not include web-based platforms like Netflix, as it refers to independently created content.
} 
"bombarded with warped images of their humanity" (Jackson, 2014, p. 65). Scott (2014) examines subversive representations of Black women in early comedy television. Some Black women from early situational comedies humanized their characters by not using stereotypes. For example, although the sitcom Beulah (1950) had secondary Black characters relegated to stereotypes, Ethel Waters in the title role did not use the language or rhetoric attributed to those Black stereotypes providing a positive, oppositional, resistant representation of Black women.

Lower socio-economic depictions of Blackness often featured Black-on-Black violence and sexualized imagery that many Black leaders find harmful, but some Black films like John Singletons' Boyz $n$ the Hood (1991) or F. Gary Gray's Set it Off (1996) took these stereotypical depictions and humanized them (Reid, 2005, p. 84). These films boasted Black production teams, which include writers, directors, cinematographers, and casting directors and do not rely on stereotypes to provide alternate views of Blackness. They presented a Black experience that confronted some of the adversity Black communities face without a gaze of superiority or judgement, but with a gaze of understanding and in some ways, pride. These Black filmmakers created films that varied from the white-washed sitcoms from the 80s and 90s, instead showing the realities of Black folks who live in lower socio-economic classes. These representations of Blackness have value, but they do not resonate with everyone. Where are the representations for Black individuals outside of these experiences? More representations from Black creators is perhaps needed to fill in the gaps where stereotypes are getting recycled and recirculated. 
Mark Reid (2005) outlines how early Black films from Black filmmakers did not utilize the typical representations of Blackness that were based in racism, rather they inserted social issues and Black cultural content into whatever genre their film was about. In addition, early Black films often suffered because it was difficult to realize their vision on film due to modest production finances (Reid, 2005, p. 16). Similarly, modern production processes fail to provide the financial capital to create opportunities for Black stories to flourish. Production companies that finance films did not see Black films as profitable because they believed they could only be marketed to the smaller, Black audience, and thus there was a smaller margin for profit. Without the financial backing of a production company, the cost to make and distribute a film, including all the production assistants, camera people, gaffers, writers, editors, craft services and all the staff necessary to make a film or television show, is likely infeasible for the average person. In response, creators like Ramsey and Hughes have used alternative media platforms to share representations of Black womanhood that differ from the stereotypical roles typically found in traditional media. As the barrier of the production is removed, can minorities self-define what kind of representation they want to create? With the emergence of YouTube and other alternative media platforms, have marginalized groups found ways to self-define representations of their experiences? To a certain degree, the answer is yes. However, YouTube has its own barriers to negate, particularly with their recommendation and advertising algorithms that can privilege some bodies and content over others, compromising potential financial gain and video reach.

Within the past ten years, scholars have begun researching the benefits of using YouTube to self-represent, specifically within minority and stigmatized groups. 
Academics have researched how persons with mental illness (Wollheim, 2007; Fletcher, 2016), autism (Brownlow et al., 2013), and the trans community (Horak, 2014; Raun, 2016) have utilized YouTube to create their own depictions of themselves and create an online community, instead of following and adhering to stereotypes perpetuated in popular media. Bradley (2015) noted creator Issa Rae as someone using alternative media to present a multidimensional Black woman character to the world. Rae's success with her YouTube series, The Mis-Adventures of Awkward Black Girl, led to HBO picking up the concept and creating the critically acclaimed comedy Insecure with Rae at the helm. Lionsgate creative director Dana Gills stated that "what we see happening in the digital space is very exciting. Creators of color who may not have had an opportunity to get into writers' rooms have created their own lane and blown up" (Kerwin, 2017, para. 45). This does not always translate to traditional media production statistics. In 2018, 40 of the top 100 films featured female leads or co-leads, and of those 40, only 5 were Black (Smith, Choueiti, Choi \& Pieper, 2019; Inequality Across 1200 Popular Films, 2019, p. 2). Furthermore, Black women are underrepresented behind the camera in roles like directors, producers, directors of photography, editors, and composers (Smith et al., 2019). For example, when reviewing the producers of the top 300 films between 2016 2018, only 1.6\% are underrepresented women (Smith, Choueiti, \& Pieper, 2014).

There is little literature about the opportunities alternative platforms can possibly provide in creating diverse representations of Blackness. Furthermore, connections between nuanced representations and resistance have not been discussed. In what ways can these representations provide media that Black women can look at and identify with while educating white viewers and speaking against the dominant view and how does 
comedy influence how this is done? While existing stereotypes of Black women are often exemplified in sitcoms like Beulah or The Fresh Prince of Bel-Air (1990), genre forms like comedy and their impact on the work are not always discussed. My research identifies ways comedy is used as a tactic to challenge representations and facilitate education. As more diverse representation is needed in order for Black women to see themselves in media, Ramsey's and Hughes' content brings light to situations that occur in Black women's lives on a daily basis.

\subsection{Research Question}

With the influx of alternative media providing new digital spaces for creators of colour using comedy as resistance it is pertinent to ask: How do Black women use both political comedy and alternative media to challenge the stereotypical and racialized representations of themselves in traditional media? How are Black comediennes using comedy and alternative media like YouTube as tools in challenging representations and educating their viewers? How does using YouTube impact the content these creators are making?

In my attempt to generate answers to these questions, theoretically I rely on critical race theory, post-colonial theory, intersectional and Black feminisms, postmodern theory, and theories of satirical comedy (see Chapter 2 for detailed discussion on theoretical framework). Methodologically, first, I selected Francesca Ramsey and Akilah Hughes as case studies as their work occupies the intersection of political comedy and Black women's experiences. I focused on my case studies' YouTube videos as YouTube is the most popular platform for self-uploaded content and as they provide concise texts 
to analyze (Arthurs, Drakopoulou, \& Gandini, 2018). I analyzed 30 YouTube videos (15 per case study) using NVivo and a coding schema that was determined inductively, using a qualitative thematic text analysis approach to ensure meaning was created from the data and the content itself was emphasized through examples from the data (see Chapter 3 for detailed description on methodology).

\subsection{Researcher Identity, Intersectionality, and Positionality}

As my research takes an intersectional approach to understanding the work from Black comediennes, my own intersecting aspects of identity can shape my methodological, epistemological, and ethical decisions made throughout this research, often bringing voice to the data itself, acknowledging the inseparable nature of my case studies identities, and my own positionality (Collins, 1993; Crenshaw, 1991). As a Black woman, this research is very close to me. My case studies, Hughes and Ramsey, and my overall research trajectory has been impacted by my personal media consumption. Throughout this research process I have been actively engaged in recognizing all aspects of my identity and how it can affect my position and knowledge making practices and it is important to be aware of the tensions that can arise when researching aspects of culture and race (Milner, 2007). Previous work conducted with Black feminist epistemology suggests that invoking my lived and embodied experiences can provide special insights into conducting this research (Collins, 2009).

My Black woman identity as a researcher is important as it provides access to experiential knowledge of Black issues and Black women's experiences. This is not to say that Black experience is monolithic, and my experience is the same as another 
individual's, but that the embodied knowledge I bring can be positively useful in understanding issues that are specific to Black individuals. For example, my experience in the Black community makes me sensitive enough to notice connections between content, humour, and systems of powers like colonialism or something seemingly unrelated like community beliefs influenced by Black churches. My identity and experiential knowledge of Black communities and Black women's experience allows for a more thorough investigation of the case studies and data.

Although Hughes and Ramsey are from the United States of America and are speaking from their experience in that context, many of the themes found in this research is not specific to a particular country or nation, rather they are specific to those of African descent in the western world. Therefore, terms like African-American or AfricanCanadian are not suited for this thesis. As a result, I have chosen to use the word Black to describe individuals of African descent. It is important to note I capitalize the word Black when speaking about Black individuals and the Black community. While scholars like bell hooks, Patricia Hill Collins, and Cornel West do not capitalize this word in their work, I have decided to capitalize Black because I am not talking about the colour black, but rather Blackness as a culture, race, and ethnic category. As Catherine MacKinnon says, "Blacks, like $A$ sians, Latinos, and other 'minorities,' constitute a specific cultural group and, as such, require denotation as a proper noun" (as cited in Crenshaw, 1991, p. 1244). Temple University professor Lori L. Tharps states that using a lowercase b relegates individuals of African descent to a place of subhuman; it is racial respect to capitalize the b in Black (Tharps, 2014). The capitalization of Black in this thesis respectfully identifies a group of people of African descent without subjugating them to a 
specific nation as many of the systems of power addressed in this work transcend borders.

\subsection{Thesis Outline}

The thesis is organized into five chapters. Following the introductory chapter, Chapter 2 discusses existing literature on political comedy in alternative media and identifies gaps within the literature. This chapter also introduces the theoretical framework used to analyze the videos from Hughes and Ramsey. I discuss theories of intersectional feminism, post-colonialism, comedy, postmodernism, and critical race theory, which are utilized to investigate how my two case studies use self-produced political comedy videos to present nuanced depictions of Black women.

Chapter 3 identifies the methodology used to conduct this research and highlights its appropriateness for my research questions. This chapter outlines how I used the methodology and describes the process of conducting the research including data collection and analysis. This chapter also includes tables of the selected videos and codes used to analyze the videos.

In Chapter 4, I present the results of my analysis through the three themes that inductively emerged from the research. This chapter breaks down each theme giving connections to theories and systems of belief that underlie the content using examples from the videos themselves to illustrate the point.

Finally, Chapter 5 summarizes the findings of this project. It connects my overall argument with my findings and presents my contributions to existing literature. In addition, I identify limitations of this research, offer suggestions for future paths of 
research, and provide a brief reflection on my positionality throughout this research and final thoughts. 


\section{Chapter 2: Literature Review and Theoretical Framework}

\subsection{Introduction}

This research looks at two Black comediennes, Franchesca Ramsey and Akilah Hughes, on YouTube and explores how they use political comedy to challenge the stereotypical and racialized representations of themselves in traditional media and how using YouTube as their platform of dissemination impacts the form of their work. To provide context to my research, I examine existing literature on this subject and theories concerned with society's perceptions of Black women.

There are two main sections of this chapter. The first reviews literature surrounding humour as resistance in the Black community and in feminist circles and existing literature of Black comediennes on YouTube. Here, I situate my research as a valuable addition to the field. The second section looks at the theoretical framework used to analyze and contextualize the videos in my data set. Critical race theory, post-colonial theory and Black feminisms are discussed as they are distinctly attached with the identity and life experiences of my case studies and their cultural products. Tactics of comedy and the relationship between postmodernism and comedic resistance are also examined.

\subsection{Literature Review}

\subsubsection{Humour as a Practice of Resistance in the Black Community}

Before delving into the specific literature of Black comedians and their use of humour as resistance it is important to mention some historical acts of comedic resistance and define the type of political comedy Hughes and Ramsey typically create. Political comedy and political satire is one area in which comedy as resistance can occur. Late 
night talk shows like The Late Show with David Letterman or Jimmy Kimmel Live! use political themes in monologues to create laughter and provide commentary on current events and politics. Political comedy is "an umbrella term that encompasses any humorous text dealing with political issues, people, events, processes, or institutions" (Young, 2017, p. 3). Political satire, which is often the content Hughes and Ramsey create, is crafted to "elicit laughter while also casting judgement" while interrogating systems of power in society (Young, 2017, p. 3). If done correctly, political satire, unlike political comedy, should make the audience laugh, feel a little bit bad, but also hopeful about opportunities for change. In this way, political satire can behave as resistance to social norms often present in political institutions.

The practice of humour as resistance has a long history, with court jesters, clowns, and fools permitted to make fun of the royal court and audience in their presence under the façade of stupidity (Rodrigues \& Collinson, 1995). These individuals were allowed to call attention to harsh realities of the lower class while laughing at the pretentiousness of the court and its ruler (Rodrigues \& Collinson, 1995). This early account of resistant humour is subordinate; it allows the individual to decompress from moments of tension, such as poor working or living conditions in the underclass in Europe, right under the nose of those who are creating these conditions. Similarly, Bryant (2006) writes about Czech nationals in Nazi occupied Czechoslovakia that used comedy as a safety valve to release the tension they were under in such a volatile situation. Humour was able to create a small bit of hope and pride in themselves and their country in a harmless way by using irony and ambiguity to be subtle in their resistance (Weaver, 2010). For these 
Czech nationals, jokes became a way to keep strong under the working conditions and cope with the Nazi regime.

When addressing humour as resistance within the context of Black comedians, there are a few articles that work with ideas of comedy and humour as an opportunity for subversion and education. Bailey (2012) and Willett, Willett, and Sherman (2012) argue that comedy can be a useful tool in deconstructing societal perceptions of stigmatized groups. This is not to say that this type of comedy is primarily for majority white, male, heteronormative audiences, but rather it provides the forum to be reflexive of one's beliefs, whether you identify as part of the group or not. They do this by taking two different subjects of study: Bailey (2012) takes Black male comedians, while Willet et al. (2012) look at Feminist activism. Their salient points are similar, focusing on the opportunities that humour allows for unity within minority groups, while noting ways that humour primes its viewers to be receptive of different perspectives. Differing from Willet et al. (2012) who focus on the positive, Bailey (2012) also points out the negative ways that Black male comedians can be interpreted by white audiences.

In “African American Humor as a Discourse of Resistance”, Bailey (2012) situates Black comedy as subversive. Through the utilization of the comedic work of Dave Chapelle, Chris Rock, Paul Mooney, and Richard Pryor, Bailey (2012) notes the ways Black comedy can be a tool to "make whites uncomfortable" and deconstruct racism in society (p. 259). Looking at the negative, Bailey (2012) acknowledges that white audiences may attribute the humour to the performance of Blackness which reinforces stereotypes and prevents these viewers from obtaining the deeper meaning. Willett et al. (2012) argue that the disruption of conventional norms through humour and 
ridicule provides an opportunity to release ones thought processes from societal standards. In addition, they argue that feminist conversations should make humour a part of their activism as it also produces a sense of intersubjectivity and creates unity amongst different moralities (Willett et al., 2012).

My research combines looking at humour from the viewpoint of Blackness and feminism, particularly within the alternative media world. Bailey's (2012) focus on male comedians identifies a space my research would fill, as I research two comediennes. Similarly, although Willett et al. (2012) provide a sound look at the use of humour in feminist activism, they do not consider the value in using alternative digital media platforms, also identifying where my research intends to broaden this emerging field. Willett et al. (2012) and Bailey (2012) attempt to provide a history of comedy and humour, looking at its subversive nature and poststructuralist philosophy, providing context for the videos my case studies, Hughes and Ramsey, are doing.

\subsubsection{Black Women in Comedy on YouTube}

The second category that was found in this literature review is Black women doing comedy on YouTube. The two articles that provide research most similar to the question of how political comedy and alternative media can challenge representations research are Jessyka Finley’s (2016) “Black Women’s Satire as (Black) Postmodern Performance” and Regina Bradley’s (2015) “Awkwardly Hysterical: Theorizing Black Girl Awkwardness and Humor in Social Media". These two articles specifically tackle Black comediennes on YouTube and their work to provide oppositional representations of Black womanhood as an act of resistance. Both articles use Issa Rae and her series The MisAdventures of an Awkward Black Girl, while Finley also examines comedy of 
Saturday Night Live, Black political figures, and another YouTube comedienne, Azie Mira Dungey and her web series Ask a Slave. Finley's and Bradley's articles both regard Issa Rae's work on YouTube while centering the idea of awkwardness as a trope to elevate conversations around Black womanhood (Bradley, 2015). Bradley (2015) states that Rae's use of awkward "humanizes, visualizes and pushes back against standard performances of (comedic) femininity" (p. 149) and Finley (2016) pinpoints that awkwardness provides a representation of a "Black woman on the margins [of] [B]lackness" (p. 256), or outside of what is typically associated with Black women. In other words, awkward is the term used for Black women who would be considered quirky if there were another race. Awkwardness provides a representation of Black women who do not see themselves in the assertive Black women characters, or the mammy, matriarch, sapphire, or prostitute.

While Bradley (2015) primarily focuses on awkwardness, Finley (2016) frames Black women's satire as a postmodern performance and her study of Rae and Dungey web series' focuses on their narrative qualities. Finley (2016) states that Dungey's series intends to show racism and discrimination of Black women within the historical context of slavery and deploys "a satire invested in resisting (but not transcending) domination... to call attention to what the ignored reality of racial domination means for [B]lack people" (p. 256).

The field of Black YouTuber comediennes is emerging with very few scholars fully examining their content. Instead, they are briefly mentioned in a larger argument about parody or Black women's representations. Ramsey has been featured briefly in scholarly work commenting on the content of her videos and the topics of oppression and 
discrimination that they address (Rentschler, 2014; Rowe, 2019; Slobe, 2018). This is most notable in Slobe's (2018) work on the "mock white girl” voice that notes Ramsey's video Shit White Girls Say... to Black Girls, but this article takes a sociolinguistic approach to the video. Hughes has been mentioned briefly in scholarly work for one of her videos on intersectionality (Gordon, 2016).

While Finley (2016) and Bradley (2015) discuss many of the tactics used in postmodern political satire by Black comediennes, they only address one specific way of providing nuanced representation of Black women, awkwardness. In addition, Finley's (2016) discussion of satire in Dungey's work conveys that the audience are non-Blacks, while videos from Hughes and Ramsey are intended both for non-Black audiences and Black audiences. Using Hughes and Ramsey as case studies allows my research to add to existing work on Black YouTubers, utilizing their work that centers Black womanhood and everyday racism with satirical rhetoric. The work of Finley (2016), Bradley (2015), Bailey (2012), and Willett, Willett, and Sherman (2012) reveal many of the ways comedy can be used as resistance and education, but my work seeks to reveal not just how the comedy is constructed but the ways Hughes and Ramsey construct affirmations of their audiences' experiences in their videos.

Bailey (2012) and Finley (2016) tackle Black women in comedy on YouTube, but both focus on the narrative content of the videos and Black representations of their case studies while Finley's also touches on comedy through a postmodernist lens. Research that focuses on narrative content, and the representations of Blackness that are portrayed in that content, have immense value and is a large part of my analysis, but there is a gap in research that focuses on how comedy, historical context, and the platform 
lends itself to a certain type of form. The existing forms on YouTube lend to a certain type of content that some comediennes are leaning into. For example, some are parodying popular YouTube video genres like beauty tutorials as the backdrop for their political satire. What visual form lends to the comedy and the resistance practice is also worth investigating. My research adds to existing research by examining intersections between identity, power, platforms, and agency, focusing on the political comedy of Hughes and Ramsey. While these aforementioned articles touch on many of these interests, my research brings them into dialogue together.

\subsection{Theoretical Framework}

To comprehensively investigate and unpack how Black women use both political comedy and alternative media in challenging stereotypical and racialized representations of themselves, my theoretical framework is built on multiple theories. These theories can be separated into several categories: post-colonial studies and critical race theories, intersectional and Black feminisms, comedy as resistance, and the role technological design has in social media. These categories speak to the intersections of identity, resistance, and power that arise from this research.

\subsubsection{Intersectionality, Critical Race Theory, and Colonial Ideologies}

The identity of my case studies, Hughes and Ramsey dictate that I bring an intersectional approach to my research and analysis. As Black women, they face oppression and marginalization from two sides, as women and as Black Americans. Intersectionality is an approach coined by Kimberle Crenshaw (1991) to encourage her readers to recognize that multifaceted nature of identity shapes experiences. In particular, 
Crenshaw (1991) points to ways that race and gender (or sexuality, class, etc.) shape the "multiple dimensions of Black women's... experience" (p. 1244). Intersectionality, which can be used to discuss the meeting point of other marginalized identities, points out that the various complexities of one's identity cannot be separated from another, in every aspect of that person's life. Intersectionality highlights that the daily experiences of a Black woman in legal practice, representation, etc. is specific to both being Black and being a woman. These two aspects of their identity intersect and viewing their identity as separate can erase the specificity of that individual's experience, grouping their experience in with the majority. For example, a Black comedienne's raunchy, hypersexualized stand-up routine may seem misogynistic to white feminists and perpetuating stereotypes to Black men, while to a Black woman it is satirical and subversive, challenging Black society's notion of what is acceptable. In this sense, grounding my research from theory to method in intersectionality is important to ensuring that I view Hughes' and Ramsey's content in the context it was meant to be viewed.

Blackness is a foundational part of my research as racist ideologies are often what Hughes and Ramsey are attempting to resist. As Black women, their bodies are an inherent part of who they are and knowing the cultural and historical frameworks that in turn influence the way they perceive and are perceived is crucial to understanding the work they are doing. When thinking about race and identity in regard to Hughes and Ramsey, post-colonial work and critical race theory that draws on the historical connections between Black womanhood, microaggressions, cultural appropriation, and essentialism are key. In addition, postmodern and Black feminist work provides a background in which to investigate the social expectations of women and representations 
of Black womanhood. This section will break down works from critical race theory, postcolonial theory, and intersectional and Black feminisms which provide much of the foundational tools to investigate Hughes' and Ramsey's videos.

As my research is primarily concerned with Black women in the western, colonial context, concepts of race, anti-Blackness, and equality must be addressed. Other issues, such as microaggressions and cultural appropriation are also crucial to understanding the social landscape in which my case studies create their videos. The colonial context I am referring to is the history of European nations, such as Spain, England, and France, holding political and economic domination over weaker nations or groups of people (Delgado \& Stefancic, 2017; Slemon, 1994). Colonialism facilitates the domination of people and cultures and in North America it is exemplified in the stolen land and genocide of Indigenous peoples and the slave trade (Bond \& Inwood, 2015). Colonialism and racism rely on the ideology that certain groups of people are inherently better than others. The, typically white, colonizers place their beliefs and ideologies above all others and proceed to discriminate, segregate, and be violent to others based on the colour of their skin (Delgado \& Stefancic, 2017). In addition, colonialism created practices that remove indigenous people from their land and thus erased and dismissed their relationship to it (Hiller \& Carlson, 2018; Bond \& Inwood, 2015). Colonization is a foundational part of the United States of America, as land was stolen from Indigenous peoples across the continent and the economics were built on the backs of slaves. This legacy of settler colonialism and slavery works to promote racism, disenfranchising minority groups for the benefit of the white majority from every class - elite, middle or 
underclass - advancing their mental and material status over persons of colour (Delgado $\&$ Stefancic, 2017).

One of the ways colonialism continues to disenfranchise Indigenous and other people of colour in the United States is through structural and institutionalized racism. Structural racism is a "confluence of institutions, culture, history, ideology and codified practices that generate and perpetuate inequity among racial and ethnic groups" (Hardeman et al., 2016, p. 2113). Coming from the doctrine of white supremacy or the belief that white individuals are inherently superior than all other races and ethnicities, structural racism seeks to oppress others for the benefit and progress of the white population (Hardeman et al., 2016). Specifically in the American context, the centuries long oppression of Indigenous, Black, and other people of color has made it so many of the legal structures protect the experiences of the white population and fail to take other experiences into account (Haneman, 2019). From medical practices and health care (Hardeman et al., 2016), to tax subsidies (Haneman, 2019) and law enforcement (Boyd, 2018), many of the systems that citizens must go through to live were designed to benefit the white population and often in turn disenfranchise minority groups. As a result, colonialism continues to affect Indigenous, Black, and other people of colour in ways we cannot avoid.

Racism, as critical race theory states, is difficult to address due to its normalization in our society. It is, as Delgado and Stefancic (2017) state, ordinary as it becomes embedded in societal practices and only blatant claims of racism are deemed worthy of acknowledge and rejection. In this way, the subtlety of microaggressions are overlooked in favour of the "bigger issues" like employment inequalities. Of course, 
employment inequalities are important, but the small yet shocking encounters with racism that characterize microaggressions are typically unnoticed by the majority race and is thus more common and harmful for a minority. It "construct[s] a world in which minorities and women are constantly on the defensive" (Delgado \& Stefancic, 2017, p. 144). Microaggressions do not occur only in contexts of race, but also intersections of race, gender, and class, among others.

While microaggressions are an example of the ordinariness of racism, cultural appropriation is an example of the blatant co-opting of a cultural product without respect for its cultural meaning. Cultural appropriation refers to the active exploitation of a culture's "symbols, artifacts, rituals, genres, and/or technologies by members of another culture" without regard or permission from the culture itself (Rogers, 2006, p. 476). It is less about intent, and more about the system of white supremacy and white privilege that underlie the notion that one has the authority to co-opt aspects of a culture; it is about the historical and systemic roots of one's racial positionality that must be addressed when wearing clothes or practicing customs of a culture that they do not belong to (Kleisath, 2014). For example, wearing a traditional Tibetan garment during a Losar celebration can be hurtful to Tibetans, even if you have been learning the language or were encouraged to wear Tibetan clothing from your language teacher (Kleisath, 2014). Although the intent was to honor and appreciate the culture, the history of persecution of the Tibetan people and the occupation of their land make wearing aspects of their culture inherently hurtful, harmful, and discomforting. Here, intent does not change impact, which is often the case in cases of cultural appropriation. Cultural appropriation can be complex, but it is 
ultimately a colonialist practice that is abhorrent to many as it can rely on stereotypes that are offensive to members of the culture.

As my case studies, Hughes and Ramsey, are both Black women, it is important to touch on a faction of racism that specifically affects them, anti-Black racism. AntiBlack racism is a practice of racism only enacted to Black individuals. It upholds colonialist ideologies that Black people are the least desirable race. Black individuals historically are pitted as the opposite of normal, the most deviant of all races, "society's quintessential phobogenic ${ }^{3}$ objects, embodying that which is feared and loathed" (Wun, 2014, p. 4). It is not simply a white on Black racism, but also non-Black non-Whites on Blacks racism. In other words, other individuals of colour not part of the Black community may also cling to systemic notions of Blackness as the ultimate inferior race because in the context of the United States state repression is built around Blacks. Drawing from work done by James et al. (2010) on racism in the African Canadian context, Pon, Gosine and Phillips (2011) state:

The concept of anti-Black racism emphasizes the particular racism experienced by Black people in Canada, which is rooted in the history of slavery and the colonial period. Anti-Black racism calls attention to the specific laws and practices that led to the segregation in education, housing, and employment experienced by Black people (p. 389).

This history and effects of colonization persists today, affecting the ways Black individuals endure racism on a daily basis and affecting what the general population

\footnotetext{
${ }^{3}$ A concept from Frantz Fanon which means a fear causing person or object (Hook, 2004).
} 
deems as worthy, profitable, and entertaining especially in regard to media representation.

\subsubsection{Feminine Beauty, Fetishization, and Respectability Politics in the Colonialist Context}

Another aspect of colonization that has continued to persist can be found in the practice of white women as the pinnacle of beauty. The white feminine beauty ideal posits that the European features of whiter skin, straight, blonde hair, thin noses, and light-coloured eyes are the epitome of beautiful (Bryant, 2013; Baker-Sperry \& Grauerholz, 2003; Jorgensen, 2019; Robinson-Moore, 2008; Harper \& Choma, 2018). The closer you are to that European standard, the more beautiful you are. This white feminine beauty ideal has been historically documented through cultural products like classical art and paintings (Ribeiro, 2011) and fairy tales (Baker-Sperry \& Grauerholz, 2003; Jorgensen, 2019), and has continued to be perpetuated in advertising (Duke, 2000; Duke, 2002; Sypeck, Grey \& Ahrens, 2003; Frith, Shaw \& Cheng, 2005) and other media like film and television (Harper \& Choma, 2018; Vandenbosch \& Eggermont, 2012; Swami et al., 2010).

This white feminine beauty ideal is a colonialist ideal as whiteness is systemically held as above all other races and types of beauty (Harper \& Choma, 2018). This ideal is in direct opposition to the natural aesthetics of many women but particularly to racialized women and its pervasiveness in society asserts that in the context of my research, Black is not beautiful. There is a history of Black women internalising this white feminine ideal due to its presence in U.S. slavery. The hierarchy established during slavery in America placed slaves of lighter skin and straighter hair in a position to obtain preferential 
treatment (Makkar \& Strube, 1995). In other words, if you are a light skinned Black person with "good hair", you get to work in the house rather than the field because you are better than the darker skinned slave. The slaver engrains in his slaves that those individuals are inherently a higher quality of human than those with kinky hair and dark skin.

Yet, at the same time, these dark skinned, kinky haired women are fetishized and objectified. The lighter skin slave comes to be from the result of the slaver raping a darker skinned slave woman. As a result of the white colonizer, the private realities of Black women's bodies became public subverting the notion that women need to be protected and rendering Black women as "not off-limits, untouchable, or unseeable" (Guy-Sheftall, 2002, p. 18). The disturbing reality of Sarah Baartman, or the Hottentot Venus, who was objectified and displayed in Europe as a sexual deviant and physical anomaly and dissected and examined for her sexual parts, reveals the way the white man has been trained to see Black female bodies as the "primary pornographic outlet for White men in Europe and America" (Walker as cited in Collins, 2009, p. 143). This treatment of Baartman's Black body reaffirms notions from slavery that Black women's bodies are to be used, are always ready for sex.

In addition to Baartman, other presentations of Black women in the 19th century were explicitly interested in their sexual parts, buttocks or genitalia, with the purpose of scientifically proving that whites and Blacks were a different species (Gilman, 1986). The treatment of Baartman and her body made a way for sexual stereotypes in the United states as can be seen in the treatment of racialized celebrities like Jennifer Lopez or Nicki Minaj, and it is also linked to the pornographic entanglement of Black bodies (Collins, 
2009). Gilman (1986) says that the Hottentot Venus became the essence of who a Black woman was, and as the sexualized Venus became synonymous with prostitution, so did the perception of Black women. In this way, Black women's bodies have been viewed as only sexual, always "ready", and "unrapable," as per Crenshaw's notion that there are "good bodies that can be raped and bad bodies that cannot" (1991, p. 1271).

The fetishization of Black women's bodies has led to an increase in the Black communities attempts to stifle sexual expression using respectability politics. Respectability politics, coined by Evelyn Brooks Higganbothan, though a practiced behaviour for a while, emerged from the Black Baptist Church and promoted things like "temperance, cleanliness, thrift, polite manners, and sexual purity" (Harris, 2003, p. 213). These behaviours were meant to make Black communities feel like they were respectable, but it was also to make the white population see that they were respectable, according to the western ideals (Harris, 2003). Respectability politics are visible in white heteronormative teachings like "don't speak too aggressively or with too much passion" or "don't dress too revealing". With respectability politics and sexuality, Black communities' police their Black women to present a sterile, non-sexualized version of themselves in an attempt to negate the historical objectification of women's bodies. As a result, a link between sexual integrity and self-worth is established through respectability politics which in turn feeds into the notion that Black women's sexuality is a taboo topic. Though respectability politics seeks to alter the perception of Black women as "unrapable", it stifles the Black women's freedom to express their sexuality with agency. Black women have sex too and many want to express that sexuality for themselves without the fear of being condemned by their own self-policing society. 
Respectability politics is also used to police relationships based in patriarchal ideologies. Patriarchal ideologies are long-standing beliefs that women are less than men, and they demand that men have dominance over women. These ideologies are rooted in sexism, driving the belief that women are lesser beings than men (Fraser, 2015).

Patriarchy is not only ideological, it is also structural, meaning that it is grounded in both beliefs and values as well as "access to and positions within social institutions" (Yodanis, 2004, p. 656). In the context of relationships, marriage has historically been the ultimate space of male ownership over women, with traditions of money exchange like paying a dowry or bridepiece ${ }^{4}$ simulating an exchange of ownership from father to husband. Furthermore, marriage was often seen as the only way out of one's home, and thus it was a desirable outcome despite its pitfalls.

Many scholars (Collins, 2002, 2004; Crenshaw, 1991; Mackinnon, 1987; Gilman, 1986) have discussed how respectability politics is used to discipline and police Black women for fear of being labelled as hypersexual or deviant in the community. But Collins (2009) also states that self-defining one's sexuality may provide a space to present Black female sexuality that does not simply objectify Black bodies, but also becomes a place of resistance by gaining erotic control of one's body.

\footnotetext{
${ }^{4}$ A dowry is a sum of money given to the husband of a newly wedded woman by her father. Sometimes this exchange of money served to pass wealth down from the family to the daughter, and sometimes it was a prize or incentive to marry their daughter. A bridepiece is given to the family of the woman a man wishes to marry as a token of appreciation but also a price for "purchasing" the daughter (Anderson, 2007;

Bottocini \& Siow, 2003).
} 


\subsubsection{Self-Definition and Postmodern Representation}

Self-definition is a concept that highlights the way Black women have become aware with the way they watch and are being watched, utilizing the tools of their oppressor as a way to protect themselves from the dominant social or racial group (Collins, 2009). Self-defining one's own reality is important and creates a space to resist against the common oppressive images of Black women. It is not Black women that typically represent themselves as mammies, matriarchs or inferior, so placing the ownership of representation in the hands of Black women themselves provides opportunities for less stereotypical portrayals of Black womanhood (Collins, 2009). Collins (2009) furthers this discussion by asserting that self-definition not only redefines what the general understanding of who Black women are, it also works to reveal the abused authority of those that had defined Black women in the past. Collins (2009) states, "by insisting on self-definition, Black women question not only what has been said about African-American women but the credibility and intentions of those possessing the power to define" (p. 125).

The notion of self-definition is important when examining representations of Blackness and womanhood as it shows how creating your own representations of Blackness can inherently challenge the common and often stereotypical portrayals. Audre Lorde (1978) says self-definition is necessary for the resistance against the common antiBlack and Racist notions in society.

For Black women as well as Black men, it is axiomatic that if we do not define ourselves for ourselves, we will be defined by others - for their use and to our detriment. The development of self-defined Black women, ready to explore and 
pursue our power and interests within our communities, is a vital component in the war for Black liberation (Lorde, 1978, p. 45-46). Self-definition works against colonialist practices of controlling images. It seeks to display the daily labour Black women do to re-inscribe meaning of their life while instructing those who have judged them based on their gender and skin colour.

Self-definition is inherently a postmodern notion. I refer here to bell hooks' (1990) use of postmodernism, a critical cultural notion that calls attention to the experience of "difference" and "Otherness" (p. 23). Black postmodernism, or postmodern Blackness as hooks calls it, is important in contemporary research about Black representation as it seeks to emphasize the otherness of individuals within a group. It seeks to challenge the hegemonic representations of Blackness in favour for more individualistic experiences. For a time, Black movements sought to fight back against the racist, colonialist, hegemonic perceptions of the Black community by focusing on presenting a collective opposing identity (hooks, 1990). While this universalizing agenda fought against the dominant racist ideology, it presented a hegemonic view of Blackness that in some ways can sustain a white-supremacist understanding of Blackness.

By centering on the difference and otherness emphasized by postmodern thinking, members of the Black community can critique this hegemonic, essentialist view of Blackness. Essentialism asserts that there is one, singular, limited experience of Blackness. Postmodern thinking challenges that, allowing us to "affirm multiple [B]lack identities, varied [B]lack experience" (hooks, 1990, p. 28). It encourages individuals to challenge colonialist one-dimensional representations of Blackness, decolonizing portrayals of the Black experience by presenting them as Black experiences. Self- 
definition promotes the same work in cultural products, like YouTube videos, by showing the nuances of experiences rather than the collective essentialist understanding of Black culture. It is in postmodern thought that self-definition has the potential to be the centering of resistance struggle, as it is a departure from the polished essentialism of some Black female representations and instead emboldens portrayals of the Black scholar and the uneducated Black, the large systemic issues and the ordinary daily life. This Black postmodern sensibility is pertinent to my case studies analysis as in informs the resistant qualities of self-definition and comedy.

\subsubsection{Comedy and Postmodernism}

To investigate comedy's role in resistance, in this thesis I look at satire as a comedic form while focusing of tactics of signifying and exaggeration. I also look at satire from a Black perspective by utilizing theories of Black postmodernity or the "continued displacement, profound alienation, and despair" of Black individuals (hooks, 1990, p. 26). As discussed in Section 2.2.1, comedy as a resistance practice has occurred in royal courts in the form of jesters (Rodrigues \& Collinson, 1995) and in Nazi occupied Czechoslovakia (Bryant, 2006). Political satire can facilitate an opportunity to call out discriminatory social and political ideologies while still making the audience laugh (Young, 2017).

As previously stated, some of Hughes' and Ramsey's videos fall under the broad umbrella of satire. In literature, satire is often not defined, or only defined within the context of the particular work(s) that journal article or book is examining. A few scholars admit that satire is a difficult thing to define (Caron, 2016; Dickson-Carr, 2001), and some works proceed with their analysis as if their audience already knows what satire is. 
According to James E. Caron (2016), satire is a comic form, tactic, and mode that is "an act of judgment based on an implicit or explicit (moral) value often made with an intent to reform or change the comic butt (target) of a ridiculing presentation" (p. 156). It does not mean that there will be reform through this process of ridicule, but that there is the potential for "a change in thinking, perception, or belief, even a repentance of the old way of thinking, perceiving, believing" (Caron, 2016, p. 156). Satire has the potential to fail, mainly because it must be funny; it must toe the proverbial line between funny and serious, which can trivialize the greater critique it is attempting to make (Krefting, 2019). This is important to note, because satire does not necessitate reflection or change, but the potential for it.

One comedic tactic found in satire as well as the content of my research is signifying. Signifying is a popular form of verbal expression often found in the Black humour (Peters, 2012). It is characterized by using indirect language to "provide playful commentary or serious social critique couched in the form of verbal play" (Smitherman, 2006, p. 69). It works to utilize the double meaning of a word or phrase to humorously examine an object, individual, or system of belief. Signifying relies on an "interpretive difference between word and action" to turn commonplace ideas on its head, but also make things funny (Smith, 2005, p. 186). In other words, the Black humour tradition of signifying uses words and phrases that have double meaning to make situations and content humorous while also creating opportunities for audiences to contemplate normalized ideologies.

One of the comedic tactics used in the signifying process is exaggeration, but it is also a satirical tactic on its own. Exaggeration is a classic narrative tool used in comedy 
to draw attention to a person, object, or ideology by emphasizing it. This emphasis can come from making the portrayal bigger than necessary or making it smaller than it should be. According to Knox (1957), exaggeration acts as a "distorting mirror" meant to force the viewer and creator to confront themselves and their beliefs (p. 804). The distorting mirror's purpose is to make the common humorous, often to the point of foolishness, through various means. Sometimes the humour comes from the characters being over the top in portrayal and costume, and sometimes it is the camera and editing that brings forth the means of exaggeration and distortion. In the case of satire, exaggeration is a key tool to pointing out the nonsensical, something that satire attempts to get its audience to see.

While exaggeration is one tactic found in the content analyzed, it would be remiss of me to not examine satire within the context of my case studies. As Hughes and Ramsey are both Black women making satirical videos about their position within society, it is pertinent to utilize the literature that looks at Black satire, and more specifically, Black postmodern satire. Utilized in both Finley (2016) and Bradley (2015) and discussed in section 2.2.2, Black postmodernity informs the concept of self-definition and also speaks to comedy and resistance. Postmodern satire for Black women is brilliantly described by Jessyka Finley (2016) in the following quote. 
[B]lack women's use of satire [is] a performative strategy that enables them to spotlight and put pressure on deeply embedded historical narratives. These narratives ultimately serve to rationalize the kinds of ideological assumptions and structural inequalities that relegate black women to the margins of United States society (p. 237).

The historical narratives Finley (2016) refers to here is, quite simply, the history of slavery in the Americas. When considering the North American colonialist experience of the vile, abusive conditions of slavery, many harmful, stereotypical, and dehumanizing views of Black women have persisted into common understandings of Black women. Finley (2016) is asserting that Black women use satire as a way to understand and employ their own resistance against the ideological norm and the historically racist and sexist narratives around Black women.

Black postmodern satire recognizes these historical narratives that, amongst other things, sexualize Black women while still considering them as lesser humans, and employs the postmodern processes of dislocation from "society, from self, from humanity, and in the supposedly post-racial twenty-first century, even from race," to highlight the discrimination that saturates our society (Guerrero, 2016, p. 267). By examining my case studies through this lens, we are privy not only to seeing how their production of comedy seeks to help Black comediennes tackle their daily experiences of racism and sexism, but it shows how satire in this context is inherently oppositional and resistant to the majority society's long upheld colonialist ideologies. Although it may not lead to change, it provides opportunities for the creator and their audience to rethink their position amongst these ideologies. 
Satire is complicated but can be used to draw attention to the long-standing but discriminating beliefs that exist in our society. Black postmodernity draws attention to comedy as resistance's ability to create space for different narratives. Satire as postmodern performance in essence challenges, "incites, demands, asserts, accuses, and opposes" (McKenzie, 2001, p. 32). Black postmodernity provides a way of understanding how political comedy comes from a place of activism and resistance, specifically from a racialized point of view.

\subsection{Summary}

Black comedienne's use of alternative media and political comedy to present alternative representations of womanhood requires knowledge in several areas. Firstly, it is important to acknowledge the work that precedes this research. Even though this area is currently under-researched, focusing on the use of comedy as resistance and Black women's comedy online has revealed similar research that I have drawn upon. Young (2017), Bryant (2017), Rodrigues \& Collinson (1995), Willet et al. (2012) and Bailey (2012) have provide a short history of satire and comedy within the feminist and Black communities respectively, while Bradley (2015) and Finley (2016) conduct specified research on Black women and comedy on YouTube. My research on Hughes and Ramsey adds to existing research on humour and resistance and Black comediennes and YouTubers by showing how comedic tactics of resistance like postmodern satire can be a method to create nuanced representations. In addition, this research can demonstrate how these YouTubers address not only non-Blacks with the intent to educate, like examples in 
Finley's work, but how they target Black viewers, delivering moments where they can feel affirmed in their own experiences.

The theoretical framework for my research incorporates theories concerned with Black women and comedy. Critical race theory and postcolonialism as well as intersectional and Black feminist theory and postmodernism, work to look at the preexisting systems of control that represent the ideologies my case studies' content seek to complicate. Ideologies founded in racism like anti-Blackness, microaggressions, and respectability politics are important to examining the content of Hughes' and Ramsey's videos. It is also important to highlight the legacies of slavery and colonialism like beauty ideals, fetishization of Black women and cultural appropriation. Works from feminist writers Patricia Hill Collins (2009) and bell hooks (1990) provide the foundation of how to examine my data as works of self-definition and within a Black postmodern framework.

Black postmodernism is an intellectual framework that showcases the benefits of having a variety of representations of Blackness and also helps to unpack the link between comedy as a resistance practice. While using signification, or double meanings, and exaggerations are important tactics in satire, a postmodern look at satire reveals the process by which Black women use satire to at once highlight and distance themselves from the historically discriminatory beliefs around Black women. It is the distancing of self that creates humour while still drawing attention to racist and sexist ideologies. This push-pull of satirical comedy is visible in Hughes' and Ramsey's videos and is foundational in understanding their political comedy. 


\section{Chapter 3: Methodology}

This chapter outlines the methodological practices of this thesis and is broken down into three parts. I first provide a brief overview of the methodologies chosen to investigate my research question of how Black comediennes use alternative media and political comedy to challenge stereotypical and racialized representations of Black women in traditional media. Proceeding an overview of the research method, I provide a detailed description of my case studies and why they were chosen and detail my data selection and collection method. I close this chapter by specifying the data analysis process and providing the theme derived from the data.

\subsection{Research Design}

The research method that best suits my topic and research question is a qualitative approach using case studies to conduct thematic qualitative text analysis. Qualitative research demands that the research develops inductively, or that meaning is made from the data itself, allowing the experiences of the social actors to be recognized as part of the knowledge making process and for their words to speak for themselves (Lindlof \& Taylor, 2011). This type of approach is very appropriate for my research on Black comediennes on YouTube and how they utilize political comedy and alternative media in challenging stereotypical and racialized representations of themselves in traditional media. As this question asks for the investigation of a marginalized group, using a method that puts the data first is important to bring depth to the research and prevent any chances of epistemic violence. It is also important to not hold a viewpoint that reduces my case study individuals to stereotypes and reinforces an essentialist point of view. 
Gunaratnam (2003) states that qualitative methodologies when researching race should be discursive, a "mutual constitution of embodied experience and social discourse," and requires a reflexivity that acknowledges "that research is a part of a social and historical relation and produces rather than simply reflect[ing] what [one is] researching" (p. 7). I seek to achieve this by combining social discourse with historical and social theory to examine Black comediennes and resistance on YouTube, and as such the qualitative methods, case studies, and thematic text analysis, looks at the ways race, gender, and resistance are constructed within this comedic practice. Acknowledgement of my own embodied experience through reflecting my identity, intersectionality, and positionality (see 1.3) helps create a product that itself is an act of resistance. Although I had a general research question guiding me, there is no hypothesis and thus the data is allowed to speak for itself, celebrating the voices of these Black comediennes and their political comedy.

Thematic qualitative text analysis is the method of analysis used to examine the videos of these two Black YouTube comediennes as a way to systematically investigate their work for comparable themes, thus allowing the data to dictate its analysis. Thematic qualitative text analysis does not require a specific data collection method but provides seven steps for analysis that I followed. These steps are as follows: (1) Initial work with the text, highlight important passages, and write memos, (2) develop main topical categories, (3) open-coding process, (4) compile the data assigned to each code, (5) determine subcategories, (6) close coding process and (7) category based analysis and presentation of results (Kuckartz, 2013, p. 68-69).

These steps, as outlined by Kuckartz (2013), are a systematic process to analyzing the text of a data set for thematic similarities. This process allowed the findings to be 
inductive and provided the means to investigate the content for the underlying theories, ideologies, and contexts that inform the videos. It is important to note that while Kuckartz (2013) is specifically referring to interview content when they say text, this analysis method can be applied to other media forms such as videos.

While I was using thematic qualitative text analysis to analyze the data collected, I decided to use case studies as research design and method of data collection to investigate multiple perspectives on this topic (Lewis, Ormston, Ritchie, \& McNaughton Nicholl, 2014, p. 66). Case study research design was selected, as it allows for an indepth investigation of a single individual, group, or event to explore the complexities of a present phenomenon (Yin, 2014). It is especially useful for trying to test theoretical frameworks by using them in real-world situations (Yin, 2014). Furthermore, because of its flexibility, rather than proving or disproving a hypothesis, it might introduce new and unexpected results creating openings for alternative research trajectories (Yin, 2014). In other words, case study research design provides the ability to look at the phenomenon Black comediennes nuanced representation within its real-world context, connecting the discriminatory ideological context that is a part of it. In addition, having two perspectives on a topic builds understanding that is "holistic, comprehensive, and contextualized," traits key to ensuring that marginalized voices and their cultural products can be wellrepresented in this thesis (Lewis et al., 2014, p. 67).

\subsection{YouTube and Case Studies Selection}

As I am researching how Black female comedy creators on YouTube employ both political comedy and alternative media in challenging the stereotypical and racialized 
representations of themselves in traditional media, my primary source of data collection is from the social media platform, YouTube. I chose YouTube as the alternative media platform from which to identify my case studies as it is the leading video upload site and is the second most visited website in the world (Arthurs, Drakopoulou, \& Gandini, 2018). Although my case studies are active users of Twitter and Instagram, YouTube allowed me to examine their longer form and more popular work. It also provides existing categories of form, such as the faux news show or the beauty tutorial, that also informs the content Hughes and Ramsey create. As I am interested in form as well as narrative content, YouTube is the best literal and figurative site of exploration for determining links between form and content in resistance practices.

I have catalogued a select number of uploaded videos, which can be found in tables 1 and 2, created by the Black YouTube comediennes, Franchesca Ramsey and Akilah Hughes, for their YouTube channels. Franchesca Ramsey is a self-identified writer, actress, comedian, and videoblogger based out of New York City (Ramsey, 2016b). She is also a published author of an autobiography Well, That Escalated Quickly: Memoirs and Mistakes of an Accidental Activist (2018), a former writer and contributor for The Nightly Show with Larry Wilmore on Comedy Central, and host of the MTV News web series Decoded. Ramsey’s YouTube channel, “Chescaleigh," has 286 uploaded videos and 245,251 subscribers. The first uploaded video is dated June 2007 and the most recently uploaded videos (uploaded on the same day) are from March 2019 and features Former First Lady Michelle Obama. Prior to those recent videos, the last upload was in February 2018, indicating her inactivity on the platform. 
Akilah Hughes identifies herself as a comedian and Upright Citizens Brigade trained sketch and improv person based out of Brooklyn, New York. She makes YouTube videos and is a writer for sites such as Femsplain and Refinery29. Hughes has done work with HBO's Pod Save America (2018), is a Sundance Fellow, a 2019 USC Civic Media Fellow, and has a collection of essays called Obviously: Stories from my Timeline coming out in late September 2019 (Hughes, n.d.). Hughes' channel, “Akilah Obviously" (formerly smoothiefreak), has 323 videos and 159,025 subscribers. The first uploaded video is from in December 2006 and the most recent video promoting her book was uploaded May 2019. Hughes' activity is not high, i.e. daily or weekly, but she uploads every few months, often in reaction to current events. Ramsey has explicitly stated in her Instagram Stories that she has no plans to return to uploading YouTube videos. Hughes has expressed interest in uploading but does not want to deal with the negative and racially charged comments.

It is important to note that although the subscriber count for both case studies may seem high, this is actually quite small in comparison to other female comedy YouTubers of colour like Lilly Singh whose channel, IISuperwomanII, boasts 14,830,154 subscribers or GloZell Green with 4,733,396 subscribers. So, while Hughes and Ramsey do have a viewership, in the context of YouTube, it is not a very large viewership. Others with a viewership like theirs would not necessarily have the same career opportunities. It is indicative of the quality of their content that Hughes and Ramsey have had success outside of YouTube. It is also important to state that I did not look at comediennes that upload live stand-up comedy or sketches from popular shows like Saturday Night Live or The Daily Show with Trevor Noah. I am looking at comediennes whose content is 
informed by the platform of YouTube and use political comedy as a means of challenging stereotypical representations of themselves.

Hughes and Ramsey are the two case studies whose videos I use as data for my thematic analysis. I chose Hughes and Ramsey as their work as YouTubers who are also comediennes position them within this intersection of knowing the dominant culture of YouTube's communities. Hughes and Ramsey are thus appropriate for my research that is concerned with how the platform of YouTube influences their comedic form. In addition, identifying my case studies as YouTubers who are comediennes separates them from other well-known Black comediennes whose work on YouTube is simply filmed stand-up comedy, rather than comedy created for the platform itself.

As Hughes and Ramsey are the only Black YouTuber comediennes I found that exist in this intersection of political sketch comedy and resistance, this was a convenience sample. There are other Black women using comedy on YouTube, like GloZell Green, but the majority of her videos do not consider the same political issues that Hughes and Ramsey do. I learned of Hughes' and Ramsey's channels through my personal engagement and consumption of YouTube content and cultural products concerned with Black women and political comedy. I did search for other creators producing this type of content, but Hughes and Ramsey were the two Black women that I could find that explicitly tackle issues regarding race, politics, gender, and equality in comedic format on YouTube. It is important to note that in addition, Hughes and Ramsey also make videos that are not explicitly political in nature or explicitly comedic in nature, such as video blogs of life experiences. I determined which video is political and comedic is based on 
whether the topic is commenting or subverting assumptions or principles relating to a belief or ideology that is concerned with issues of power and status in a society.

\subsection{Data Selection and Collection}

Thirty videos total were chosen to be examined closely and carefully for thematic similarities for the overall thematic analysis. Fifteen videos from each case study were used to provide equal opportunity to add to the data. Thirty as a number was chosen to afford enough data to allow themes to emerge while still being small enough to be a feasible data size for the limitations of this thesis. According to Ritchie et al. (2014), it is important to organize data collection in a way that allows for an even distribution of data from each case to be analyzed but incorporating all the relevant videos to analyze would result in very large, unmanageable, and infeasible samples for a research project of this size. To choose these videos, the 55 most popular videos, or videos with the highest view count, for each case were placed into an Excel spreadsheet and then randomized using the function capabilities in the program. As stated previously, Hughes and Ramsey also create content that is not comedic or political in nature and as such would not be appropriate for my data set. By randomizing a larger number of videos, I increased my chances of getting videos that are both random and appropriate for the study. After the videos were randomized, I viewed the top twenty-five videos for each set and removed videos that were not applicable to the study. The videos removed from the sample were blatantly off-topic, like non-comedic sponsored videos or very serious political videos that do not seek to subvert expectations with comedy. After this preliminary viewing for 
the appropriateness of data, I then took the first fifteen videos in the randomized order for both cases and my data set and can be found in tables 1 and 2 .

Table 1: List of Videos Analyzed from Akilah Hughes

\begin{tabular}{|c|l|}
\hline $\begin{array}{c}\text { Popularity of video } \\
\text { (out of 323) }\end{array}$ & Name of Video \\
\hline 1 & Meet Your First Black Girlfriend \\
\hline 2 & Honest Everyday Makeup Tutorial \\
\hline 3 & White Party - A Lesson in Cultural Appropriation \\
\hline 4 & On Intersectionality in Feminism and Pizza \\
\hline 5 & Every Natural Hair Video Ever \\
\hline 12 & Racial Discussion Fatigue Syndrome \#RDFS \\
\hline 16 & How to Be an Introvert -- According to Tumblr Ep. 1 \\
\hline 19 & How Feminists Watch Commercials \\
\hline 20 & HOW OLIVIA POPE *HANDLED* THE WINTER HIATUS \\
\hline 21 & ALWAYS PUNCH NAZIS | This Shouldn't Be News \\
\hline 22 & How to Straighten Natural Hair -- A Horror Story \\
\hline 23 & 5 FUN NEW WAYS TO WALK IN *HEELS*!! \\
\hline 31 & 20-Something Friday \\
\hline 38 & How Do Black People Feel About Spring? \\
\hline 48 & Instagram Single \\
\hline
\end{tabular}

Table 2: List of Videos Analyzed from Franchesca Ramsey

\begin{tabular}{|c|l|}
\hline $\begin{array}{c}\text { Popularity of video } \\
\text { (out of 286) }\end{array}$ & Name of video \\
\hline 1 & Shit White Girls Say...to Black Girls \\
\hline 2 & Shit White Girls Say...to Black Girls: 2 \\
\hline 7 & 5 Tips for Being an Ally \\
\hline 9 & How Slut Shaming Becomes Victim Blaming \\
\hline 10 & The Many Problems With, I Want Mixed Babies $\sim$ \\
\hline 13 & No Mo' "No Homo" \\
\hline 21 & 5 Comebacks for Your Racist Relative During the Holidays \\
\hline 22 & Costume \#FAILS \\
\hline 23 & Happy Thanksgrandma! \\
\hline 24 & Just Stop Talking About Race!! \\
\hline 29 & The Many Problems With, $\sim$ You Sound White \\
\hline 32 & 2016 Oscar Nominees Nail Tutorial |\#OscarsSoWhite \\
\hline 35 & REBLOGS (Tumblr song) | Lady Gaga "Applause" Parody \\
\hline 36 & Oreo Pride! \\
\hline 54 & \#ScandalABC Parody $\sim$ A Scandalous Tutorial \\
\hline & \\
\hline
\end{tabular}


Following the identification of my data set, I recorded the number of views, 'likes', 'dislikes', and familiarized myself with the comments to help provide a basic knowledge of the audience engagement for each video. I did not record methodical data of whether the comediennes were interacting with commenters but rather skimmed comments to ascertain what the comment sections were like for each video. This information was not used to determine their ability to engage with their audience, but rather to note how the viewing audience may be reacting to the content and how the comediennes were navigating it. For example, when the comments for a video were racist or discriminatory, Ramsey disabled the ability to comment on the video and Hughes disabled the ability to "like" and "dislike" the video. Statistical data like this cannot draw conclusions on its own, but it can be used to enrich the information gained from other data. After I collected this data, I employed thematic qualitative text analysis to research the intersections between Hughes and Ramsey's strategic use of comedy and the forms that alternative media encourages.

\subsection{Data Analysis}

After the videos were finalized, I used NCapture to import the videos directly from YouTube's website to NVivo (QSR International), a qualitative and mixed methods research software made to organize and analyze data. Importing the data directly from YouTube offered the ability to select a specific part of a video for a specific code, providing timestamps for the section selected for easy identification if need be. The program also lets you group the videos by certain criterion, like codes, making it easy to see connections between codes and videos, and discover themes. 
Once all the videos, which were each treated as a single text, were inputted into NVivo, I employed the thematic qualitative text analysis strategies and followed the process outlined above to research the intersections between Hughes and Ramsey's strategic use of comedy and the form that alternative media encourages. As the thematic qualitative text analysis process is inductive or emergent from the data, I did not have specific terms to look for. Instead, all of the key terms or themes were revealed from the data itself. Therefore, having a clear and systematic way of reviewing the data was crucial to ensure I would get the best information I could.

The first analysis step occurred when I first watched the videos for data collection. Deciding which videos were appropriate for this research at that stage was my initial work with the text. After data collection was complete, I watched each video again looking for general content descriptions and pithy passages and recording them by hand in a notebook. In this viewing, I marked the narrative of the text and then proceeded to note anything that stood out as interesting or relevant, such as the tone of the video. Much of this step insisted that I was focused more on the big picture rather than specifics in order to not get distracted by details. The general content descriptions were used to create the main topical categories needed for step two of the process. The main topical categories identified were Blackness, womanhood, comedy, politics, and form. These categories were determined both through the content descriptions collected in step one and my research questions.

The third step of thematic qualitative text analysis is opening coding using main topical categories. To do so I viewed the videos again placing selected passages of each text into the aforementioned main categories. Many videos were in multiple categories; 
thus, I was focused on specifics within the videos rather than larger subject matter in order to get an accurate analysis of what each video was concerned with. In addition, I noted any instances of intertextuality, notions of power, political terms, and words related to race or gender relations. Through the use of Nvivo's coding tools, compiling the data (step four) for each code was very simple and helped determine subcategories from those codes. The codes for the subcategories are listed in Table 3.

This closed-coding process was labour intensive as it required multiple viewings of each video. Multiple viewings were necessary to ensure I captured both explicit and implicit references to the new codes and their subcodes. I also note that as my research looks both at narrative content and form, filmic methods like compositional interpretation, a form of analysis that derives meaning from the formal arrangement of a visual, was used to reveal implicit references to the codes. Compositional factors, such as the style is it filmed, the lighting, the editing, and what sounds or music are also used to create meaning for the audience. As the text is audiovisual in nature, taking note of these compositional factors allows for more data to code and thus adds to the interpretation and analysis of the overall data. Once I reached a point of saturation where no further links to the codes could be found in the text, I searched for possible connections; categorizing and identifying emerging themes in the notes. I continued these two steps for each text. After notes and categories were identified for each video, I began to consider all of the notes ensuring to pinpoint themes that do and do not seem to connect to tease out the broad themes for the data. As this coding process was inductive, I did not have specific terms to look for. Instead, all of the key terms or themes were revealed from the data itself. 
Table 3: List of Codes

\begin{tabular}{|c|c|c|}
\hline Code & Description & Subcode(s) \\
\hline $\begin{array}{c}\text { Affective } \\
\text { Labour (AL) }\end{array}$ & $\begin{array}{l}\text { Used when text seeks to educate on emotionally } \\
\text { exhausting topics or is commenting on the process of } \\
\text { this type of education. }\end{array}$ & $\begin{array}{l}\text { Laughing at AL, } \\
\text { Rejection of AL, } \\
\text { White Guilt }\end{array}$ \\
\hline Blackness & $\begin{array}{l}\text { Used when text refers to Blackness in any way (i.e. } \\
\text { Black community, experience, appearance etc.) }\end{array}$ & $\begin{array}{l}\text { Black Hair, In-Black } \\
\text { Divides }\end{array}$ \\
\hline Capitalism & $\begin{array}{l}\text { Used when passage is concerned with making money } \\
\text { or selling a product for profit. May include } \\
\text { mentioning brands. }\end{array}$ & $\mathrm{N} / \mathrm{A}$ \\
\hline Comedy & $\begin{array}{l}\text { Used when a particular passage is funny. As there are } \\
\text { many ways to be funny, subcodes were used for } \\
\text { greater understanding. }\end{array}$ & $\begin{array}{l}\text { Comedy for Black } \\
\text { Viewers, Metaphor, } \\
\text { Parody, Sarcasm, } \\
\text { Exaggeration, } \\
\text { Trivialization }\end{array}$ \\
\hline $\begin{array}{l}\text { Pop Culture } \\
\text { References }\end{array}$ & $\begin{array}{l}\text { Used when intertextual references to film, television, } \\
\text { and/or music is used. }\end{array}$ & N/A \\
\hline $\begin{array}{l}\text { Current } \\
\text { Events }\end{array}$ & $\begin{array}{l}\text { Used when the current events are used in the subject } \\
\text { matter. Often political. }\end{array}$ & $\mathrm{N} / \mathrm{A}$ \\
\hline Womanhood & $\begin{array}{l}\text { Used when the text refers to issues concerning } \\
\text { women or expressing an aspect of daily life as a } \\
\text { woman. }\end{array}$ & $\begin{array}{l}\text { Feminist remarks, Sex } \\
\text { Positivity, Sexual } \\
\text { Violence }\end{array}$ \\
\hline $\begin{array}{l}\text { Patriarchal } \\
\text { Ideology }\end{array}$ & $\begin{array}{l}\text { Used when text comments on beliefs grounded in } \\
\text { white male dominance. }\end{array}$ & Societal Expectations \\
\hline Fetishism & $\begin{array}{l}\text { Used when text refers to the Black female body is } \\
\text { viewed as "exotic", a sexual object, or worth } \\
\text { obsession. }\end{array}$ & $\mathrm{N} / \mathrm{A}$ \\
\hline $\begin{array}{l}\text { Marginalized } \\
\quad \text { People }\end{array}$ & $\begin{array}{c}\text { Used to indicate when content does not refer to } \\
\text { Blackness but is concerned with individuals outside } \\
\text { of the white male heteronormative class in an } \\
\text { educational or political way. }\end{array}$ & $\mathrm{N} / \mathrm{A}$ \\
\hline Racism & $\begin{array}{l}\text { Used when issues of racism, both overt and subtle, } \\
\text { are addressed or appear in the video }\end{array}$ & $\begin{array}{l}\text { Rejection of Racist } \\
\text { Language, } \\
\text { Internalisation of } \\
\text { Racism, Cultural } \\
\text { Appropriation } \\
\end{array}$ \\
\hline Shame-Fear & $\begin{array}{l}\text { Used when the text referred to aspects of Blackness } \\
\text { or womanhood as discriminatorily, as something one } \\
\text { should be ashamed of. }\end{array}$ & $\mathrm{N} / \mathrm{A}$ \\
\hline $\begin{array}{l}\text { Utilization of } \\
\text { Filmic Genre }\end{array}$ & $\begin{array}{l}\text { Used when formal or visual elements of classic genre } \\
\text { i.e. romance, horror, etc. appeared in videos. }\end{array}$ & $\begin{array}{l}\text { Parody of Genre } \\
\text { Tropes, Parody of } \\
\text { YouTube Tropes }\end{array}$ \\
\hline
\end{tabular}




\subsection{Thematic Categories}

From this process of coding, I was able to identify three main themes that I will address in full in the next chapter. The three themes were drawn by categorizing the results of the closed coding process and are as follows, the White Feminine Beauty Ideal, Rejection of Discriminatory Ideologies, and a (New) Black Womanhood. These themes were found to be the connecting tissue between videos with intersecting codes. In Chapter 4, I will be organizing my findings and analyses using a narrative approach as it allows the data to be analyzed by theme, while providing a summary and displaying findings in a persuasive manner. This type of presentation allows the researcher to show how and why certain categories and themes were teased out from the data (Drisko \& Maschi, 2015). 


\section{Chapter 4: Analyzing Akilah Hughes and Franchesca Ramsey}

\subsection{Introduction}

In this chapter I will discuss the results of the coding of Hughes and Ramsey's videos. Analysis of these codes seek to reveal some of the social topics that Hughes and Ramsey interrogate through their use of political comedy and YouTube. The codes and close narrative reading from this research has highlighted three themes in which this chapter is divided: YouTube and Perpetuations of the White Feminine Beauty Ideal, Rejection of Sexist, Homophobic, and Racist Ideologies, and A (New) Black Womanhood: Displaying and Interrogating Notions of Self. Many of the videos in my sample fit into multiple themes, but for the scope of this research I only present specific narrative analyses for some of the videos.

The first section, YouTube and Perpetuations of the White Feminine Beauty Ideal, describes the remediation of the white beauty ideal and presents videos from the sample that challenge that notion. Hughes and Ramsey's most explicitly activist videos in regard to sexism, homophobia and racism are found in the second section called Rejection of Sexist, Homophobic, and Racist Ideologies. This theme looks at how Hughes and Ramsey use humour to provide new ways to think about discriminatory ideologies and how their videos work as tools of education. The last section, A (New) Black Womanhood: Displaying and Interrogating Notions of Self, reveals these videos as product of solidarity with Hughes and Ramsey's viewers and rejects the social expectations of Black womanhood. 
In each section I present the main theme, followed by context and background, and a brief overview of the theoretical framework that supports the theme. After introducing the theme, I then provide specific examples from the videos themselves. The videos are summarized, and specific quotes or scenes are transcribed or highlighted to emphasize the work Hughes and Ramsey are doing. With each example, I discuss specific connections between the content of the video and the theoretical framework outlined in Chapter 2.

\section{2 "Here's Thirty Seconds of Self-Indulgent Hair Angles" - YouTube and Perpetuations of the White Feminine Beauty Ideal}

A peppy, feminine voice tells the viewer that "this last swipe of lipstick completes the look," while the lens zooms in closer on the subject and they turn their head to present a variety of angles showcasing the makeup on their face. This scene is not unlike the majority of beauty tutorial videos found on YouTube. A typical beauty tutorial shows its viewers how to use products like foundation, eyeliner, mascara, lip gloss, and bronzer to make themselves look like they have clearer skin, bigger eyes, fuller lips, and defined jaws and cheekbones. These cosmetic products and the tutorials that show you how to use them are just one way that various feminine beauty ideals have been incorporated into the content found on YouTube.

The white feminine beauty ideal is the notion that the European features of pale white skin, straight, blonde hair, thin noses, and blue eyes is the epitome of beauty (Bryant, 2013; Baker-Sperry \& Grauerholz, 2003; Jorgensen, 2019; Robinson-Moore, 2008). As discussed in Section 2.3.2, this notion asserts that a woman is more beautiful 
the closer they are to that European standard. YouTube is not separate from the western media practice of normalizing and prioritizing the white feminine ideal.

The white feminine ideal is most visible in beauty tutorial videos on YouTube. The creators of beauty tutorial videos are typically white, though not always women (i.e. James Charles), but the ones that are celebrating difference and advocating for diversity in the beauty industry are not nearly as popular in terms of views and subscribers in comparison to the top beauty gurus. There are gurus of colour like Jackie Aina and PatrickStarr who forefront diversity of race, gender, and sexuality and have beauty channels with hundreds of millions of views, while white gurus like NikkieTutorials, James Charles, and Tati Westbrook all have over a billion views for their channel and seldom question the diversity of the beauty industry.

When coding the data set from Hughes and Ramsey, five videos distinctly utilized the beauty tutorial format or had content in relation to the beauty industry. These five videos, "How to Straighten Natural Hair -- A Horror Story" (Hughes, 2014e), "5 FUN NEW WAYS TO WALK IN *HEELS*!!” (Hughes, 2014c), “Every Natural Hair Video Ever” (Hughes, 2014f), "Honest Everyday Makeup Tutorial” (Hughes, 2014b), and “\#ScandalABC Parody A Scandalous Tutorial” (Ramsey, 2013b), from Hughes and Ramsey work to comment on the white beauty ideal, its relationship with colonialism, sexism, and the commodification of beauty. Hughes and Ramsey utilize the aesthetics of the beauty tutorial and combine it with satire in order to bring focus on the colonial, sexist, and capitalistic values of the beauty industry. 


\subsubsection{Black Hair and the White Feminine Ideal}

In February 2019, National Public Radio's race and identity show, Code Switch, aired an episode called, "Is Beauty in the Eyes of the Colonizer?" This episode took a look at the beauty norms across the world and the ways American beauty ideals are closely related to race with the focus of upholding whiteness as superior in the beauty industry (Donella, 2019). The white feminine ideal as the western beauty standard continues to be a topic of modern conversation, and Black women are still trying to find a way to grapple with this ideology in their everyday lives. Even in my own personal life, my Indian descent grandparents warned that I should not stay out in the Caribbean sun for fear I get "even darker." Now I do my best to be in the sun for as long as possible in direct refusal of the internalisation of whiteness that my own brown grandmother has.

One way that Hughes and Ramsey reject white beauty standards is in the way they present themselves in all their videos. More specifically, in the way they style their hair. Hughes seldom straightens her hair, opting instead for a protective style of twists or for a style that showcases the natural " $z$ " shaped coils in her hair, appearing as a beautiful afro. In her videos, Ramsey has her hair in locs or dreadlocks, a style in which the hair strands "coil around themselves into fused units" (Sandeen, 2019, para. 1). These hairstyles, locs, afro, and protective braids or twists, are a rejection of the straight hair many Black women aspire to have. The white feminine ideal dictates that long straight hair is the only beautiful hair type and there is a history of Black women using harsh chemical straighteners and hot combs to straighten their hair (Lester, 2000). These politics of Black hair have caused many to internalize whiteness and develop a resentment for their hair in personal and professional environments (Lester, 2000). In fact, many Black women 
straighten their hair for interviews, because otherwise they may not be seen as professional and suitable for the job (Collins, 2009; Donella, 2019). Each time Hughes and Ramsey make a video, they are speaking against these racial biases of hair and are showcasing that hairstyles that do not conform to whiteness are still professional, neat, and beautiful.

"How to Straighten Natural Hair -- A Horror Story" is a video by Hughes that also touched on the subject of hair straightening and beauty standards. Straightening one's hair is not a practice exclusive to Black women. Many people use hot tools or chemical straighteners to get their hair straight but keeping one's hair curly is an act that many women of colour do in direct opposition to colonialist standards (Norwood, 2017). In this video, Hughes takes a stance on societal ideals of hair and puts into perspective the amount of work it takes to make kinky Black hair socially acceptable according to white feminine beauty ideal.

"How to Straighten Natural Hair -- A Horror Story" is told in the style of kids telling scary stories at sleepovers by Hughes herself, who sits with a blanket over her head and a flashlight under her chin to create a scary ambiance. The story Hughes tells is of a "girl who looked just like [Hughes] but not as hot, and she had curly hair, but she decided that it would look good... straightened [emphasis in original]!" (Hughes, 2014e). Hughes continues to convey this story of straightening her hair using the general five-step process of shampooing and conditioning the hair, detangling the curls, separating hair into sections, blow drying them in those sections until dry, and flat ironing the hair until smooth and straight. 
Through each of the steps, she highlights the unpleasant parts of straightening one's hair, such as the pain accompanied with detangling and blow drying the hair and the fact that it took four hours to complete. One memorable part of Hughes' scary story is found when she talks about flat ironing her hair.

"One thing they don't tell you about straightening natural hair is that it starts to smell like bacon. But not in the way that you want your hair to smell like bacon. Like burning" (Hughes, 2014e).

This statement is true and a bit disturbing, but it highlights the damage some do to their hair in order for it to fit into the white feminine ideal of beauty. Hot tools like a flat iron can damage hair, altering the curls patterns when in its natural state. Damage to Black hair is historical with slaves using lye, a caustic solution to straighten hair. This practice continued with Black men in the 1920-60s using congolene, a lye-based gel that could make your scalp burn and feel like the skin was being torn off (Lester, 2000). Throughout the video, Hughes talks about very real situations involved in straightening natural hair and frames them as scary. For example, she talks about how long the process takes, how it feels like you are doing so much without any progress, and how your arms can get so tired, and the process is so intense that drinking alcohol, or, as she states, poison, seems like a necessary course of action.

Another part of this video that is memorable and speaks to the white feminine beauty ideal is the ending. After the hair is straightened and Hughes has finished drinking the 'poison,' she realized:

“[T]he poison wasn’t poison, it just made her really likeable and funny... in crowds. So, she was like, 'cool. My hair looks good and I am so charming right 
now.' So, she took some more poison and then she went out, and made out with cute boys. The end" (Hughes, 2014e).

The ending of the of "How to Straighten Natural Hair -- A Horror Story" is very funny as it trivializes the entire process of straightening her hair by ending with alcohol and making out with boys, but it also highlights the correlation between the feminine beauty ideal and women's desirability to men. This reiterates one aspect of the white feminine beauty ideal that dictates “that physical attractiveness is one of women's most important assets, and something all women should strive to achieve and maintain" (Baker-Sperry \& Grauerholz, 2003, p. 711). This notion infers that only thing of value to women is their attractiveness as perceived by men and it follows the patriarchal ideology that women are to be objectified and devalued and it continues to be oppressive towards all women (Baker-Sperry \& Grauerholz, 2003, p. 711). In other words, the white feminine beauty ideal places the value of women in their attractiveness to men according to the white standard. In this sense, Hughes is calling attention to the fact that there is an association between straight hair and attractiveness by stating that the straight-haired girl could now go out and kiss "cute boys."

Hughes uses horror genre conventions to convey how traumatic the process of straightening kinky, curly, Black hair can be. Throughout the video the lighting is dull and muted containing tones of blue, green, purple, and red in its colour grading, which in turn washes out the character, literally painting them in a harsh light. This lighting also gives off the illusion that Hughes is being watched or something is going to attack. The sound in this video is ominous, more atmospheric than melodic, like the soundtrack to a haunted house. All of these aural and visual conventions or characteristics serve to 
promote the sensation of fearing the unknown, similar to what can be found in horror and suspense movies (Pérez-Guerrero \& Forero-Serna, 2018). Utilizing existing genre conventions in this beauty tutorial format takes advantage of the expectations one already has for a horror video. Hughes is able to harness pre-existing expectations of the formal elements of horror to drive home the fact that straightening curly, kinky, Black hair is scary.

Through the use of horror genre conventions, Hughes' look at straightening natural hair is exaggerated, and in that sense, it is funny. Hughes overuses some horror conventions for comedic effect. For example, periodically the sound in the video will abruptly change to emphasize what is going on narratively. A screechy noise or a moment of silence gives the viewer a moment of pause, often also creating a moment of comedic relief, like when she reveals that after drying her hair for an hour, her hair "was still big... It was not straight; it was just puffy!" (Hughes, 2014e). This exaggeration through aural and visual filmic conventions brings comedic effect and emphasizes how strenuous the hair straightening process is for Black women.

While the formal elements create the exaggeration needed for this comedic and satirical look at straightening kinky curly hair, it is still very accurate. The time and effort Black woman take to straighten their hair makes the process a nightmare and it is horrifying to the hair itself. Hughes brings this reality to forefront by using exaggeration and centering her own experiences with straightening her hair as she herself goes through the process in the video. Naturally curly, coiled, and kinky hair does not need to be straight to be beautiful. Furthermore, this type of hair does not want to be straight and 
subjected to the heat and chemical damage in order to fit into the colonialist ideal that "good hair" equals straight hair.

\subsubsection{Patriarchal Expectations of Beauty}

In the 2006 movie, She's the Man, the lead character states that "heels are a male invention made to... make it harder for [women] to run away", and it stuck with me. High-heeled shoes can be uncomfortable, so why is it expected that women wear them? Though initially made and worn by men in the $15^{\text {th }}$ to $17^{\text {th }}$ centuries, high-heeled shoes (heels) are a type of footwear with a higher heel made to make the wearer look taller (Marsh, 2017). Now, they are a feminine staple with the expectation that all women must wear them, as they make the wearer's legs longer, butt nicer, and make them seem powerful, professional, and formal (Segran, 2018; Cleary, 2015; Negru, 2016; Burcar, 2019).

Hughes touches on the relationship between the beauty ideal of heels and patriarchy in her video "5 FUN NEW WAYS TO WALK IN *HEELS*!!” (Hughes, 2014c). This video, which also utilizes list culture and how-to videos, provides a feminist take on the practice of wearing high-heeled shoes and works as commentary on this expectation. Heels can be very uncomfortable, and some people walk in a way that shows their discomfort, which can be funny. Hughes points out the hilarity in the normalized behaviour of wearing heels by presenting pain alleviating walking styles as "new, fun ways" to wear heels (Hughes, 2014c). In this video, Hughes showcases herself demonstrating five "walks" to do in heels. Two examples of this include "The Yeti" and the "The Rookie Model."

The Yeti: In this, Hughes is pictured taking long, slow strides across a sidewalk. 
"Graceful is so last year, fiercely stomp through exaggerated strides to make the most of each excruciating step. Ooo yas, you look so good, and you're almost there. You're easily clearing four times the distance you would have if you just settled for flats tonight" (Hughes, 2014c).

The Rookie Model: In this, Hughes holds herself up by the walls of a hallway and dangerously wobbles in her heels.

"Nothing makes you seem as young and fresh as wobbling around on your heels as much as possible. Like a poorly executed figure skating jump, this anxietyinducing walk is tough to watch and even tougher to perform" (Hughes, 2014c). Some of the things Hughes is describing as walks are simply movements that occur when some women have been wearing heels to the point where they are in pain. In these examples, Hughes pinpoints the way heels affect your gait and how dangerous they are. Many journals in the medical field, such as the Journal of Foot and Ankle Surgery and Footwear Science, have published on the physical effects of wearing high heeled shoes. Moore, Lambert, Jenkins, and McGwin (2015) state that wearing high-heels "significantly reduce[s] ankle muscle movement, step length, total range of movement, and balance control and concurrently increase[s] the workload on the hip flexor muscles during the transition in gait" (p. 615). Wearing high-heels though they can be aesthetically pleasing and make one feel tall and thus powerful, are in many ways hazardous. With "the Yeti" and "the Rookie Model", Hughes is commenting on the absurdity of wearing shoes that one cannot walk in, simply for the sake of aesthetics. Another walk, "the Jack Sparrow", describes when someone shifts their weight back and forth on their heels to the point where they look a bit intoxicated and Hughes 
ends this description by stating, "someone would probably make out with you, I guess" (Hughes, 2014c). This suggests that some wear heels in hopes of seeming attractive. Even fairy tales enforce this mentality. The fairy tale, Cinderella, notably indicates that highheeled shoes are associated with femininity and beauty. Popularized by French author Charles Perrault, Cinderella tells the tale of a poor, mistreated woman who finds wealth and love because of her glass high-heeled slipper, a statement of feminine standards and wealth (Buracar, 2019, p. 353). This story also dwells on the unattainable beauty ideal that heels represent, as seen in the gruesome way the stepsisters of Cinderella mutilate their feet in hopes of fitting into the delicately feminine shoe.

Much of the humour in this video comes from the truthful exaggerations of these walks people do in heels. The extent to which some of these walks are done is heightened to a ridiculous level as Hughes is purposefully walking like her feet hurt. As heel wearers do not purposefully intend to walk like a Yeti, Hughes' performance is hilarious while still accurately describing this walk that is performed to alleviate some of the stress on one's feet. As a result, "5 FUN NEW WAYS TO WALK IN *HEELS*!!” is funny while drawing attention to the fact that many women wear heels in discomfort and showing that this practice is pointless.

While wanting to be attractive is perfectly reasonable, wearing footwear that is hazardously uncomfortable and can cause physical impairment seems unreasonable. The "fun" new ways that Hughes presents point out how unnecessary it is to succumb to the patriarchal ideal that because heels make your legs look longer and thinner, thus making the wearer more attractive, women must wear them. 


\subsubsection{The Commodification of Beauty}

One aspect of beauty ideals I have not commented on is the relationship between beauty ideals and commodification. Hughes and Ramsey take on this subject in in "Every Natural Hair Video Ever" (Hughes, 2014f), "Honest Everyday Makeup Tutorial” (Hughes, 2014b), and “\#ScandalABC Parody A Scandalous Tutorial” (Hughes, 2013b). These videos seek to point out ways that the commodification of beauty is perpetuated in online spaces through the formal conventions of YouTube beauty tutorials. For example, Hughes and Ramsey use close-ups of the item or the product to showcase its colour or brand name. In "\#ScandalABC Parody A Scandalous Tutorial," Ramsey satirizes the character Olivia Pope from ABC's Scandal, placing her in the position of a YouTuber filming a make-up tutorial (Hughes, 2013b). One of the ways this parody brings attention to beauty tutorials and their focus on incentivizing viewers into buying a product is by zooming in on the brown eyebrow pencil she uses in the look. After the eyebrow pencil breaks, although it looks like it could be sharpened back to a usable point, Ramsey as Pope panics and calls her right-hand man, Harrison.

"Harrison, we have a situation," says Pope fiercely. Harrison replies, "What's up?"

"My eyebrow pencil. I'm in the middle of a tutorial and it just broke." Pope appears greatly distressed and saddened by the pencil breaking.

"Not a problem, I'll handle it."

"It's Covergirl's -"

"Brow and Eye Maker in Midnight Brow," interrupts Harrison, as if this brow pencil is the only brow pencil ever needed. 
"I need you to get this pencil to me immediately or else this tutorial is ruined. I need you to do whatever it takes, and I mean whatever, to shut this thing down!" (Ramsey, 2013b).

This scene uses exaggeration, or overemphasis and distortion, to bring comedy to the scene and to draw attention to the blatant advertising present in tutorials (Knox, 1957, p. 804). The video places this narrative as serious, but the intensity of the exchange over something so trivial is quite humorous. Together, the humour and exaggeration serve to encourage the viewer to see one of the ways products are promoted in both narrative shows and on YouTube. In "\#ScandalABC Parody A Scandalous Tutorial," the Covergirl eyebrow pencil is presented as the only eyebrow pencil that can give Ramsey as Pope the as desired look, and without it, the "tutorial is ruined" (Hughes, 2013b). This comedic narrative serves to show the fallacy in that thinking, as a broken pencil is not the end of the world and certainly does not warrant one doing "whatever it takes" to get a specific cosmetic product.

Yet, the promotion of products on YouTube seem to encourage buying just like advertisements do. In the beauty community on YouTube, the feminine beauty ideal and its relationship to economic profit is highlighted through sponsorships ${ }^{5}$ from certain product lines and companies and free product sampling ${ }^{6}$. It is important to note that one

\footnotetext{
${ }^{5}$ A sponsorship refers to a paid relationship between a YouTuber or social media influencer and a company in which the YouTuber is paid to feature a certain product or product line. The nature of the relationship is transactional, but sometimes companies want an honest review, regardless of whether or not they are sponsoring the content.

${ }^{6}$ Free product sampling refers to when a company sends free products in a public relation or press package to a YouTuber or social media influencer in hopes that they will provide free publicity for the product in their videos or posts. These are not paid partnerships in the traditional sense, but there is still a transactional
} 
of the purposes of beauty standards is to make money. Beauty ideals function not only to other those who do not fit into the mold, but it also seeks to tell individuals of all races that the only way to truly achieve this white beauty ideal is through the purchase and use of beauty products. By zooming in on the brow pencil, clearly saying the name of the product, and conveying that this eyebrow pencil is the best, Ramsey highlights practices in the online beauty community that perpetuate the notion that the only way to be physically and aesthetically desirable is through the purchase and use of cosmetics.

Beauty tutorials have taken up the torch of advertising certain products by simply naming and using them in the video, showcasing how it works and subtly saying, if you want this look you need this product. In this sense, the promotion of products in tutorials can be more enticing, as the products are being promoted by a voice the viewer has learned to trust - the YouTuber (Wu, 2016; Nagy, 2017). In 2019, most sponsorships are disclosed, but there is a history of the disclosure of paid promotions being inconsistent and inconspicuous (Wu, 2016). In December 2018, YouTube updated its Paid Product Placements and Endorsements article to emphasize that YouTubers must disclose when a video features a paid promotion or endorsement in order to meet the requirements of Google's Ad Policy (Google, 2018). It is stated that disclosure and transparency were always expected, but it was often not adhered to. As the videos I am examining were created prior to the article's change in emphasis, my cases studies are commenting on advertising practices on YouTube that do not always uphold transparency. 
One of the problems of not disclosing a paid promotion is that a product can be presented as something the YouTuber honestly likes and uses to achieve the chosen appearance. While that could be the case, there is also the possibility that the YouTuber is not being honest about the product's effectiveness because they are being paid to promote it. Disclosing that a video is sponsored by the product or company gives the viewer the whole picture so that they can then decide whether or not they believe in the usefulness of the product and want to try it themselves. One of the videos from my sample highlights this practice well and points out how it can prey on viewers, encouraging them to buy products that may not actually work for them. This is particularly evident in "Every Natural Hair Video Ever" (Hughes, 2014f). Hughes holds a hair product in a spray bottle in her hand and applies it randomly in her hair.

'Now I'm going to try and trick you into buying a product that you think I haven't been paid to promote, but I totally have. You've never seen me use this before why would I start using it now? I don't know?"

The camera zooms in on the product in Hughes' hand and a voiceover with reverberation ominously says:

"Buy this! Buy this! Buy this!"

Hughes continues to highlight the product noting how she supposedly uses it.

"Here's a sh*tty re-enactment of how I did my hair that isn't really how I did it." Hughes changes her voice into a re-enactment tone dripping with sarcasm.

"So, then I just flipped my head upside down and just, like, keep spraying (the same product) and scrunching and if I, like, spray and scrunch enough it goes from, like, straight white girl hair to this. Like literally I had completely different 
hair until I did just this with this one product and now it looks like this, guys! You could have this hair too!" (Hughes, 2014f).

This scene is a prime example of how sponsorships are often not completely transparent. As this video refers to practices present before Google's change in policy, Hughes is commenting on the gray area in which an "honest" review of an item is not honest because the product's company is paying to promote it. The product Hughes is endorsing in this video is clearly not able to perform the way she is describing it, gesturing to how tutorials can become a space where the audience is being sold a product that is ineffective simply because they trust the YouTuber and their content. The practice of endorsing products because you are being sponsored by their company is often not dishonest and nefarious, but Hughes' satire calls attention to the instances where it can be and one way to notice them: if you have never seen the YouTuber use the product before and there is no explanation as to why they are using it now, be cautious.

Ramsey and Hughes are using tools of comedy and genre conventions to comment on the bigger issue of beauty on YouTube. There is an opportunity for individuals to use this platform to represent all kinds of beauty, not just the ones that fit into the colonialist white feminine ideal because there is increased access to upload and view different videos. Diverse beauty content on YouTube could be one of those ways, with beauty YouTubers of colour gaining a voice and changing the discussion. Unfortunately, as discussed at the beginning of Section 4.2, the beauty creators that are often promoted and highly viewed do not forefront racial difference or speak out against the commodification of the beauty industry. 
Talking about the feminine beauty ideals and the way they have been perpetuated on YouTube is one of the ways Hughes and Ramsey facilitate a change in the perception of not just Black women, but many minorities. While not blatantly fighting against a narrative that caricatures and devalues Black women, Hughes and Ramsey use comedic tactics and genre conventions that are specific to YouTube beauty tutorials to provide a message that is contrary to the popular belief system. Using the form typically seen in beauty videos primes the viewer to expect what to see while exaggeration and satire provide opportunities to subvert notions of whiteness. They do their best to provide a counternarrative to the notion that white is right and women are only valued for beauty. In these videos, Hughes and Ramsey play on the fundamental desire for beauty and call attention to the harmful patriarchal, capitalistic, and colonialist ideologies they can perpetuate.

\section{3 "If white people can say cracker, why can't I? - Rejection of Homophobia, Colonialism and Racism}

Black women are often doing work for all marginalized groups, not just the ones they are a part of, and they do so often without recognition. This is true for the gay rights movement in the 1960s with Stormé DeLarverie, Marsha P. Johnson, and Sylvie Riveria, a Black butch lesbian, Black trans woman, and Latina trans woman respectfully, fighting back at the Stonewall Riots (Julig, 2018). It is also true for the popular \#metoo movement as it was created by Black activist Tarana Burke in 2007 before being co-opted by white actress Alyssa Milano in 2017 with no credit given to Burke (Garcia, 2017). The Stonewall Riots were started by women against the white heterosexual norm, and \#metoo 
was started to highlight the sexist and patriarchal ideologies that underpin sexual harassment (Fraser, 2015; Yodanis, 2004).

These Black women and others like them speak out against discriminatory beliefs because they know what it means to be discriminated against. As racialized and gendered beings, Black women sit at an intersection of oppression, and like the women mentioned above, they seek to fight for the rights of many, not just their own (Crenshaw, 1991; Nash, 2008). When coding my selected videos, I realized many of Hughes and Ramsey’s videos spoke against harmful ideologies that uphold heterosexual whiteness. Specifically, Hughes and Ramsey comment on the homophobia, cultural appropriation, and racist and anti-Black ideologies that are prevalent in today's society.

In 2014, the film Dear White People commented on the practice of American college campus and Halloween costume parties that are blatantly racist and appropriate Black culture. In October 2018, a student at Brigham Young University wore blackface for a Halloween costume contest (Harris, 2018, para. 4-6). The practice of appropriating and offending a culture through clothing and stereotypical behaviour seems to prevail even when it is collectively recognized that it is wrong, and the perpetrators are reprimanded. Cultural appropriation or "the use of a culture's symbols, artifacts, genres, rituals, or technologies by members of another culture", is a colonial act closely linked with the commodification of a marginalized group (Rogers, 2006, p. 474). When persons from a culture that holds a high position of power co-opt a culture, it is often done with no regard to the original cultural significance. The act of cultural appropriation is directly addressed in two videos from my sample, "White Party - A Lesson in Cultural Appropriation” (Hughes, 2014e) and “Costume \#Fails” (Ramsey, 2012a). 
As Black women, Hughes and Ramsey tackle issues surrounding anti-Blackness and racism in general. Anti-Black racism is a system of power that sees descendants of Africans that were enslaved as unequal to other races. Prejudice, stereotyping, and discrimination towards these folks are deeply entrenched through policies and practices and is often normalized and rendered invisible to white society (Mullings, Morgan, \& Quelleng, 2016; Wun, 2014).

Homophobia, cultural appropriation, racist and anti-Black ideologies are ultimately founded in colonialist, heteronormative, and patriarchal beliefs (Delgado \& Stefancic, 2017; Kleisath, 2014; Sullivan, 2003). These ideologies seek to discriminate and disenfranchise individuals based on sexual orientation, culture, and skin colour. The following videos by Hughes and Ramsey provide examples in which discriminatory ideologies are normalized in everyday experiences. The videos continue to utilize exaggeration in their comedy to reveal the hateful beliefs underlying these normalized comments and behaviours. Hughes and Ramsey's work aims to educate, relate and invigorate those affecting and rejected by these dominant ideologies.

\subsubsection{The Rejection of Homophobic Ideologies}

The rejection of homophobic ideologies became visible particularly while coding Ramsey's videos. The two videos that distinctly interrogate external homophobia are “Oreo Pride!" (Ramsey, 2012d) and "No Mo' 'No Homo"” (Ramsey, 2012c). These videos use parody and exaggeration to highlight these discriminatory notions. The exaggerated comedy that is used in these videos act as a distorting mirror that draws attention to patterns that are typically acceptable, both in others and in ourselves (Knox, 1957). The distorting mirror of exaggeration in comedy does not just supply the means to 
laugh at the situation, but to also look at ourselves, displaying the fact that we may say or do things that initially seems harmless, but are in fact discriminatory (Knox, 1957).

The first video that works to call out homophobic and anti-gay sentiments is “Oreo Pride!" by Ramsey. This video from 2012 addresses a picture posted on the official Oreo Facebook page in support of Gay Pride Weekend. Oreo posted a picture of the cream-filled cookie with many coloured layers of cream making a rainbow in reference to the gay flag. The response included many comments bashing Oreo for supporting homosexuality with many saying they were never eating Oreos or Kraft products again (Stopera, 2012).

In this video, Ramsey satirizes local news shows by utilizing the formal news conventions like sitting at a desk, plain backgrounds, and personal testimonies or on the street footage, and turning the content of the news into a joke. Ramsey provides this information about the Oreo Facebook post and response in a clear, intentional, newscaster tone and cadence and makes an exaggeration linking the homophobic comments with weight loss. In other words, since these homophobic individuals follow Oreo so closely, and want to boycott Oreos, they might lose weight. Ramsey pokes fun at the mentality that since homophobia and discrimination is what underlies individuals boycotting Oreos maybe it will help some bigots lose weight. Fortunately, Ramsey does not linger on fat jokes, but brings the attention through the use of images and video footage that a company supporting LGBTQ+ rights is not reason to stop consuming its food products. Ramsey shows how excessive the response to the Oreo post was by exaggerating that people would lose weight by being homophobic. The absurdity of this claim is just as absurd as boycotting a cookie. 
Having a large company support like Oreo support LGBTQ+ rights in 2012 was a big deal in American society. At this point in time, same-sex marriage was not legal nationwide. In fact, it was outlawed and unrecognized until 2015 when the Supreme Court of the United States ruled it unconstitutional to ban marriage equality (Obergefell et al v. Hodges, 2015). Therefore, the reaction to boycott Oreos was not surprising, but it was still hurtful. That individuals could hate that someone is queer so much that they would actively not eat a particular food simply because they support this human right is unreasonable. It is indicative of how deeply embedded homophobic beliefs are in society. Another video that Ramsey uses to comment on homophobia is in "No Mo' 'No Homo." In this video, Ramsey tackles the qualifier "no homo" which is used when someone says things that are kind about the appearance of someone of the same sex (Ramsey, 2012c). It is typically added to the end of a phrase to indicate a statement had no intentional homosexual implications or to rid the speaker of "possible homosexual double-entendre" (Weiner, 2009, para. 2). Ramsey explicitly states that she finds the disclaimer, "no homo," pointless and that she is surprised it is still being used. In order to prove her point or provide means of understanding why she sees this phrase as unnecessary, Ramsey creates qualifiers of her own using the same rationale behind "no homo," which is 'I think you are physically beautiful, but I do not want to have sex with you'. She uses "no klepto" for kleptomania when asking to borrow a friends clothing, tells a dog how cute it is and adds "no beasto" for bestiality, and calls a baby adorable and adds "no pedo" for pedophilia (Ramsey, 2012c).

The phrases Ramsey says to spark the use of the invented qualifier are quite harmless and are phrases often said in everyday life. Qualifiers are not used in those 
situations because no one assumes that a person who asks, "can I borrow this sweater" wants to steal your clothes or saying "your baby is so cute" reveals that you are sexually attracted to babies. By using the comedic technique of exaggeration, Ramsey calls attention to the qualifier "no homo" and reveals that it is both an unnecessary and inherently homophobic phrase.

For years, homosexuality was deemed deviant and unnatural and while for many this view has changed, there is still an aversion towards being associated with this "deviance" (Sullivan, 2003). Much of homophobia is a result of fundamentalist biblical beliefs, as noted in this passage stating "if a man also lie with mankind, as he lieth with a woman, both of them have committed an abomination: they shall surely be put to death; their blood shall be upon them" (Leviticus 20:13, The King James Version). As Christianity is somewhat foundational in much of modern western society, this belief of homosexuality as an abomination, a crime, still exists today. Ramsey hints towards this with the term "no klepto," which places homosexuality in the same category of something like kleptomania. This calls attention to the reality that like stealing is a crime, many internalize the notion that being gay is wrong and criminal.

Within the Black community, homophobia, both internal and external, is highly prevalent. As the term "no homo" was popularized in the hip-hop community (Weiner, 2009), Ramsey is specifically speaking to Black communities and the historical and cultural factors that has produced homophobia. As a culture with a long relationship with faith-based groups with biblical beliefs that assert that homosexuality is an "abomination," Black communities often uphold anti-gay values and intolerance, even if individuals are not religious themselves (Sullivan, 2003, p. 4). In this way, homophobia is 
not just a societal value within the "the [B]lack church," it has permeated the belief system of those who do not observe or practice Christian religions. Ramsey is not just challenging homophobia in general, but she specifies it to her own Black viewers. She is speaking for the queer individuals of the Black community that see homophobia through even a popular phrase. Calling attention to the pointlessness and absurdity of using this phrase by creating her own qualifiers, Ramsey asserts that adding a qualifier like "no homo" to a sentence reveals the fear behind being considered a homosexual and the homophobia that exists in Black communities.

"No More 'No Homo"” and "Oreo Pride!" use comedy, specifically exaggeration, to bring a mirror up to homophobic statements that some say without acknowledgement of how hurtful and discriminatory it may be. "No Mo' 'No Homo"” in particular comments on a statement many use without the intention of being hurtful but equating the unnecessary colloquialism and its homophobic background with pedophilia or kleptomania reveals the underlying biases present. Through the use of exaggeration, Ramsey encourages reflection on everyday things individuals do and say that are rooted in prejudiced, homophobic practices. By taking the comedy to an over-the-top level, these comedic videos affirm the personal experiences queer individuals have regarding these homophobic remarks. In addition, it seeks to provide moments of reflection and education in a way that is accessible.

\subsubsection{Rejection of Cultural Appropriation}

Hughes" "White Party - A Lesson in Cultural Appropriation" (2014g) and Ramsey's "Costume \#Fails" (2012a) are two videos that address the colonial issue of cultural appropriation and are positioned within the genre of what I call informational 
videos. These informational videos take a larger subject and by using examples and other visuals, break that larger subject into small manageable sections that the general public can understand and thus access and use this information in their daily lives. These videos are visually set against a relatively plain background and use clear language to focus on the content.

"White Party - A Lesson in Cultural Appropriation" and "Costume \#Fails" use exaggeration and examples like in "No Mo' 'No Homo"' (Ramsey, 2012c), calling attention to instances when those of a dominant culture take aspects of a minority culture without honoring their original purpose and base their understanding of that minority culture on stereotypes. In "White Party", Hughes recounts the types of themed parties that take stereotypical ideas of Black, Mexican, and Indigenous communities and present them as pimps n' hoes parties, fiesta parties, and enchanted forest parties respectively (Hughes, 2014g). In "Costume Fails", Ramsey comments on native American costumes, the use of afro and dread wigs, and blackface (Ramsey, 2012a). These themes co-opt an aspect of a minority culture by stereotyping people from that group without appreciation or respect of the culture. This is the essence of cultural appropriation, co-opting part of a culture without respecting it (Kleisath, 2014; Rogers, 2006). Ramsey also points out that individuals who appropriate cultures often do not consider the historical oppression associated with these costumes and themes that people of colour have endured as a result of colonialism (Ramsey, 2012a).

Hughes and Ramsey use satire to put the offensive nature of cultural appropriation in context with the dominant white culture. In "White Party - A Lesson in Cultural Appropriation," Hughes uses the concept of a "white party", a party where people of 
colour dress, speak, eat, and act stereotypically white American, to reveal the harmful colonialist nature of cultural appropriation by turning the themed party on its head (Hughes, 2014e). The video is funny through its exaggeration of white stereotypes. People of Black, Japanese, Latina, and South Asian descent are shown wearing sweater vests or button up shirts with cardigans tied over the shoulders paired with ill-fitting khakis and Hughes narrates the scene posing the unspoken question, how would you feel if you were at a party and heard the following things?

"If white people can say Cracker, why can't I?"

"Don't clean that up we can get our maid to clean it for way under what we pay our kids to clean it."

"Check out Maria and Jesus doing the step-and-clap on the dancefloor. You can tell how much they love Bastille ${ }^{7}$ by how much further from the beat their claps get as the song goes on" (Hughes, 2014g).

Some of the statements mirror some of the things Hughes has heard or seen in these situations. The question above about the word "cracker" is a direct repurposing of the question, "if Black people can say 'n-gger' why can't I?" Other statements showcase the stereotypical nature of these parties like the two Latinos purposefully dancing offbeat to insinuate that all white people have no rhythm or the Muslim woman who insists that all white people have enough money to have maids.

As white culture is the dominant American culture, the general society knows that these beliefs are not true of white society. Conversely, because Indigenous, Black, and

\footnotetext{
${ }^{7}$ A British band known for the song "Pompeii."
} 
Mexican cultures are not dominant in American society, individuals may not know which stereotype is true and which is false. Costume parties that are steeped in appropriation can perpetuate stereotypes about these minority groups. Hughes attempts to show that if a themed "white party" holds falsehoods, maybe the "pimps and hoes" party has falsehoods too. Hughes showcases that for cultures that are not socially dominant, the nuances of a people or culture can be lost in favour of stereotypes. This is often the issue with cultural appropriation, even if done with good intent or with the intent to appreciate the culture, there is always the possibility of harming someone because nuances to the cultural product is missed (Kleisath, 2014). This could be acting a stereotypical way while in traditional garb or failing to recognize that wearing that garb could bring up centuries of oppression from one group to another. Hughes seeks to inform individuals that participate in these parties and practices to be reflexive of how their actions can affect others.

Ramsey addresses appropriation similarly to Hughes, by trying to place appropriation within a white American context. In "Costume \#Fails", Ramsey (2012a) puts herself in a blonde wig as the white voice in situations of appropriation. For example, when talking about how it is okay for her to "be an Indian ${ }^{8}$ for Halloween" because her great-greatgrandfather on her mother's side was a quarter Cherokee, blonde Ramsey is confronted with regular Ramsey.

"[Sarcastically] Sure! Who cares about colonialism or the countless laws that were created to erase Native Americans from this country? It was just genocide.”

\footnotetext{
${ }^{8}$ Here Ramsey is specifically using the colonialist term for the Indigenous or Native American people as it is still a term inappropriately used by settlers (non-natives) in areas of Canada and across the United States. It is assumed through Ramsey's visuals that dressing like an "Indian" is wearing a Native American headdress that would typically be worn by leaders and given as gifts from their community (Monkman, 2016).
} 
Blonde Ramsey responds condescendingly. 'I'm like, paying homage to their culture... it's like borrowing [emphasis added]" (Ramsey, 2012a).

In what is presented as blonde Ramsey's home, regular Ramsey compliments her television to which blonde Ramsey said she got it for graduation. At this time, regular Ramsey proceeds to take the television (Ramsey, 2012a).

"What are you doing," says blonde Ramsey.

"Oh, I'm just gonna borrow [emphasis added] it and put it up in my house"

"You can’t just borrow my TV!"

"You know what," regular Ramsey takes down a painting that was hanging on blonde Ramsey's wall.

"Please don't touch that," blonde Ramsey says with concern.

“I think I'm gonna take this too!” Regular Ramsey says pleasantly. "I don't know what it means... But it's kind of ironic, 'cause I know it means something to you.

It means absolutely nothing to me! Happy Halloween!” (Ramsey, 2012a).

This conversation between blonde Ramsey, who stands in for the excuses and ideologies of white society, and regular Ramsey clearly demonstrates the error of these excuses and the metaphor of the TV and painting translates the idea that what is called "borrowing" by colonial standards, is stealing. It is taking without any thought into how it may affect the owner.

A group of people, like our First Nation and Indigenous peoples, so systemically and systematically oppressed should never have to see their culture misused and disrespected. Even if one's ancestor was a quarter Cherokee, that does not mean that they know the oppression Indigenous peoples have faced, neither does it mean that they 
understand all the significances of wearing a traditional Cherokee garment. It is important to recognize your own racial and cultural positionality before engaging in an act that may be appropriation, because your behaviour can be an extension of colonialism and oppression rather than an appreciation of a group's culture (Kleisath, 2014).

Cultural appropriation is not black and white, there are a lot of grey areas and intent does not change the impact. Hughes and Ramsey use satire and parody in these two videos to contextualize the impact of cultural appropriation, particularly to white viewers. Although these videos are at times very comical, they both work to educate their viewers on what it means to wear, say, or do things that primarily belong to a minority culture and asks that instead people have fun without "wearing a culture as a costume" (Hughes, 2014e).

\subsubsection{Racist Ideologies and Anti-Blackness}

Throughout my research of Hughes' and Ramsey's videos, Blackness, comedy for Black viewers, and internalisation of racism were three codes that had videos that contained a rejection of anti-Blackness (Wun, 2014; Pon, Gosine \& Phillips, 2011). Here, Hughes and Ramsey not only reveal ways they experience the often-inconspicuous notions of anti-Blackness, but also seek to inform non-Black audiences of these microaggressions. At the same time, these videos also provide relief for Black viewers in their comedic takes on these tense situations and how to deal with them. Seven videos explicitly look at anti-Blackness as an ideology, and three videos confront racism in various ways. The complete list of videos that deal with the issue of anti-Blackness and racism can be found in Table 4. 
One of the ways Hughes and Ramsey comment on racist and anti-Black ideologies is by taking notable public incidents of the time and looking at it through a lens that centers Blacks and other minorities, rather than looking at it through a white colonialist lens. There are two videos that specifically do this, Ramsey’s (2016) "2016 Oscar Nominees Nail Tutorial| \#OscarsSoWhite” and Hughes' (2017) “ALWAYS PUNCH NAZIS.”

In 2015, the Academy Award nominations considered only men for the honor of Best Director and white performances for any of their acting awards which resulted in the hashtag, \#OscarsSoWhite which sought to bring attention to the issue. There were films like Selma (2014), a biographic picture about the 1965 marches for the right for AfricanAmericans to vote, that received a nomination for Best Picture and Best Original Song but was not represented in any other awards. Many were displeased that at the lack of nominations for director, Ava DuVernay, and the actor that portrayed Martin Luther King Jr., David Owoleyo, as they were both deserving of nominations in the Best Director and Best Actor nominations (VanDerWerff, 2015). In 2016, critically acclaimed films about Black characters, Creed (2015) and Straight Outta Compton (2015), were expected to get nominations acknowledging the Black stories and performances they produced. When the 2016 nominations were announced, "the only Academy [nominations] for two of the year's biggest films about African-American characters went to white people" (Buckley, 2016, para. 2). The only nomination for Creed went to supporting actor Sylvester Stallone, and the two white writers of Straight Outta Compton received the only nomination for Best Original Screenplay. Furthermore, it was the second year in a row that had no people of color nominated for any acting awards (Buckley, 2016). 
In response to this systemic devaluing of Black stories and performers in Hollywood, Ramsey uploaded "2016 Oscar Nominees Nail Tutorial| \#OscarsSoWhite," a parody of the typical beauty tutorial mentioned previously that provides an avenue for Ramsey to talk about the lack of diversity in the 2016 Academy Award Nominations. Ramsey used the nail tutorial to visualize the absence of diversity by only using various shades of white, pale pink, and taupe.

This ... look is inspired by the men and women honoured in the best actor and best supporting actor categories. Now this year I'm not using any Black or brown hues because we don't have any people of colour portraying slaves, or women of colour being abused or playing stereotypical subservient roles. If only Creed had been a slave movie, maybe [actor] Michael B. Jordan could've stood a chance. Instead, we're going for a look I like to call ombré beige (Ramsey, 2016).

Ramsey draws attention to the history of Academy of Motion Picture Arts and Sciences, the organization that facilitates and rewards the Academy Awards, only honoring individuals of colour when they play specific roles. Ramsey hints to films like 12 Years a Slave (2013) that received 9 nominations and won Best Picture, Best Adapted Screenplay, and Best Supporting Actress just the year before \#OscarsSoWhite was created. Moreover, Best Supporting Actress winner Lupita Nyong'o played a woman of colour, Patsey, a slave that was brutally abused sexually and physically. 12 Years a Slave displayed the horrors of slavery and deserved all of its recognition, but it is also a story that can allow white audiences to distance themselves from the reality of slavery, its legacy of how racial minorities are treated in the United States, and, though based on a 
true story, there is a white saviour character in Brad Pitt's character Samuel Bass that allows for white audiences to seem themselves redeemed.

Since the hashtag \#OscarsSoWhite began in 2015, several news articles (Goodfellow, 2016; Bastién, 2017; VanDerWerff, 2019) have stated that many of the Black roles and Black-centred films are often only honored and rewarded when Black actors play stereotypical roles and/or white audiences see themselves redeemed in it like 12 Years a Slave, Driving Miss Daisy (1989), or Hidden Figures (2017). Ramsey draws this out in this brief comment to point out what has been deemed worthy of honour amongst Black stories.

Ramsey's ombré beige look consists of pale hues representing the lack of diversity in these nominations and she paints each nail a different colour based on the person nominated. As she names off an actor or actress, Ramsey shows a representative colour for them. She does not discredit the actors and their performances, but instead seeks to show the stark visual of what it means to have no people of color recognized for their ability (Ramsey, 2012a). In addition, Ramsey (2012a) speaks about some of the reasons the Academy nominations lack in diversity, namely its high percentage of white and male voters, and questionable practices of the Academy, such as rewarding cis-men for playing trans-women.

“2016 Oscar Nominees Nail Tutorial| \#OscarsSoWhite” seeks not to put down white performances or ask that the Academy Awards create a quota of how many Black films or artists should be recognized. Instead, this video uncovers the anti-Blackness that is prevalent in society and societies artistic organizations, reaffirming the colonialist notion that Blackness is meant to be feared, not celebrated (Wun, 2014; Pon, Gosine \& 
Phillips, 2011). The systems in present, like the voter demographic, are meant to place white stories as the norm and Black stories as the opposite of such, just as colonialist ideals place Black bodies as less than human and the most unfavorable of all races (Wun, 2014). It furthers notions that Black stories, performers, and artists are only for Black consumers, and that non-Blacks cannot find value in them. This idea that Black content is only for Blacks repurposes ideologies of segregation, stating that there should be a separation in schools and bathrooms, even in entertainment products (Delgado \& Stefancic, 2017). This is not to say that Black stories do not present a different experience, but to say that just as non-Whites have watched and connected to movies with primarily white characters and stories, so can white individuals find meaning in Black stories. This ideology sustains a segregation between white and Other, and this incident with The Academy Awards reveals how the legacy of colonialism and reality of racism encourages its voters, consciously or unconsciously, to believe films that feature white performances are inherently superior than performances by people of color (Delgado \& Stefanic, 2017).

Ramsey's uses the beauty tutorial genre to visually display the immense overrepresentation of whiteness in the entertainment industry in 2016, a sentiment supported by the "Racial Inequality in Film 2007-2013" study from the University of Southern California Annenberg Inclusion Initiative ${ }^{9}$ (Smith, Choueiti, \& Pieper, 2014; "How Racially Skewed", 2016). This overrepresentation of whiteness upholds ideologies that Black stories are irrelevant and unworthy of recognition. These practices though

\footnotetext{
${ }^{9}$ When compared to the US Census, white actors are given a disproportionate number of acting roles and Oscar acting wins than their percentage of the population ("How Racially Skewed", 2016).
} 
perhaps not conscious, function as a perpetuation of racism by repackaging the idea that white is superior to all other races and ethnicities (Delgado \& Stefanic, 2017; Wun, 2014; Pon, Gosine \& Phillips, 2011; Bonds \& Inwood, 2016; Hardeman et al., 2016). Ramsey's video strives to change that thinking by pointing out one of the ways systemic racism presented itself through the 2016 Academy Awards nominations.

"ALWAYS PUNCH NAZIS" is part of Hughes' series, This Shouldn't Be News where she tackles current events often surrounding white nationalism and President Donald Trump. In this episode, Hughes sits at a desk like the anchor of a classic newscast and presents the topic of the day in a very straightforward manner. In January 2017, the creator of the alt-right movement, a neo-Nazi and white supremacist was punched in the face during an interview and it was caught on camera. Hughes presents the incident and different responses to it by using the genre conventions or visual characteristics of a news show. Hughes explicitly brings comedy into her discussion by incorporating remixed versions of the original footage which sets the moment of impact to different well-known songs. Otherwise, Hughes leans into the news genre, and though she is being exaggerated and metaphorical in her quick and sardonic script, the humour and reflective intention is lost. Hughes' main point of this video can be summed up in the following excerpt. [Maybe punching Nazis] is the ethical choice, because people only become Nazis when they didn't get that urge punched out of them in childhood. I know it's fun to do the mental gymnastics of whether or not Plato or Socrates or Jaden Smith or whoever else in your Philosophy 101 text would agree with your logical conclusion that punching Nazis is bad because violence is not the answer, but no one cares! You are under no obligation to hear a Nazi out! "But Akilah, what if 
they're not actually Nazis?" Anyone who thinks Hitler had mostly good ideas and argues that there was any silver lining to the tragic, unimaginable horrors done onto Jews during the holocaust, can catch these hands ${ }^{10}$. Half the reason the Holocaust went unchecked for as long as it did was because of this lamentable desire for social loafing, where they'd rather be polite or peaceful to monsters instead of shutting them down forcefully. It's not like every person in Germany in the early 1940s was a Nazi, it's just that the "good people" [emphasis in original] decided that it wasn't worth the trouble to fight back against the fascist, racist, anti-Semitism as it gained traction in their country. Well guess what, it's not 1940 anymore. We won't sit back quietly while you hail Hitler with your pathetic Nazi youth haircut (Hughes, 2017).

From the first sentence in the quote above, "[maybe punching Nazis] is the ethical choice, because people only become Nazis when they didn't get that urge punched out of them in childhood," it may sound like Hughes is promoting violence and child abuse, but what she is actually pointing towards is the practice of not challenging the discriminatory and racially superior ideologies that some individuals grow up with, just to be polite (Hughes, 2017). Hughes uses what Smitherman calls signifying, or "a style of verbal play that focuses humorous statements of double meaning on... an event" (as cited in Bailey, 2012, p. 257). In the video, Hughes continues to point out that these fascist and racist notions grow into things like genocide when the citizens fail to oppose these ideas

\footnotetext{
${ }^{10}$ A colloquialism deriving from the late 1960 s term meaning will be punched, beaten, or fought with.
} 
publicly. So, while punching a Nazi may not be the peaceful method, according to Hughes, maybe it metaphorically needs to happen.

“ALWAYS PUNCH NAZIS" is sharp, scathing, and quite funny, especially when edited with the remixed clips of the punch itself, but to a degree it does not support Hughes in her goal of using humour as a gateway to reflection. Bailey (2012) states that comedy from Black individuals can expose feelings that whites would rather keep hidden, making Black audiences laugh while making whites uncomfortable and the response to this video asserts that Hughes' white audience felt uncomfortable. The response to this video was overwhelming and perhaps made some white audiences uncomfortable as the 'like/dislike' feature of the video was disabled, a practice Hughes did in several of the videos in data set that had negative comments. At the same time, as a Black viewer watching this video, I found myself laughing in agreement, not because I believe that violence is the way to stop white supremacy, but because speaking out against what is wrong is the simplest but sometimes hardest way to make a difference.

Furthermore, it was refreshing to see a Black woman reject the respectability expectations to address an issue in a palatable, western colonialist way in order to seem 'unthreatening' or to reduce fear (Delgado \& Stefanic, 2017; Harris, 2003). Instead, Hughes embraces the emotions she felt. By choosing to present this issue of white supremacy centered around her personal anger and passion, Hughes defines her own engagement to this incident without subscribing to respectability politics. In other words, she does not resort to a whitewashed and westernized discussion of this individual being punched but instead presents her own unadulterated representation of a Black women's 
reactions to this incident. In addition, her discussion demonstrates many of my own feelings when dealing with the white majority on issues of racism.

The message that citizens need to speak out against small moments of racism and injustices in order to stop the big moments is arguably overshadowed by the fact that her statement is taken as truth rather than satire. Hughes leans into the news genre using conventions like sitting at a desk, having a plain background, and incorporating video footage from the incident, but because the satire is delivered with an exaggeration of anger, some viewers may view her exaggeration as the "angry black women" stereotype and take the call to violence as literal rather than metaphorical. Hughes is using postmodern satire, highlighting the historical narrative of Nazi Germany, and revealing the ways some are trying to hide the horrors of this regime (Finley, 2016). Hughes rejects the rationalization of the racist "ideological assumptions and structural inequalities" that white supremacy relies on to flourish, and uses comedy that highlights things white audiences would rather stay hidden (Finley, 2016, p. 237; Bailey, 2012). By calling out the underlying historical narratives and rejecting the use of a nonaggressive voice that respectability politics requests, Hughes creates a moment for audiences to think about the times we fail to speak out against injustices for fear of hurting other people or being hurt ourselves.

Creating videos that reject discriminatory practices and ideologies like cultural appropriation, homophobia, and racism are not easy for Hughes and Ramsey, but it provides opportunities for them to display counternarratives about these practices. These videos seek to center the marginalized groups in question, and challenge the stereotypes, hurtful language, and acts of racism both seen and unseen. Hughes and Ramsey use 
humour as a gateway to encourage new ways of thinking about a known topic or current event.

Table 4: List of Videos on Racism and Anti-Blackness

\begin{tabular}{|l|l|}
\hline 1 & The Many Problems With, $\sim$ You Sound White $~$ \\
\hline 2 & The Many Problems With, $\sim$ I Want Mixed Babies $\sim$ \\
\hline 3 & Shit White Girls Say...to Black Girls $\sim 2$ \\
\hline 4 & Shit White Girls Say...to Black Girls \\
\hline 5 & 5 Comebacks For Your Racist Relative During The Holidays \\
\hline 6 & Costume \#FAILS \\
\hline 7 & White Party - A Lesson in Cultural Appropriation \\
\hline 8 & ALWAYS PUNCH NAZIS \\
\hline 9 & On Intersectionality in Feminism and Pizza \\
\hline 10 & 2016 Oscar Nominees Nail Tutorial \#OscarsSoWhite \\
\hline
\end{tabular}

\subsection{A (New) Black Womanhood: Displaying and Interrogating Notions of Self}

As a second-generation Canadian, I often feel pulled in a variety of directions and much of that comes from being a Black woman in a predominantly white environment. Whether the issue is not feeling feminine enough or not feeling Black enough, I have previously felt like I existed in this 'not enough' limbo alone. The representations of Black women on television and in movies growing up did not improve my sense of idenity, as very few characters provided an expression of Black womanhood that was eccentric, non-traditional, or unique like myself. As stated previously, alternative media like YouTube provides a platform to distribute all kinds of content, including content that plays with the notion of Blackness and womanhood, two things that for my case studies, Hughes and Ramsey, cannot be separated.

The gendered and racialized bodies of these two comediennes are an inherent part of the videos they create and often the intersection of race and gender do not need to be an explicit part of their work (Crenshaw, 1991). While coding my data, themes of 
feminism, womanhood, Blackness, and the overlap of these were revealed. The data also revealed some societal expectations of Black women. In this section, I am looking at several videos from my data set that specifically tackle experiences of Black women and providing examples from them. Some of the videos focus on womanhood, some focus on Blackness. As this work strives to be intersectional in its examination of these comediennes, it is important to recognize that as Black women, all of their videos do present a Black womanhood, but for analysis purposes, I am looking at videos with explicit commentary and representations of Black womanhood.

The videos that fall under these codes provide representations that are aware of the daily issues and interactions Black women face. Being someone's first Black girlfriend, having a white best friend who fails to see the microaggressions they exhibit, constantly being asked when you are getting married, and the daily annoyance of being a feminist with a critical eye and watching television commercials are all things that a Black woman may have to negotiate. Hughes and Ramsey's videos utilize Collins' (2009) concept of self-definition, or "the power to name one's own reality," and present the banal transformed with humour, allowing Black woman viewers to laugh, identify with, and be entertained with the connection that they are not alone. These videos create an opportunity for non-Black viewers and Black male viewers to rethink what they do and say. Moreover, this nuance in representation has the ability to encourage individuals to see the similarities in their differences. Hughes and Ramsey do not present Black women as singular and stereotypical, rather they present stereotypes to the point of absurdity or they present multifaceted women with individualized quirks and 
motivations. It is a fresh and welcome postmodern change in the representation of Black women.

The multi-faceted characters Hughes and Ramsey portray are each nuanced and different, rejecting the historical representations of Black women as aggressive, ill tempered, and ignorant (Ashley, 2014; Kretsedemas, 2010). Black postmodernism provides a way to see this divergence from the stereotypical, essentialist view of Black women. Black postmodernism promotes an interrogation of essentialism, or the notion that identities have certain inherent and fixed traits, so that one can assert that there can be many forms of Blackness (hooks, 1990). This recognition of multiple experiences encourages a diversity of representation that tackles societal expectations of both women and Blackness. In other words, hooks" Black postmodernism has the ability to "affirm multiple [B]lack identities, varied [B]lack experience" (hooks, 1990, p. 28). To investigate how Hughes and Ramsey express a Black postmodernist sensibility ${ }^{11}$ in their videos, I will present eight examples from the following videos: "Shit White Girls Say to Black Girls," "Meet Your First Black Girlfriend," "Happy Thanksgrandma," "Instagram Single," "20-Something Fridays," and "How Feminists Watch TV Commercials." These six videos all speak to the daily life of being a Black woman, with some focusing more on womanhood and some focusing more on Blackness.

\footnotetext{
${ }^{11}$ The Black postmodernist sensibility I refer to here is an intellectual framework, which draws from bell hooks and Lisa Guerrero, that showcases the benefits of having a variety of representations of Blackness and also helps to unpack the link between comedy as a resistance practice (as stated on page 35 of this thesis).
} 


\subsubsection{Microaggressions, Fetishization, and the Everyday ${ }^{12}$}

One of the first connections I noticed when coding was the representation of what it means to be in a Black female-presenting body and experiencing the comments from white and non-Black friends that are meant to be sensitive and insightful but are actually microaggressions or a "stunning small encounter with racism, usually unnoticed by members of the majority race" (Delgado \& Stefancic, 2017, p. 179). In other words, videos like "Shit White Girls Say to Black Girls" (Ramsey, 2012e) and "Meet Your First Black Girlfriend" (Hughes 2013b) are about the subtle but racist things that typically white friends and loved ones say without recognizing their impact. These two videos present what may seem absurd and over the top but these microaggressions are things Black women hear all the time. By creating content that examines the everyday occurrences of racism Hughes and Ramsey reveal the "extraordinary in the ordinary" (Lefebvre, 1987, p. 9). These videos work to combat discriminatory ideologies and could be referred to in other themes, but what they describe and present about Black womanhood, is the focus of this section. Three distinct aspects of white and Black relationships exhibited in these two videos are the fetishization of Blackness, the entitlement of whiteness, and qualifiers.

Like the term "No Homo" referenced earlier in this chapter, qualifiers are words or phrases added to a sentence to prescribe a particular meaning. Qualifiers can be useful in communicating an idea and although many are made in good intent, their impact can

\footnotetext{
12 The everyday here refers to the sociological concept first noted by Garfinkel (1964) and as defined by Lefebvre (1987) and which states that the everyday is "a set of functions which connect and join together systems that might appear to be distinct" (Lefebvre, 1987, p. 9). In other words, it encourages analysis of common, ordinary life and how it connects larger systems of power in ways that are "seen but unnoticed" (Garfinkel, 1964, p. 226).
} 
be closer to a microaggression. In this video, these microaggressions come from people who are supposed to be your friend or partner. Qualifiers like "not to sound racist" are used to justify saying racist comments without "being racist", like "not to sound racist [emphasis in original] ... but Jews were slaves too and you don't hear us complaining about it all the time" (Ramsey, 2012e). Other qualifiers that they bring up are associated with distancing themselves from Blackness as seen in the following:

"So cute for a Black guy [emphasis added]"

"It's almost like you're not Black [emphasis added]"

"They're not like stereotypical Black people [emphasis added]" (Ramsey, 2012e). These statements act as microaggressions, separating positive aspects of a person from their Blackness or rewarding someone for their perceived lack of Blackness. Using qualifiers like this allow the notion that Blackness is inferior to persevere. It is a small act, but a hurtful and degrading one when it comes from someone you deem a friend. Another form of microaggressions that appear in "Shit White Girls Say to Black Girls" and "Meet Your First Black Girlfriend" interrogate the things people say to Black women without thinking about how it may impact them. In other words, these non-Black individuals are only concerned with how something benefits or affects them, regardless of how others feel. Statements like "you can say the n-word, but I can't? How is that okay?" from "Shit White Girls Say to Black Girls" are a good example of this (Ramsey, 2012e). Instead of accepting that there is a word one cannot say out of respect for this entire group, this person makes the fact that they cannot say it about themselves with no regard to how that affects others. 
In addition, these same loved ones commit microaggressions, or subtle acts of racism (Delgado \& Stefancic, 2017), that appropriate Black colloquialisms incorrectly without regard to how they affect members of the Black populace. Sometimes these terms, like "ashy"13 or "nappy" are simply used incorrectly as indicated in "Meet Your First Black Girlfriend" (Hughes, 2013b) and other times individuals use terms like "ghetto", as seen in "Shit White Girls Say to Black Girls" (Ramsey, 2012e), to describe items the white character does not find to be aesthetically pleasing, perpetuating the notion that people and things from the ghetto or impoverished, Black populated residential areas, are undesirable. When white individuals use Black colloquialisms without thinking about the ways that they can perpetuate stereotypes and make members of the Black community uncomfortable, they put themselves above their fellow humans. This is what microaggressions do, they make these racist remarks ordinary and deem them as unimportant because of their subtly, as discussed in section 2.3.1. Furthermore, microaggressions from white individuals have the ability to represent the history of colonial and racist oppressors by continuing subjugation in this subtle way. Using and misusing terms without recognizing how it may affect someone else reveals a disregard for the Black population and a sense of entitlement; a belief that they can say and do whatever they want regardless of its impact on others.

Hughes' "Meet Your First Black Girlfriend" tackles microaggressions focused on the entitlement of whiteness but instead of the audience hearing it from the white friend, the viewer experiences the response from the dramatized version of Hughes. The camera

\footnotetext{
${ }^{13}$ The term ashy is a Black colloquialism that describes a person of colour with dry skin. On dark skin, dryness can make skin look dull and sometimes gray, like ash.
} 
acts as the white viewer receiving the responses from Hughes in the following examples about watching films with subject matter concerned with slavery and its historical effects, sexual intimacy, and stereotypes about Black male genitalia.

Look, I would like to watch The Help, or Django[: Unchained], or 12 Years a Slave with you, but if you're gonna make sex weird because of it, I don't want to, alright? I know you don't think slavery was cool, but if you could just talk to your white friends about your guilt instead of making me feel it, that' $d$ be fine (Hughes, 2013b).

Unclothed in bed, seemingly during an intimate moment, You're seriously going to ask me how it compares to a black guy's right now? You're serious? Like you're really doing this? (Hughes, 2013b)

These two examples are very real situations for a Black woman in an interracial relationship. Issues like white guilt and stereotypes should be addressed, but they should be addressed in a way that is productive, like the first of these two examples. The white male, particularly in the second example, does not think about the way his actions and words affect Hughes before he says it, and by focusing on the responses to the microaggressions rather than the microaggressions themselves, the viewer gets to see the how she is affected by his statements. To ask something along the lines of "how does my penis compare to a black guy's" during sex is completely inappropriate, based off a stereotype, and self-centered. By showing Hughes' response to such a question highlights these things and attempts to make the viewer either feel shame for asking or vindication for having experienced similar questions and exhibiting the same internal or external 
response. The fascination and sexualization of Black bodies are old concepts and Hughes does not give power to those ideologies.

Blackness and Black women are often fetishized and hated in both overt and subtle ways. This fetishization is influenced by the history of slavery and the idea that Black women are "unrapable" sexual deviants, with body parts made for objectification (Crenshaw, 1991, p. 1271; Guy-Sheftall, 2002; Gilman, 1986). One of the ways fetishism can appear subtly is in the fascinated comments on Black hair where white women are in awe of it as if it was a foreign alien substance. Comments found in "Shit White Girls Say to Black Girls" like "you can do so much with your hair" are meant to be kind but considering other non-Black individuals use derogatory descriptions for Black hair such as, "Cheetos" or a "Brillo ${ }^{14}$ pad", it is an empty compliment that praises Black for its difference while also shaming it (Ramsey, 2012e). This is reminiscent of slave master wives being intimidated and hateful towards Black women because their husbands were attracted to them ("Master-Slave Relationship", 1500-1865).

Another way the fetishism of Black women presents itself is seen in "Meet Your First Black Girlfriend." Much of the male fascination with Black women stems from the belief in an intrinsic superiority of a white patriarchal form of sexual expression or the heterosexist notion that Black women are an inherently sexual entity, that is always sexual, always ready for sexual activity and thus some sort of pornographic creature (Gilman, 1986; Collins, 2009). The fetishization of Black women's bodies is apparent in this example, as Hughes asserts how her white boyfriend must deal with his friends when

\footnotetext{
${ }^{14}$ A popular brand of steel wool pads made to clean in the kitchen.
} 
they ask what it is like to be in a physically and emotionally intimate relationship with a Black woman.

There are only two acceptable responses. One, make a really funny joke about eating fried chicken every night, or two, tell them to stop exoticizing your relationship because I'm just a human woman like any other human woman (Hughes, 2013b).

This example is poignant for several reasons, Hughes rejects the heterosexist notion that Black women are fundamentally a sexual being different from other women, while not removing Hughes' own sexuality. Hughes does not react to this hyper-sexualization by removing all sexuality from her expression, instead she calls attention to their racist and sexist ideologies. In other words, Hughes self-defines her sexuality in an act of resistance to the common understandings of Black women's sexuality and rejects any prescribed stereotypes that would impact that.

The fetishization of Black women stems from the sexual violence and oppression of Black women slaves by plantation owners and Black women's association with sex work (Collins, 2004; Gilman, 1986). Historically, Black women are not seen as agents of their own sexuality but rather a victim of the hypersexuality prescribed on their bodies (Collins, 2009). Instead of internalising this sexist sexual history, Hughes is open about her sexual expression not by denying her sexual prowess but by telling her white boyfriend that people are people regardless of their physiology and that it is none of their business. Their intimate relationship is their own. Striking a balance between the respectability politics that see Black women's sexuality only in the context of commodification and having sexual agency without objectification is a daily negotiation 
for many Black women and Hughes uses this conversation as a representation of this aspect of modern Black womanhood.

\subsubsection{Navigating Social Expectations as a Black Woman}

Black women move through life not only negotiating acts of subtle racism and microaggressions from white friends, we also must manage social expectations from our Black communities and normalized expectations from the general populace. Many of these social expectations speak not only to Blackness but to patriarchal notions of womanhood, namely, that women are for procreating and their lives are incomplete without men. "Happy Thanksgrandma," is a dramatization of Ramsey's real-life experiences. Ramsey (2011) impersonates her grandmother, visually and aurally, and engages in a conversation around the dining table at Thanksgiving. At this point in Ramsey's career she is getting married to her long-time white boyfriend and her "grandmother" expresses her excitement.

"We real excited about you getting married Franny ${ }^{15}$ " her grandmother says in a southern accent.

“Aw, thanks grandma! We're really excited too!” Ramsey replies genuinely. "Now ya have a white dress to match ya lil' white boyfriend." Ramsey is visibly offended at her words.

"Oh, I'm sorry - husband," grandma replies. "That's right. Been living together for almost five years and now it's gon' be husband - oh, okay. That's alright, Franny” (Ramsey, 2011).

\footnotetext{
${ }^{15}$ A nickname for Franchesca, Ramsey's first name.
} 
Here, Ramsey comments on the scrutiny of dating outside one's race, a practice that was illegal until the late 60s, as well as the secular act of living with a partner before married. These two beliefs, that interracial dating or marrying is an indication of betrayal to a community and living with a partner before you get married is inappropriate, are prevalent in Black American communities in particular. There is an expectation for Blacks that "there is a direct, inverse relationship between closeness to whites and allegiance to [B]lacks" (Steinbugler, 2015, p. 1690). In addition, close ties between the community churches solidified Christian ideals and expectations of celibacy before marriage in many Black homes (Barnes, 2005). These beliefs have a long history and many Black individuals no longer adhere to this social expectation. Later on, Ramsey's grandmother inappropriately comments on her body.

"Ooooo, Franny them boobies looking mighty big!"

Ramsey scoffs. "Uhhh, whoa! Not really appropriate table conversation."

Grandma stares with scrutiny. "You pregnant?"

"No. No no no no no no. Absolutely not."

"Oh, you just gain a little weight."

"Yeah,” Ramsey says with self-consciousness and insecurity. "A little."

"You's too skinny before anyway if you ask me I say you's too skinny. I never thought you looked good too skinny. You look, yeah, you alright now Franny. You look good."

"Oh. Thanks," Ramsey replies solemn and sarcastic. "You always know exactly [emphasis in the original] what to say" (Ramsey, 2011). 
This conversation reveals two misconceptions that Black women must manage, specifically around Black female bodies and their sexuality. Firstly, that partners that live together only get married when they are expecting to have a child. Secondly, that there is an acceptable version of the Black woman's body and that it is anyone's right to talk about it. As Ramsey and her partner lived together for five years and are only now getting married, Ramsey's grandma suggests that she must be pregnant because there is no other reason they should get married. This is a common traditionalist and misogynistic thought process in many Black communities that are often influenced by a community church. Ramsey's grandmother's comments on her body are insensitive and inappropriate as Ramsey's body is her own and should not be subjected to public scrutiny. Unfortunately, Black female bodies have a history of being open to the public. As Black people were exploited, commodified, and sold naked as slaves, their bodies were not their own; the slave masters owned them for work and raped them ("Master-Slave Relationship", 15001865). This objectification of the fetishized Black female body as public persists.

In addition to these lingering impacts of slavery, Ramsey's grandma's concern over pre-marital pregnancy and her public comments of Ramsey's body are derivative of respectability politics or the intraracial undermining of cultural practices in favor of dominant societal ideologies (Harris, 2003). In other words, respectability politics encourage Black communities to self-govern their performance of Blackness, urging them to abandon their own cultural and moral beliefs and perpetuate colonial and westernized ideals. Here Ramsey's grandmother is policing her body in two ways, by sexualizing her bigger breasts that must be a product of a sexual act and deciding her body looks better "not too skinny." Through the comedic but still serious dramatizations 
in "Happy Thanksgrandma," Ramsey brings levity to a heavy situation while highlighting intraracial societal expectations and encourages a comradery between the audience by showing Black viewers that other people have similar experiences and they are not alone.

Just as "Happy Thanksgrandma" interrogates Black social expectations, Hughes' "Instagram Single" touches on the general social expectations of a $21{ }^{\text {st }}$ Century young woman, through the portrayals of self on Instagram. This video comments on the social capital of having a boyfriend or more specifically an Instagram Husband and the generalized idea that the social media platform remediates social expectations, particularly around women. According to Hughes, "an Instagram Single is basically somebody who's single in real life, but everybody thinks that they have a significant other because they take pictures of two of everything and really just convince them that they have a boyfriend" (Hughes, 2016).

"Instagram Single" uses a mockumentary or satirical, fake, documentary style to argue that Instagram husbands are an unrealistic, heteronormative desire. In this video, a fictionalized version of Hughes sits down as if being interviewed and a camera follows her around providing visuals for the techniques she uses to convince her followers that she is in a relationship. She is shown plating two meals and photographing it as if a couple is going to eat before dumping the contents from one plate onto the other. Hughes is also shown trying to take a photo of herself that looks like someone else has taken it, even using props like teddy bears to achieve the desired angle. As Hughes is interviewed, she reveals her belief that there is little better than having a boyfriend. Statements explaining that she's "constantly trying to convince people that [she's] not alone 24/7," 
and that it is exhausting and expensive, but she does not "see the trend of having a boyfriend and being happy going anywhere" support this (Hughes, 2016).

Hughes uses "Instagram Single" to comment on the unrealistic social expectations Instagram remediates, in this case around women needing to be in relationships. The quotes above say that happiness is connected to men, and this is a patriarchal notion that promotes putting power into the man's control. Marriage is an expected trajectory for women and at one point was the only way women were able to gain freedom from their parental home and create a home and family of their own (Perkin, 1989). Marriage for many was desirable, the way of obtaining the best life, and the social expectation. The concept of the Instagram Husband or a male partner that helps you take the most ideal photos of yourself repurposes this connection between the ideal life and a male partner, maintaining that the only way to achieve the best Instagram is by having an Instagram husband.

By presenting this argument through the genre of mockumentary, the viewer already knows they should be making fun of the subject, but the exaggeration of satire draws the viewer to laugh at the absurd lengths Hughes is taking to look like she is in a relationship on social media. It is ridiculous that someone would lie so profusely in hopes of being perceived as in a relationship, and as a distorting mirror, the comedy in this video encourages the viewer to see the ways that Instagram culture promotes that women should have a male partner in order to be successful on the site (Knox, 1957). Hughes is arguing that Instagram and social media where you visually share your life, reproduce these heteronormative patriarchal sensibilities. 
In North American society, women have the ability to do anything they want, but pressure and societal expectations from within the Black community and in general society are still present. Ramsey (2011) and Hughes (2016) comment on these expectations in "Happy Thanksgrandma" and "Instagram Single," rejecting notions of respectability politics and patriarchal control by challenging them through sketch comedy. While "Instagram Single" and "Happy Thanksgrandma" are funny in different ways, specifically because of the former's use of exaggeration, the truth in both of these videos of situations allows the Black women who are viewing to relate to the situation and reflect on societal norms that still persist.

\subsubsection{Everyday Black Womanhood and the Banal}

"20-Something Fridays" is part of a series about 20 -something year-olds going through daily life (Hughes, 2014a). There are episodes about going to brunch and birthday parties. This particular episode describes the evening for a fictionalized version of Hughes who is dealing with the expectations of going out on a Friday night. Hughes arrives home after a seemingly taxing week of work, instantly puts on a onesie, and starts watching a movie (Hughes, 2014a). It is apparent that she is exactly where she wants to be; relaxing at home in her comfy clothes (Hughes, 2014a). As Hughes settles in, she gets messages from three different friends inviting her for activities, first to the gym, then out for dinner, and finally to a house party (Hughes, 2014a). She begrudgingly dresses for the first two events only to receive a last-minute text from her friends cancelling (Hughes, 2014a). It is subtle but evident that Hughes wants to stay home but she does not attempt to say no, as if she would be missing out or not living up to the expectations of social Friday night. After each plan is cancelled Hughes puts back on her onesie and attempts to 
settle in for a simple evening (Hughes, 2014a). She continues to accept plans she is not particularly interested in, until finally she is honest with herself and her friends and denies the third offer to go to a party (Hughes, 2014a). We then see her doing a dance workout on her own in her home and it looks like she is having a great time (Hughes, 2014a).

"20-Something Fridays" is seemingly simple, banal, and unimportant, but that is its appeal. Using banality in this postmodern satire puts pressure on, as Finley (2016) states, the historical norm as of Black women as extroverted aggressors. While this may be the case for some, there are Black women who do not see themselves as sassy or loud and these women deserve representation as well. In addition, by focusing on something seemingly pointless like Friday night plans, the content it dislocated from the typical understandings of Black women. Like Guerrero (2016) says, by focusing on something so removed for typical representations, we as viewers are confronted with how we see social expectations of individuals in their 20s and Black women in their 20s. By centering Black womanhood in an area not typically for them, the viewer is provided with a different and oppositional way of viewing Black women.

It is a common thought process for a lot of people, regardless of race and gender, to accept plans out of duty or fear of missing out on something. Although saying yes to events can lead to some memorable occasions, there is value in being able to speak one's mind and say no. This video is a genderless, raceless issue, but because Hughes is a Black woman, these typical properties and perspectives are inscribed onto her. We as the viewers are encouraged to see ourselves in the Black woman character. The banality and 
specificity of this experience is poignant, and it shows a side of Blackness that is often passed over for more extroverted loud versions of Black womanhood.

Another example of banality also comes from Hughes in "How Feminists Watch TV Commercials". Hughes and her white friend are feminists watching television and commenting on the commercials. We see and hear snippets of classic commercials lines like "still cutting your legs with razor and soap" for feminine razor products or "stubborn belly fat keeping you down" for a weight loss product (Hughes, 2014d). As the commercials continue the two women comment on them and the assumptions they make like all women shave their legs, or women's hands are too delicate and clumsy to be able use a regular "men's" razor without being cut when in reality they are the same product, the pink just costs more ${ }^{16}$ (Hughes, 2014d). The women also talk about the weight loss commercial and discuss the ways the aesthetics of a woman's body is framed like it is the most important issue in their life. For example, Hughes comments saying, "I blame my fat belly more than the patriarchy for all these glass ceilings" (Hughes, 2014d). As the commercials Hughes and her friend were watching finishes, the reality show, Keeping $U p$ with the Kardashians ${ }^{17}$, begins and the women exclaim with excitement (Hughes, 2014d). This juxtaposition between their critical take on the commercials and their excitement to watch a reality show that could be seen as not feminist and capitalistic showcases the reality that women who self-define as feminists are all different. Keeping Up with the Kardashians has been seen as both potentially feminist and potentially

\footnotetext{
${ }^{16}$ This is based off the studies dating back to the 1990s about the Pink Tax, a term used to describe the added cost to create higher prices for various consumer products and services marketed to women than those that are "virtually identical but target male consumers" (Jacobsen, 2018, p. 242).

${ }^{17}$ A reality show featuring the celebrity personalities of the Kardashian and Jenner families.
} 
harmful to feminist endeavours as aspects of self-objectification and the commodification of themselves in beauty and lifestyle brands are a large part of this family's businesses. It would seem likely that the feminist who critiques razor commercials would also criticize the nature of such a television show. Instead, Hughes shows that they may uphold the values of feminism in its various iterations, while also finding pleasure in the commercialized lives of reality stars. In this sense, Hughes provides a representation that works against common controlling images of feminists, juxtaposing viewers expectations of the characters in the video. Just as Hughes and Ramsey work to present an idea of Black womanhood that is active, dynamic, and ever-changing, Hughes re-inscribes meaning and combats the idea that there is only one type of feminist through something as dull and ordinary as watching the commercials on television.

These videos show an alternative to the norm when it comes to Black female representation. They range from the banal to the specific scenarios concerning a white boyfriend to managing the expectations society puts on us, all while being authentic as well as funny. The (new) Black womanhood these preceding videos show is certainly not new, but it is a newer contribution to representations of Black women. It forsakes the traditional stereotypes of the mammy, jezebel, or sapphire for specificity in portrayals of Black woman's experiences that provide more ways to us to be understood. Hughes and Ramsey tackle aspects of the everyday by addressing microaggressions, these societal expectations of Blackness and womanhood, and providing an alternative view of what it means to be a Black woman. 


\subsection{Summary}

Hughes and Ramsey's videos range from beauty tutorials to news shows to how to's. Each of their videos addressed here touch on aspects of social norms, discrimination, and womanhood. The political comedy that Hughes and Ramsey present in this sample can both reveal societal discriminations and biases as well as educate and entertain. It is a tool that Hughes and Ramsey use to address sensitive issues, vindicate Black viewers, and reject colonialist, sexist, and racist ideologies. The comedy primes viewers to look at these issues differently and provides levity to difficult discussions. Based on these findings, I argue that through centering Black womanhood in their videos, satirizing oppressive and discriminatory ideologies, and framing instances of everyday racism in absurd and exaggerated terms, Hughes and Ramsey affirm the sexist, racially charged, and racist experiences that Black women endure on a daily basis.

The white feminine beauty ideal and its oppressive history in colonialism creates a social belief that Blackness is not beautiful. This reality is something Black women deal with daily and the internalisation of white beauty can be harmful. Hughes and Ramsey are cognizant and reflexive of these beliefs and confront and decolonize these oppressive ideologies by satirizing beauty tutorials as one of the media forms that uphold white feminine beauty ideals. Their satire rejects notions of white feminine beauty (Bryant, 2013; Baker-Sperry \& Grauerholz, 2003; Jorgensen, 2019; Robinson-Moore, 2008), beliefs that purchasing products is the only way to attain that look, and that women's beauty is only for the onlooking men. As they create videos that feature themselves as characters, they address how these ideologies affect Black women in particular. Through political satire that exaggerates (Knox, 1957), Hughes and Ramsey create a space to 
reflect on, call out, and perhaps change these colonialist (Harper \& Choma, 2018) and patriarchal notions (Swami et al., 2010) of femininity.

Discriminatory ideologies like racism, sexism, and homophobia are presented by Hughes and Ramsey with nuance. Hughes and Ramsey interrogate stereotypes that are perpetuated by patriarchal ideologies, colonialism and its legacies of slavery, racism, and white supremacy, stereotypes typically associated with Indigenous and people of colour, queer, and Black individuals, and push those stereotypes to the absurd. By using exaggeration as the tactic of comedy with this particular set of identities, Hughes and Ramsey are able to highlight phrases, practices, and systems that continue to uphold and promote racism, colonialism, and homophobia, whether in an overt way like using the term "no homo," or in an unintentional way like the lack of Black performances being nominated in the 2016 Academy Awards. While Hughes' and Ramsey's work around discriminatory ideologies are somewhat centered around their own experiences, Ramsey shows her work as an ally by speaking to the Black community and their use of a homophobic qualifier. This highlights instances of harm for someone other than Ramsey herself, combats patriarchal notions of masculinity, and rejects them. Comedic exaggeration (Knox, 1957) and signifying (Peters, 2012; Smitherman, 2006; Smith, 2005) pushes these discriminatory practices to the absurd for the purpose of satire (Young, 2017; Guerrero, 2016), and systemic racism (Hardeman et al., 2016), homophobia (Sullivan, 2003), colonialism (Delgado \& Stefancic, 2017; Slemon, 1994, Bonds \& Inwood, 2016), and white supremacy (Bonds \& Inwood, 2016; Hardeman et al., 2016) are addressed in a way that is bold, providing a strong visual and comedy for viewers 
who have experienced this type of discrimination while simultaneously confronting other viewers.

As Hughes and Ramsey center themselves in their videos, they are also centering Black womanhood as they experience it. In this sense, they approach their work intersectionally (Crenshaw, 1991), not separating their content from the multiplicity of who they are. In particular, Hughes and Ramsey combat notions of fetishization of Black female bodies and the resulting respectability politics that polices the acceptable ways for a Black woman to act. Their work negates these two notions. Hughes and Ramsey express the experience of themselves as Black women in an interracial relationship and the work they have to do to balance being a sexual being with desires and managing hypersexualized and fetishized versions of themselves that other people may see. Within the Black community, and the legacy of the Black church and the prevalence of patriarchal ideologies there, Hughes and Ramsey combat societal expectations of marriage or having a heteronormative relation and address these issues as Black women. In centering themselves as the individuals in situations of patriarchy influenced sexism (Fraser, 2015; Yodanis, 2004), fetishization (Guy-Sheftall, 2002; Collins, 2009; Gilman, 1986; Crenshaw, 1991), interracial relationships (Steinbugler, 2015), the black church (Barnes, 2005) and their resulting respectability politics (Harris, 2003), Hughes and Ramsey self-define (Collins, 2009; Lorde 1978) what Black womanhood can be.

Many of Hughes and Ramsey's videos touch on multiple themes, and multiple aspects of these themes, because systems of colonialism, discrimination, and womanhood for Black women are inextricably linked. Black women are influenced and affected by colonialism (Delgado \& Stefancic, 2017, Slemon,1994; Bonds \& Inwood, 2016), 
patriarchal ideologies (Fraser, 2015; Yodanis, 2004), and stereotypes (McGarty, Yzerbyt, \& Spears, 2002). But at the same time, many of these videos from Hughes and Ramsey are not explicitly raced such as "No Mo No Homo," 5 FUN NEW WAYS TO WALK IN *HEELS*!!," "How Feminists Watch Commercials"; they tackle issues that affect many people in general. This is important to what Hughes and Ramsey are trying to do, because their acts of self-definition for these specific scenarios has a greater chance for impact. Indeed, some of these dominant ideologies oppress and affect some bodies over others, but these detailed encounters with colonialism and discrimination highlight the threads that connect people. Hughes and Ramsey are not trying to just appeal to a Black audience but rather they use specificity to offer more opportunities for people to see themselves in their work. By using self-definition (Lorde, 1978; Collins, 2009), postmodern satire (Guerrero, 2016; Finley, 2016), tactics of exaggeration (Knox; 1957), and signification (Peters, 2012; Smitherman, 2006; Smith, 2005) to characterize their representation, focusing on individual experiences rather than stereotypes, Hughes and Ramsey show that many North Americans, Black or non-Black, can subjected to the same dominant ideologies.

The videos analyzed in this chapter from Hughes and Ramsey highlight the daily oppression that Black women and other minority groups are going through while still providing opportunities for non-Blacks and non-women to be educated on these experiences. This research pulls these acts of discrimination and systems of oppression from the abstract to the real. My research of Hughes' and Ramsey's videos, which focus on daily experiences like walking in heels, wearing makeup, attending parties and talking to loved ones, adds to discussions on Black women's representations by showing how 
these creators uncover oppressive ideologies like colonialism (Delgado \& Stefancic, 2017; Slemon,1994; Bonds \& Inwood, 2016), racism and microaggressions (Delgado \& Stefancic, 2017; Wun, 2014; Pon, Gosine \& Phillips, 2011), and patriarchy (Fraser, 2015; Yodanis, 2004), that are present in Black women's lives and reject them using political satire (Young, 2017; Guerrero, 2016), providing comedic resistance (Rodrigues \& Collinson, 1995; Bailey, 2012; Willett et al., 2012) to stereotypical representations and affirming Black women's experiences. 


\section{Chapter 5: Conclusion}

On September 24, 2019, Hughes is coming out with a book of personal essays entitled Obviously: Stories from My Timeline, and it promises to depict the difficulties of living in the rural south to building an online presence and how she "used comedy to survive" (Canfield, 2019, para. 5). Comedic forms are cathartic and laughing can be healing. Using comedy in narratives about Black women facilitate a space where more representations of Black woman can exist, not essentializing Black women's experience but providing more opportunities for women of this demographic to see themselves in media. This thesis has demonstrated that Black women can appropriate comedy and alternative platforms such as YouTube to build a space where comedic forms meet with narrative content to create nuanced representations that resist traditional portrayals of Blackness and speak out against discriminatory ideologies that affect minorities. Under certain circumstances, comedy and alternative media can be utilized to facilitate a space of change. It can encourage individuals to reflect on their own beliefs and habits and think about where they come from and how they may affect others.

In this final chapter of my thesis, I summarize the findings of this research project and revisit my research questions, theoretical framework, and methodology. In addition, I will continue to connect my resulting argument with my findings. This section will also present my contributions to existing literature. It is important to note that this research is characterized and limited by the scope of a master's thesis and its time limit, and as such I address recommendations for future research. This chapter concludes with a brief reflection on my positionality throughout this research and final thoughts. 


\subsection{Research Questions, Argument, and Methodology}

I began this thesis by posing the following questions: How do Black women use both political comedy and alternative media to challenge the stereotypical and racialized representations of themselves in traditional media? How are Black comediennes using comedy and alternative media as tools in challenging representations and educating their viewers? How does using an alternative media platform impact the content these creators are making?

Using Franchesca Ramsey and Akilah Hughes as case studies, I argue that Black women use political comedy and alternative media platforms to satirize oppressive and discriminatory ideologies and behaviours, framing instances of every day racism in absurd and exaggerated terms, which ultimately provides representations of Black womanhood that affirm the sexist, racist, and racially charged experiences and microaggressions that Black women endure on a daily basis. My research shows that using Black postmodern satire centers the Black creators in their work and humanizes these harmful experiences with oppressive ideologies even while making the content funny through exaggeration, thus creating opportunity for education. I argue that because Hughes and Ramsey highlight everyday encounters with oppressive systems and ideologies, comedic practices of satire, exaggeration, and signification create opportunities for individuals to confront and reflect on subtle acts of discrimination and educate themselves on their behaviour. My research also shows that the platform, YouTube impacts the content Black comediennes are making through their acts of 
parodying popular content and common genres as entry-points to their resistant content.

This tactic primes the viewer for certain expectations, often calling attention to the absurdity of beliefs that are perpetuated on YouTube.

All of these findings were facilitated by the qualitative case study method my research questions required. By using an inductive method of thematic text analysis and randomly choosing videos, these themes revealed themselves directly from the text. In using this inductive approach many connections between videos were drawn, often requiring me as the researcher to look through the comedy to the underlying ideologies of racism, colonialism, and sexism that Hughes and Ramsey were speaking towards. After using comedy as a lens, this thesis's intersectional feminist foundation was used to analyse the content. An intersectional approach in literature and methodology allowed me to connect these oppressive ideologies and the content of the video with the formal tactics of comedy and satire. This allowed me to fully analyze my data and show how important the forms used in Hughes' and Ramsey's videos can impact how they are received and how meaning is made from them.

\subsection{Summary of Key Empirical Findings}

My research has resulted in four key empirical findings. First, postmodern satire and its ability to make the familiar strange provides a space to challenge colonial white feminine beauty ideals and its commodification. Hughes and Ramsey examine these colonialist ideologies by exaggerating them, either in the portrayal of the incident or in visual forms like Hughes' use of conventions from the horror genre. Hughes connects experiences of patriarchal expectations of beauty through examining the practice of 
wearing heels, revealing connections between European beauty standards and patriarchal desire by pinpointing how the practice of wearing uncomfortable, physiologically dangerous shoes can be for the benefit of the (often male) onlooker. Hughes and Ramsey highlight commodification practices by utilizing the familiar beauty tutorial and making it strange by highlighting its ability to covertly advertise and assert that beauty must be purchased. The videos analyzed in section 4.2 use postmodern political satire by individualising the experiences of beauty standards and call attention to the harmful colonialist, racist, patriarchal, and capitalistic ideologies they can maintain.

Second, my research displays that comedic tactics of satire can reveal the absurdity of discriminatory ideologies and reject them. Hughes and Ramsey use political satire and parody to pinpoint how discriminatory ideologies of homophobia, cultural appropriation, and anti-Black racism are founded in colonial, patriarchal, homophobic, and racist ideologies. Comedic practices like signifying and exaggeration highlight the social systems and practices that continue to uphold and promote racism, colonialism, and homophobia. Exaggerating stereotypes of Black and Indigenous people of colour, members of the LGBTQ+ community, and other people of colour, creates opportunities to reveal the absurdity of these beliefs, its founding in oppressive ideologies, and its impact. Using exaggeration, Ramsey works as an ally to the queer community calling out every day acts of homophobia and rejecting them, thus supporting members of the LGBTQ+ community and affirming them in their experiences.

Third, my research reveals that satirical tactics of comedy and practices of subversion can combine to challenge and reject oppressive ideologies like colonialism and racism. Hughes' and Ramsey's videos on cultural appropriation, Nazi 
punching, and the Academy Awards act as parody, taking ideologies of colonialism and racism and revealing their structural and systemic nature, by subverting social expectations. Their cultural appropriation videos subvert expectations by placing white viewers in the position of being appropriated, encouraging them to be reflexive of their positionality and why they think acts of appropriation are appropriate. Their videos on racist and anti-Blackness subvert expectations by parodying the tutorial and news genres to speak to acts of structural racism in Hollywood and complacency towards white supremacists, presenting them in an unapologetic manner, without regard to upholding respectability politics. Hughes and Ramsey use satire and parody to subvert notions of discrimination, encouraging viewers to reflect on their ideologies of discrimination, and how they can negatively impact others.

Lastly, my research ultimately demonstrates that by centering and, at the same time, presenting nuanced representations of Black womanhood, Black postmodern political comedy can be utilized to practice the notion of self-definition, thus resisting notions of Black women's realities that rely on common oppressive representations. While dealing with the racist, patriarchal, and colonialist ideologies underlying microaggressions, fetishization, and societal expectations, Ramsey and Hughes self-define representations of everyday Black womanhood with specificity from their own experiences. Stereotypical characterizations are traded in for specific comedic portrayals of women as they interact with white friends and boyfriends, deal with the heteronormativity and patriarchal expectations from family and society, and just hang out in their day to day lives. In these videos, Hughes and Ramsey show that comedy can create an intersection between self-definition and humour that allows for resistance 
against misrepresentation while also rejecting the oppressive ideology behind the misrepresentation.

In centering Black womanhood in their videos, Hughes and Ramsey speak to those outside of that group, showing aspects of Black women's lives that are different from the stereotypes typically shown, providing representation that non-Black women can associate with. More importantly, these videos provide representations for Black women that affirm the sexist, racist and racially charged experiences they have in daily life. Societal expectations they have come to expect from family and Black communities, like the necessity of having a Black male partner or adhering to respectability politics, are rejected in favour of diverse portrayals of Black women.

\subsection{Theoretical Contributions}

In Chapter 2, I looked at theories that are foundational to understanding the intersections of identity, power, and comedy within the context of Black comediennes on YouTube. Post-colonial studies and critical race theory were used to assess legacies of colonialism, how they affect Black women specifically, and other ways that racism presents itself. Intersectionality and Black feminist works inform how to understand the everyday experiences of Black women and how colonialism and racism colours those experiences. Tactics of satire, like signification and exaggeration, were used within the context of postmodernism, showing how comedy can work as space of resistance, providing opportunities for more individualized representation and potential to change the thinking of viewers. 
This research has contributed to this existing literature on comedy as resistance and Black comedy online in two ways. First, by showing how political comedy and postmodern satire can create representations that are resistant to traditional stereotypes. Black postmodern political satire can be a tactic of creating positive or realistic representations and resistance. Black postmodern political satire incorporates the specificity and individualism of Black postmodernism that is able to create portrayals that are potentially more representative of Black women's experiences, with the comedic tactics of political satire which takes a subject typically normalized and makes it strange through exaggerations and signifying. Black postmodern satire as a theory addressed in existing literature, but by foregrounding the politicization of Black satire, increased investigations into representations and resistance to dominant discriminatory ideologies can be addressed.

Second, this research establishes that comedy can be used as a formal tool to examine complex issues in a way that does not chastise but encourages viewers to reflect about why they believe what they believe by pushing the representations of the issues to the point where the accepted seems unacceptable. Hughes and Ramsey use exaggeration and signifying to make the common absurd, thus highlighting what might be wrong with it. Their work is not perfect and watching one of their videos does not mean one will change their mind but seeing Black womanhood and experiencing discriminatory ideologies outside of the standard challenges social norms and creates a space to examine beliefs. Hughes' and Ramsey's work are filled with meaning, combatting things as banal as Instagram use and as serious as microaggressions, and this research has brought that to the forefront. 


\subsection{Recommendations for Future Research: Platform Studies, Banality, Black Postmodern Political Satire as an Educational Tool}

Although YouTube may remove some barriers of production it is not a perfect platform. Yes, YouTube is the most watched and used video uploading platform that allows individuals to upload videos without the traditional gatekeeper, and thus I initially saw YouTube as the ideal place for the kind of educational and entertaining content from Hughes and Ramsey to live, but it is important to note that as I conducted my research, I noticed that Ramsey and Hughes stopped using YouTube. They still had online presences on other social media platforms, but they were instead working with traditional media networks like HBO and Comedy Central, writing books, and giving keynotes. For example, Ramsey's last political video was posted in 2016 and Hughes' posted in August $2018^{18}$. The decrease in YouTube uploads from Hughes and Ramsey indicates an opportunity for future research that foregrounds the affordances and limitations of these alternative platforms and ways YouTube as a platform may be prohibiting their work. One such way to look at this would be through an investigation of the algorithms that make their work profitable and visible on a highly saturated platform like YouTube.

My focus on remaining inductive throughout my methodological practices and analysis using qualitative thematic text analysis also revealed a thematic opportunity for future research. Banal representations of Black women were not something I have come across before in representations of Blackness, but as showing ordinariness can often combat stereotypes, an investigation on banal representation could provide more insight

\footnotetext{
18 Ramsey has uploaded parodic content since then, but those videos do not qualify as political comedy.
} 
into how creators like Hughes and Ramsey are negating negative stereotypes and affirming Black experiences in the everyday.

In addition, as satire creates opportunities to experience a change in thinking, there is potential to investigate ways Black postmodern political satire can do the same thing. Future research on this subject could conduct interviews using a selection of these videos and look at their potential as an educational tool or as a tool to reaffirm and legitimize Black women's experiences. Black postmodern political satire can be tool to examine these complex issues of oppression in a way that does not chastise, and considering concepts outside of this research such as white fragility, this specific type of satire may be a soft way to begin conversations about racism and other forms of discrimination that are structural and interpersonal in our society.

\subsection{Notes from the Researcher and Final Thoughts}

I started this research thinking about my own representation, and as much as there are limits to what YouTube and comedy can do to present more nuanced representations, I am happy that even these videos by Hughes and Ramsey exist. I feel seen in these videos, but they have also led me to question my own experiences and behaviours. Do I overlook microaggressions in relationships in fear that I lose a friend or am labelled "defensive" and "angry" when I confront them? Although the phrase "no homo" is something I used once or twice before recognizing how offensive it was, I was able to extrapolate why exactly I felt that way and felt disappointed at my communities where the term had been used. I had many "aha" moments while conducting my research, finally being able to put words to things I felt. In some cases, I sent videos from my data 
set to friends to explain how I was feeling and I often showed videos in my tutorial sessions and other classes, just to see what other people thought of them.

Although I argue that Hughes and Ramsey center Black womanhood in the videos as a way of affirming the sexist, racist, and colonialist experiences that Black women experience, I do not think you have to be a Black woman to see yourself in this work. The more representation is less reliant on stereotypes of oppression, the more representations can create opportunities for non-Black women to identify and reflect on their experiences with some of these issues, like beauty ideals or the pressure to get married from family members. To me, representation is largely about having media portrayals that are created for you, but it is also about stepping out of one's comfort zone and seeing connections outside of one's identity markers. Hughes and Ramsey center Black womanhood, satirize oppressive and discriminatory ideologies, and frame instances of everyday oppression in exaggerated terms, affirming the daily experiences woman have with these ideologies. I look forward to seeing how these two women continue to show variety in representation, using comedy and centering themselves in their work, on whichever platform they choose to use. 


\section{References}

Anderson, S. (2007). The economics of dowry and brideprice. The Journal of Economic Perspectives, 21(4), 151-174. Retrieved from http://www.jstor.org.proxy.library.carleton.ca/stable/30033756

Arthurs, J., Drakopoulou, S., \& Gandini, A. (2018). Researching youtube. Convergence: The International Journal of Research into New Media Technologies, 24(1), 3-15. doi: $10.1177 / 1354856517737222$

Ashley, W. (2014). The angry black woman: The impact of pejorative stereotypes on psychotherapy with black women. Social Work in Public Health, 29(1), 27-34. doi:10.1080/19371918.2011.619449

Bailey, C. (2012). Fight the power: African american humor as a discourse of resistance. Western Journal of Black Studies, 36(4), 253.

Baker-Sperry, L., \& Grauerholz, L. (2003). The pervasiveness and persistence of the feminine beauty ideal in children's fairy tales. Gender and Society, 17(5), 711726. doi:10.1177/0891243203255605

Barnes, S. L. (2005). Black church culture and community action. Social Forces, 84(2), 967-994. doi:10.1353/sof.2006.0003

Bastién, A. J. (n.d.). The Oscars have always had a poor record with black filmmakers. Retrieved August 22, 2019, from The Outline website: https://theoutline.com/post/1151/the-oscars-and-black-filmmakers

Botticini, M., \& Siow, A. (2003). Why Dowries? The American Economic Review, 93(4), 1385-1398. Retrieved from http://www.jstor.org.proxy.library.carleton.ca/stable/3132295 
Bonds, A., \& Inwood, J. (2016). Beyond white privilege: Geographies of white supremacy and settler colonialism. Progress in Human Geography, 40(6), 715733. doi: $10.1177 / 0309132515613166$

Boyd, R. W. (2018). Police violence and the built harm of structural racism. The Lancet, 392(10144), 258-259. doi:10.1016/S0140-6736(18)31374-6

Bradley, R. N. (2015). Awkwardly hysterical: Theorizing black girl awkwardness and humor in social media. Comedy Studies, 6(2), 148-153. doi:10.1080/2040610X.2015.1084176

Bryant, C. (2006). The Language of Resistance? Czech Jokes and Joke-telling under Nazi Occupation, 1943-45. Journal of Contemporary History, 41(1), 133-151. https://doi.org/10.1177/0022009406058687

Bryant, S. L. (2013). The beauty ideal: The effects of European standards of beauty on black women. Columbia Social Work Review, 80-91. doi:10.7916/D8DF6PQ6

Brownlow, C., O'Dell, L., \& Rosqvist, H. B. (2013). COMMENTARY: Challenging representations of autism - exploring possibilities for broadcasting the self on YouTube.Journal on Developmental Disabilities, 19(1), 90.

Buckley, C. (2016, January 14). Oscars 2016: It's a Nearly All-White Nominees' List Again. The New York Times. Retrieved from https://www.nytimes.com/2016/01/14/movies/oscars-the-revenant.html

Burcar, L. (2019). High heels as a disciplinary practice of femininity in Sandra Cisneros's the house on mango street. Journal of Gender Studies, 28(3), 353-362. doi:10.1080/09589236.2018.1472556 
Canfield, D. (2019, March 22). Akilah Hughes on telling "Stories From My Timeline" in upcoming book “Obviously.” Retrieved August 22, 2019, from EW.com website: https://ew.com/books/2019/03/22/akilah-hughes-obviously-book-preview/

Caron, J. E. (2016). The quantum paradox of truthiness: Satire, activism, and the postmodern condition. Studies in American Humor, 2(2), 153-181. doi:10.5325/studamerhumor.2.2.0153

Cleary, M. (2015, June 28). The history of the high heel - and what it says about women today. Retrieved August 22, 2019, from BostonGlobe.com website: https://www.bostonglobe.com/ideas/2015/06/27/high-heels-symbolmisogyny/wGGdJ1R5kNxw0QRtHEE7UL/story.html

Collins, P. H. (2004). Black sexual politics: African americans, gender, and the new racism. New York: Routledge.

Collins, P. H. (2009). Black feminist thought: Knowledge, consciousness, and the politics of empowerment. Routledge.

Crenshaw, K. (1991). Mapping the margins: Intersectionality, identity politics, and violence against women of color. Stanford Law Review, 43(6), 1241-1299. doi:10.2307/1229039

Delgado, R., \& Stefancic, J. (2017). Critical race theory: An introduction (3rd ed.). New York: New York University Press.

Dickson-Carr, D., 1968. (2015). Spoofing the modern: Satire in the harlem renaissance. Columbia: University of South Carolina Press.

Donella, L. (2019, February 6). Is beauty in the eyes of the colonizer? Retrieved August 22, 2019, from National Public Radio website: 
https://www.npr.org/sections/codeswitch/2019/02/06/685506578/is-beauty-in-theeyes-of-the-colonizer

Duke, L. (2000). Black in a blonde world: Race and girls' interpretations of the feminine ideal in teen magazines. Journalism \& Mass Communication Quarterly, 77(2), 367-392. doi: $10.1177 / 107769900007700210$

Duke, L. (2002). Get real!: Cultural relevance and resistance to the mediated feminine ideal.Psychology and Marketing, 19(2), 211-233. doi:10.1002/mar.10010

Drisko, J. W., Maschi, T., \& Oxford University Press. (2015). Content analysis. New York: Oxford University Press.

Finley, J. (2016). Black Women's satire as (black) postmodern performance. Studies in American Humor, 2(2), 236-265.

Fletcher, E. H. (2016). Dis/Assembling schizophrenia on YouTube: Theorizing an analog body in a virtual sphere. Journal of Medical Humanities, 37(3), 257-274. doi:10.1007/s10912-014-9286-4

Flood, A. (2016, February 9). Girl's drive to find 1,000 'black girl books' hits target with outpouring of donations. Retrieved from https://www.theguardian.com/books/2016/feb/09/marley-dias-1000-black-girlbooks-hits-target-with-outpouring-of-donations

Fraser, C. (2015). From "ladies first" to "asking for it": Benevolent sexism in the maintenance of rape culture. California Law Review, 103(1), 141-204.

Frith, K. T., Shaw, P., \& Cheng, H. (2005). The construction of beauty: A cross-cultural analysis of women's magazine advertising. Journal of Communication, 55(1), 5670. doi:10.1093/joc/55.1.56 
Garcia, S. E. (2017, October 20). The Woman Who Created \#MeToo Long Before Hashtags. The New York Times. Retrieved from https://www.nytimes.com/2017/10/20/us/me-too-movement-tarana-burke.html

Garfinkel, H. (1964). Studies of the routine grounds of everyday activities. Social Problems, 11(3), 225-250. doi:10.2307/798722

Gilman, S. L. (2010). Black bodies, white bodies: Toward an iconography of female sexuality in late nineteenth-century art, medicine, and literature. The feminism and visual culture reader, 166-180.

Goodfellow, M. (2016, February 3). Black actors only win an Oscar when they make white people feel better about their racist past. Retrieved August 22, 2019, from The Independent website: http://www.independent.co.uk/voices/black-actorsonly-win-an-oscar-when-they-make-white-people-feel-better-about-their-racistpast-a6850946.html

Guerrero, L. (2016). Can I live? contemporary black satire and the state of postmodern double consciousness. Studies in American Humor, 2(2), 266-279. doi:10.5325/studamerhumor.2.2.0266

Gunaratnam, Y. (2003). Researching race and ethnicity: Methods, knowledge, and power. London; Thousand Oaks, Calif: Sage Publications.

Guy-Sheftall, B. (2002). The body politic: Black female sexuality and the nineteenth century euro-american imagination. In Wallace-Sanders, K. (Ed.), Skin deep, spirit strong: The black female body in american culture (pp. 13-35). Ann Arbor: University of Michigan Press. 
Haneman, V. J. (2019). contemplating homeownership tax subsidies and structural racism. Wake Forest Law Review, 54(2), 363.

Hardeman, R. R., Medina, E. M., \& Kozhimannil, K. B. (2016). Dismantling structural racism, supporting black lives and achieving health equity: Our role. The New England Journal of Medicine, 375(22), 2113-2115. doi:10.1056/NEJMp1609535

Harper, K., \& Choma, B. L. (2018). Internalised white ideal, skin tone surveillance, and hair surveillance predict skin and hair dissatisfaction and skin bleaching among african american and indian women. Sex Roles, 80(11-12), 735-744. doi:10.1007/s11199-018-0966-9

Harris, A. (2018, October 31). America Can’t Seem to Kick Its Racist Costume Habit. Retrieved August 22, 2019, from The Atlantic website: https://www.theatlantic.com/education/archive/2018/10/americans-keep-wearingracist-halloween-costumes/574516/

Harris, P. J. (2003). Gatekeeping and remaking: The politics of respectability in african american women's history and black feminism. Journal of Women's History, 15(1), 212-220.

Hiller, C., \& Carlson, E. (2018). THESE ARE INDIGENOUS LANDS: Foregrounding settler colonialism and indigenous sovereignty as primary contexts for canadian environmental social work. Canadian Social Work Review, 35(1), 45-70.

Hook, D. (2004). Fanon and the psychoanalysis of racism. London: LSE Research Online. Retrieved from http://eprints.lse.ac.uk/2567

Hooks, B. (1990). Yearning: Race, gender, and cultural politics (1st ed.). Toronto: Between the Lines. 
Horak, L. (2014). Trans on YouTube. Transgender Studies Quarterly, 1(4), 572-585. doi: $10.1215 / 23289252-2815255$

How racially skewed are the Oscars? (2016, January 21). The Economist. Retrieved from https://www.economist.com/prospero/2016/01/21/how-racially-skewed-are-theoscars

Hughes, A. (n.d.). About Me. Retrieved August 22, 2019, from Tumblr website: https://itsakilahobviously.com/FAQ

Hughes, A. [smoothiefreak]. (2013a). How Do Black People Feel About Spring? Retrieved from https://www.youtube.com/watch?v=fohA2ff_vL4

Hughes, A. [smoothiefreak]. (2013b). Meet Your First Black Girlfriend. Retrieved from https://www.youtube.com/watch?v=HDiU0aqqKp0

Hughes, A. [smoothiefreak]. (2014a). 20-Something Friday. Retrieved from https://www.youtube.com/watch?v=JB6WBkpmvU0

Hughes, A. [smoothiefreak]. (2014b). Honest Everyday Makeup Tutorial. Retrieved from https://www.youtube.com/watch?v=efT AadPH7Yg

Hughes, A. [smoothiefreak]. (2014c). 5 FUN NEW WAYS TO WALK IN *HEELS*!! . Retrieved from https://www.youtube.com/watch?v=iZYFKVrYlqk

Hughes, A. [smoothiefreak]. (2014d). How Feminists Watch Commercials. Retrieved from https://www.youtube.com/watch?v=VIpgi_JBGwE

Hughes, A. [smoothiefreak]. (2014e). How to Straighten Natural Hair -- A Horror Story. Retrieved from https://www.youtube.com/watch?v=YEkiRSTTCqI\&t=93s

Hughes, A. [smoothiefreak]. (2014f). Every Natural Hair Video Ever. Retrieved from https://www.youtube.com/watch?v=HA_vkcTFLX0\&t=1s 
Hughes, A. [smoothiefreak]. (2014g). White Party - A Lesson in Cultural Appropriation. Retrieved from https://www.youtube.com/watch?v=Ipx3fKn4G3U

Hughes, A. [smoothiefreak]. (2015a). How to Be an Introvert -- According to Tumblr Ep. 1. Retrieved from https://www.youtube.com/watch?v=cf851wZEmXQ

Hughes, A. [smoothiefreak]. (2015b). HOW OLIVIA POPE *HANDLED* THE WINTER HIATUS. Retrieved from https://www.youtube.com/watch?v=vfoX6oNDqmM Hughes, A. [smoothiefreak]. (2015c). On Intersectionality in Feminism and Pizza. Retrieved from https://www.youtube.com/watch?v=FgK3NFvGp58\&t=141s Hughes, A. [smoothiefreak]. (2015d). Racial Discussion Fatigue Syndrome \#RDFS. Retrieved from https://www.youtube.com/watch?v=j6Kcsm5wp-4

Hughes, A. [smoothiefreak]. (2016). Instagram Single. Retrieved from https://www.youtube.com/watch?v=XIiyOB8enXA\&t=31s

Hughes, A. [smoothiefreak]. (2017). ALWAYS PUNCH NAZIS | This Shouldn't Be News. Retrieved from https://www.youtube.com/watch? $\mathrm{v}=$ Cvwr 1 TpKznk\&t=1s

Jacobsen, K. A. (2018). Rolling back the "pink tax": Dim prospects for eliminating gender-based price discrimination in the sale of consumer goods and services. California Western Law Review, 54(2), 241.

Jackson C. K., Visible but devalued through the black male gaze. In Goldman, A. Y., Ford, V. S., Harris, A. A., \& Howard, N. R. (Eds.). (2014). Black women and popular culture: The conversation continues. Retrieved from https://ebookcentralproquest-com.proxy.library.carleton.ca 
Jorgensen, J. (2019). The most beautiful of all: A quantitative approach to fairy-tale femininity. Journal of American Folklore, 132(523), 36-60. doi:10.5406/jamerfolk.132.523.0036

Julig, C. (2018, June 29). 12 Women Who Were Instrumental to the LGBTQ+ Rights Movement. Retrieved August 21, 2019, from Shondaland website: https://www.shondaland.com/act/a21993326/women-instrumental-pride-lgbtqrights-movement/

Kerwin, A. M. (2017, September 27). The 'Angry Black Woman' Makes Real Women Angry. Ad Age. Retrieved from https://adage.com/article/media/angry-blackwoman-makes-real-women-angry/310633/

Kendrick, C. (2013). Satire and speculation in Milton's Limbo. Milton Studies 54(1), 229-258. Penn State University Press. Retrieved July 14, 2019, from Project MUSE database.

Kleisath, C. M. (2014). The costume of shangri-la: Thoughts on white privilege, cultural appropriation, and anti-asian racism. Journal of Lesbian Studies, 18(2), 142-157. doi:10.1080/10894160.2014.849164

Knox, I. (1957). Comedy and the category of exaggeration. The Journal of Philosophy, 54(25), 801-812. doi:10.2307/2022480

Krefting, R. (2019). Hannah gadsby: On the limits of satire. Studies in American Humor, 5(1), 93-102. doi:10.5325/studamerhumor.5.1.0093

Kretsedemas, P. (2010). "But she's not black!”: Viewer interpretations of "angry black women" on prime time TV. Journal of African American Studies, 14(2), 149-170. doi:10.1007/s12111-009-9116-3 
Kuckartz, U., 1951. (2014). Qualitative text analysis: A guide to methods, practice and using software. Los Angeles: SAGE.

Lefebvre, H. (1987). The everyday and everydayness. Yale French Studies, (73), 7-11 (C. Levich, Trans.). doi:10.2307/2930193

Lester, N. A. (2000). Nappy edges and goldy locks: African-american daughters and the politics of hair. The Lion and the Unicorn, 24(2), 201.

Lewis, J., Ormston, R., Ritchie, J., \& McNaughton Nicholls, C. (2014). Qualitative research practice: A guide for social science students and researchers (Second ed.). London; Thousand Oaks, CA;: SAGE Publications.

Lindlof, T.R. \& Taylor, B.C. (2011) Qualitative Communication Research Methods, Thousand Oaks: Sage.

Lorde, A. (1978). Uses of the erotic: The erotic as power. Trumansburg, N.Y;Brooklyn, N.Y;: Out \& Out Books.

MacKinnon, C. A. (1987). Feminism unmodified: Discourses on life and law. Harvard university press.

Makkar, J. K., \& Strube, M. J. (1995). Black women's self-perceptions of attractiveness following exposure to white versus black beauty standards: The moderating role of racial identity and self-esteem. Journal of Applied Social Psychology, 24(17), 1547.

Marsh, A. (2017, July 12). High heeled shoes were originally created for men | teen vogue. Retrieved August 22, 2019, from Teen Vogue website: https://www.teenvogue.com/story/heels-history-men 
"Master-slave relationship, enslavement, African American identity: Vol. I". (15001865). Primary Resources in U.S. History and Literature, Toolbox Library, National Humanities Center.

Milner, H. R. (2007). Race, culture, and researcher positionality: Working through dangers seen, unseen, and unforeseen. Educational Researcher, 36(7), 388-400. doi:10.3102/0013189X07309471

Monkman, L. (2016, March 26). Behind First Nations headdresses: What you should know. Retrieved August 22, 2019, from CBC website: https://www.cbc.ca/news/indigenous/behind-first-nations-headdresses-1.3506224

Moore, J. X., MPH, Lambert, B., MSPH, Jenkins, G. P., MSPH, \& McGwin, Gerald, MS, PhD. (2015). Epidemiology of high-heel shoe injuries in U.S. women: 2002 to 2012. Journal of Foot and Ankle Surgery, the, 54(4), 615-619. doi:10.1053/j.jfas.2015.04.008

Mullings, D., Morgan, A., \& Quelleng, H. (2016). Canada the great white north where anti-black racism thrives: Kicking down the doors and exposing the realities. Phylon, 53(1, 20-41. Retrieved from http://www.jstor.org/stable/phylon1960.53.1.20

Nagy, L. (2017). 'This video is sponsored by': The effect of disclosure timing and modality on persuasion knowledge and brand attitude in sponsored YouTube videos. (Thesis). Tilburg University, Tilburg.

Nash, J. C. (2008). Re-thinking intersectionality. Feminist Review, 89(89), 1-15. doi:10.1057/fr.2008.4 
Negru, H. (2016, May 19). High heels have turned into the tangible symbol of the patriarchal workforce. Retrieved August 22, 2019, from Elite Daily website: https://www.elitedaily.com/women/heels-symbol-of-patriarchalworkforce/1498657

Nigatu, H., \& Clayton, T. (2016). Another Round All Stars: Lit is Lit. Retrieved from https://soundcloud.com/anotherroundwithhebenandtracy/another-round-all-starslit-is

Norwood, C. R. (2018). Decolonizing my hair, unshackling my curls: An autoethnography on what makes my natural hair journey a black feminist statement. International Feminist Journal of Politics, 20(1), 69-84. doi:10.1080/14616742.2017.1369890

Obergefell et al. v. Hodges, 576 U. S. (2015)

Paid product placements and endorsements. (2018, December 5). Retrieved August 22, 2019, from Google website: https://support.google.com/youtube/answer/154235?hl=en

Pérez-Guerrero, A. M., \& Forero-Serna, A. (2019). Between reality and fantasy: The narrative strategies of the horror genre in productions by laika studios (20092015). Communication \& Society, 32(2), 13-27. doi:10.15581/003.32.2.13-27

Perkin, J., \& Taylor \& Francis Group. (1989). Women and marriage in nineteenthcentury england. Chicago: Lyceum Books. doi:10.4324/9780203401958

Peters, E.A. "Signifying” in Cushman, S., Cavanagh, C., \& Rouzer, P. (Eds.). (2012). The princeton encyclopedia of poetry and poetics: Fourth edition. Retrieved from https://ebookcentral-proquest-com.proxy.library.carleton.ca 
Pon, G., Gosine, K., \& Phillips, D. (2011). Immediate response: Addressing anti-native and anti-black racism in child welfare. International Journal of Child, Youth and Family Studies, 2(3/4), 385. doi:10.18357/ijcyfs23/420117763

Ramsey, F. [chescaleigh]. (2011). Happy Thanksgrandma! Retrieved from https://www.youtube.com/watch?v=mkKbMjO6gHI\&t=60s

Ramsey, F. [chescaleigh]. (2012a). Costume \#FAILS. Retrieved from https://www.youtube.com/watch?v=TN2WaZAUY2U

Ramsey, F. [chescaleigh]. (2012b). How Slut Shaming Becomes Victim Blaming. Retrieved from https://www.youtube.com/watch?v=113h8fzv-BM

Ramsey, F. [chescaleigh]. (2012c). No Mo' "No Homo." Retrieved from https://www.youtube.com/watch?v=5qNBzHaXINI

Ramsey, F. [chescaleigh]. (2012d). Oreo Pride! Retrieved from https://www.youtube.com/watch?v=Hf8yHGgsOps\&t=11s

Ramsey, F. [chescaleigh]. (2012e). Shit white girls say... to Black girls. Retrieved from https://www.youtube.com/watch?v=ylPUzxpIBe0\&t=3s

Ramsey, F. [chescaleigh]. (2012f). Shit White Girls Say...to Black Girls: 2. Retrieved from https://www.youtube.com/watch?v=YnwqECbNm4Y

Ramsey, F. [chescaleigh]. (2013a). REBLOGS (Tumblr song) | Lady Gaga "Applause" Parody. Retrieved from https://www.youtube.com/watch?v=eokK2lbTZjo Ramsey, F. [chescaleigh]. (2013b). \#ScandalABC Parody: A Scandalous Tutorial. Retrieved from https://www.youtube.com/watch?v=rZ7cB7sVeM8 
Ramsey, F. [chescaleigh]. (2014a). 5 Comebacks For Your Racist Relative During The Holidays. Retrieved from https://www.youtube.com/watch?v=Y3uNRdWfs_I\&t=1s

Ramsey, F. [chescaleigh]. (2014b). 5 Tips For Being An Ally. Retrieved from https://www.youtube.com/watch?v=_dg86g-Q1M0

Ramsey, F. [chescaleigh]. (2014c). Just Stop Talking About Race!! Retrieved from https://www.youtube.com/watch?v=UO1PcovTk90\&t=140s

Ramsey, F. [chescaleigh]. (2015a). The Many Problems With, "I Want Mixed Babies." Retrieved from https://www.youtube.com/watch?v=v_UapInEvIk\&t=3s

Ramsey, F. [chescaleigh]. (2015b). The Many Problems With, "You Sound White." Retrieved from https://www.youtube.com/watch?v=yWmpKSGNBSk

Ramsey, F. [chescaleigh]. (2016a). 2016 Oscar Nominees Nail Tutorial | \#OscarsSoWhite. Retrieved from https://www.youtube.com/watch?v=Rb91XpuuqFs

Ramsey, F. (2016b). About - franchesca.net. Retrieved August 22, 2019, from https://www.franchesca.net/about/

Raun, T. (2015). Video blogging as a vehicle of transformation: Exploring the intersection between trans identity and information technology. International Journal of Cultural Studies, 18(3), 365-378. doi:10.1177/1367877913513696

Reid, M. A. (2005). Black lenses, black voices: African american film now. Retrieved from https://ebookcentral-proquest-com.proxy.library.carleton.ca

Rentschler, C. A. (2014, June 22). Rape culture and the feminist politics of social media. https://doi.org/10.3167/ghs.2014.070106 
Ribeiro, A., 1944. (2011). Facing beauty: Painted women \& cosmetic art. New Haven [Conn.]: Yale University Press.

Robinson-Moore, C. L. (2008). Beauty standards reflect eurocentric paradigms-so what? skin color, identity, and black female beauty. The Journal of Race \& Policy, 4(1), 66.

Rodrigues, S. B., \& Collinson, D. L. (1995). "Having fun"?: Humour as resistance in brazil. Organization Studies, 16(5), 739-768. https://doi.org/10.1177/017084069501600501

Rogers, R. A. (2006). From cultural exchange to transculturation: A review and reconceptualization of cultural appropriation. Communication Theory, 16(4), 474503. doi:10.1111/j.1468-2885.2006.00277.x

Rowe, K. D. (2019). "Nothing else mattered after that wig came off': Black women, unstyled hair, and scenes of interiority. The Journal of American Culture, 42(1), 21-36. doi:10.1111/jacc.12971

Sandeen, D. (2019, March 14). A brief look into locs (or locks) for black hair. Retrieved August 22, 2019, from Byrdie website: https://www.byrdie.com/locs-or-locks400267

Scott, M. (2014). From blackface to beulah: Subtle subversion in early black sitcoms. Journal of Contemporary History, 49(4), 743-769. doi:10.1177/0022009414538473

Segran, E. (2018, April 13). High heels, invented for the male gaze, get a feminist makeover. Retrieved August 22, 2019, from Fast Company website: 
https://www.fastcompany.com/40556015/meet-the-women-reinventing-the-highheel-without-the-sexism

Slemon, S. (1994). The scramble for post-colonialism. In Ashcroft, B., Griffiths, G., \& Tiffin, H. (Eds.). Post-colonial studies reader (pp. 45-52). Retrieved from https://ebookcentral-proquest-com.proxy.library.carleton.ca

Slobe, T. (2018). Style, stance, and social meaning in mock white girl. Language in Society, 47(4), 541-567. doi:10.1017/S004740451800060X

Smith, A. (2005). Blues, criticism, and the signifying trickster. Popular Music, 24(2), 179-191. Retrieved from http://proxy.library.carleton.ca/login?url=https://searchproquest-com.proxy.library.carleton.ca/docview/195176116?accountid=9894

Smith, S. L., Choueiti, M., \& Pieper, K. (2014). Race/ethnicity in 600 popular films: Examining on screen portrayals and behind the camera diversity. Media, Diversity, \& Social Change Initiative.

Smith, S. L., Choueiti, M., Choi, A., Pieper, K. (2019a). Inequality in 1,200 popular films: Examining portrayals of gender, race/ethnicity, LGBT \& disability from 2007 to 2018. USC Annenberg Inclusion Initiative.

Smith, S. L., Pieper, K., \& Choueiti, M. (2019b). Inclusion in the director's chair? Gender, race, \& age of film directors across 1,200 films from 20072018*. Media, Diversity, \& Social Change Initiative.

Smitherman, G. (2006). Word from the mother: Language and african americans. London; New York:Routledge. doi:10.4324/9780203006665 
Steinbugler, A. (2015). 'I'm black and I'll always be that way': Black identities through the lens of interracial intimacy. Ethnic and Racial Studies, 38(10), 1690-1706. doi: $10.1080 / 01419870.2015 .1023820$

Stopera, M. (2012, June 26). How could anyone boycott a cookie?! Retrieved August 22, 2019, from Buzzfeed website: https://www.buzzfeed.com/mjs538/how-could-youboycott-a-cookie

Sullivan, M. K. (2004). Homophobia, history, and homosexuality: Trends for sexual minorities. Journal of Human Behavior in the Social Environment, 8(2-3), 1-13. doi:10.1300/J137v08n02_0

Swami, V., Coles, R., Wyrozumska, K., Wilson, E., Salem, N., \& Furnham, A. (2010). Oppressive beliefs at play: Associations among beauty ideals and practices and individual differences in sexism, objectification of others, and media exposure. Psychology of Women Quarterly, 34(3), 365-379. doi:10.1111/j.14716402.2010.01582.x

Sypeck, M., Gray, J., \& Ahrens, A. (2004). No longer just a pretty face: Fashion magazines' descriptions of ideal female beauty from 1959 to 1999. International Journal of Eating Disorders, 36(3), 342-347. doi:10.1002/eat.20039

Tharps, L. L. (2014, November 18). Opinion | the case for black with a capital b. The New York Times. Retrieved from https://www.nytimes.com/2014/11/19/opinion/the-case-for-black-with-a-capitalb.html

Vandenbosch, L., \& Eggermont, S. (2012). Understanding sexual objectification: A Comprehensive approach toward media exposure and girls' internalization of 
beauty ideals, self-objectification, and body surveillance: Media, adolescent girls, and self-objectification. Journal of Communication, 62(5), 869-887.

doi:10.1111/j.1460-2466.2012.01667.x

VanDerWerff, E. T. (2015, January 15). Selma was snubbed because the average Oscar voter is a 63-year-old white man. Retrieved August 22, 2019, from Vox website: https://www.vox.com/2015/1/15/7551723/selma-oscars-snub

Weaver, S. (2010). The 'other' laughs back: Humour and resistance in anti-racist comedy. Sociology, 44(1), 31-48. doi:10.1177/0038038509351624

Weiner, J. (2009, August 6). The rise of no homo and the changing face of hip-hop homophobia. Retrieved August 22, 2019, from Slate Magazine website: https://slate.com/culture/2009/08/the-rise-of-no-homo-and-the-changing-face-ofhip-hop-homophobia.html

Willett, C., Willett, J., \& Sherman, Y. D. (2012). The seriously erotic politics of feminist laughter. Social Research, 79(1), 217-246.

Wollheim, P. (2007). The erratic front: YouTube and representations of mental illness. Afterimage, 35(2), 21-26.

Wright, J.K. "Olivia Pope and Black Women in Primetime History $B$ " in Black women and popular culture: The conversation continues edited by Goldman, A. Y., Ford, V. S., Harris, A. A., \& Howard, N. R. (2014). Retrieved from https://ebookcentral-proquest-com.proxy.library.carleton.ca Wu, K. (2016). YouTube marketing: Legality of sponsorship and endorsements in advertising. JL Bus. \& Ethics, 22, 59. 
Wun, C. (2014). Unaccounted foundations: Black girls, anti-black racism, and punishment in schools. Critical Sociology, 42(4-5), 737-750. doi: $10.1177 / 0896920514560444$

Yodanis, C. L. (2004). Gender inequality, violence against women, and fear: A crossnational test of the feminist theory of violence against women. Journal of Interpersonal Violence, 19(6), 655-675. doi:10.1177/0886260504263868

Yin, R. K. (2014). Getting started: How to know whether and when to use the case study as a research method. In Case study research: Design and methods (5th ed., pp. 326). Los Angeles: Sage Publications.

Young, D. G. (2017). Theories and effects of political humor: Discounting cues, gateways, and the impact of incongruities. The oxford handbook of political communication, 871-884. 